\title{
Júlio Cesar Rodrigues Pereira
}

Razão de derivadas como medida de efeito do sexo sobre a idade de ocorrência do infarto agudo do miocárdio

Tese apresentada à Faculdade de Saúde Pública da Universidade de São Paulo, Departamento de Epidemiologia, para obtenção de título de Livre Docente

São Paulo, 2004 


\section{Agradecimentos}

Preparar uma tese de Docência Livre é por sua própria natureza uma tarefa solitária. Não me faltou, no entanto, a solidariedade de amigos que devo agradecer:

- À minha família, a nossa turma, pela tolerância com o pai e marido absorto no trabalho;

- Aos amigos dos Seminários de Lógica Fuzzy, Prof. Pedro A. Tonelli, do IME-USP, Prof. Laécio C. Barros, do IMECC-UNICAMP, Profa. Neli R. S. Ortega, pelo carinhoso interesse de discutir minhas idéias nos nossos encontros de sextas-feiras;

- Aos colegas de Departamento Prof. José Maria P. Souza e Prof. Victor Wünsch Filho, pela generosidade de ler, criticar e melhorar este trabalho;

- Ao Pena (que pena!), Prof. José Eduardo C. Moncau, que me deixou sozinho justo quando vínhamos entusiasmados nos associando no estudo da Lógica e suas aplicações aos métodos em Epidemiologia. Pena morreu antes de ler esta tese, mas nela deve ir registrado o agradecimento pela leitura e discussão que havíamos planejado;

- Aos companheiros do Friday Club, cuja amizade é contribuição a qualquer empreitada da minha vida;

- Aos companheiros do Lee: Valdir, Valéria e Camila que me ajudam em todas as iniciativas. 


\section{Resumo}

O presente estudo propõe uma estratégia metodológica, a razão de derivadas, como instrumento de estimação de efeito relativo de um atributo em relação a outro na manifestação de um evento ao longo de uma dimensão contínua. Esta estratégia é utilizada para estimar o efeito do sexo masculino em relação ao feminino na ocorrência do infarto agudo do miocárdio ao longo das idades. É conhecida uma superioridade de homens entre pacientes de infarto agudo do miocárdio, o que faz o sexo masculino ser reconhecido como fator de risco para a doença. É, no entanto, também conhecido que esta vantagem feminina tende a desaparecer após a menopausa, interessando saber a que idade ela poderia passar a ser desconsiderada. A importância dos fatores de risco para o infarto agudo do miocárdio varia consideravelmente entre diferentes populações e sua caracterização para o Brasil foi recentemente realizada pelo estudo AFIRMAR. Este estudo multicêntrico que envolveu 51 cidades, proveu a oportunidade de se examinar a idade de ocorrência do infarto agudo do miocárdio em 1.240 homens e 558 mulheres.

Às trajetórias de ocorrências de infarto ao longo das idades de homens e mulheres foram ajustadas funções que generalizam seu comportamento e as derivadas destas funções foram calculadas. Estas derivadas representam a força com que a doença se expressa segundo a idade em cada sexo e a razão da função masculina contra a feminina representa o efeito relativo do sexo masculino em contraste com o feminino para a ocorrência do infarto segundo as idades. Calculada a razão de derivadas, a função resultante estima que o risco relativo homens:mulheres é da ordem de 2 aos vinte anos, reduzindo-se a 0,5, o inverso, aos oitenta anos. A idade de 61,2 anos é identificada como o ponto de inflexão onde a força de morbidade é igual para homens e mulheres.

Estas informações não são aparentes em outras estratégias metodológicas, pelo que se concluí que a razão de derivadas possa constituir-se em contribuição efetiva ao pesquisador interessado em analisar contrastes relativos em grupos homogêneos de doentes. 


\begin{abstract}
The present study puts forward a methodological strategy, the derivative ratio, as a means to assess the relative effect of an attribute against another in the expression of an event through a continuous dimension. This strategy is applied to estimate the effect of the male sex against female in acute myocardial infarction occurrence through ages.

Men are known to account for a larger number of infarction than women, which makes the male sex a risk factor for this disease. Nonetheless, it is also known that the female advantage dwindles after menopause, being of interest to know when such advantage goes up in even chances. The importance of acute myocardial infarction risk factors widely varies among populations and its characterisation for Brazil has recently been conducted by the AFIRMAR study. This multicentre study involving 51 cities provided the opportunity of examining the age of acute myocardial infarction occurrence in 1,240 men and 558 women.

The courses of infarction occurrences through men's and women's ages were adjusted to functions and their derivatives were calculated. These derivatives represent the force of morbidity according to age for each sex and the ratio male:female estimates the relative effect of the male sex against female for infarction occurrence according to age. Once calculated the derivative ratio, the resulting function allowed knowing that at age 20 years men's morbidity force is twice that of women, a relation which is inverted to half at age 80 years. The age of 61.2 is identified as the turning point when men's and women's morbidity force are equal.

This information is not provided by other methodological strategies and thus the derivative ratio seems a promising contribution to the knowledge of relations among classes within groups defined by the presence of a given disease.
\end{abstract}




\section{Índice}

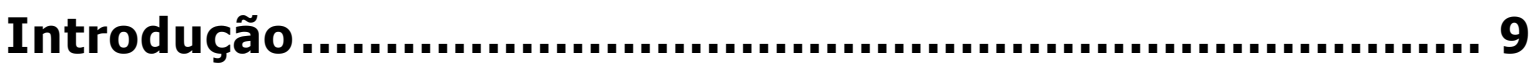

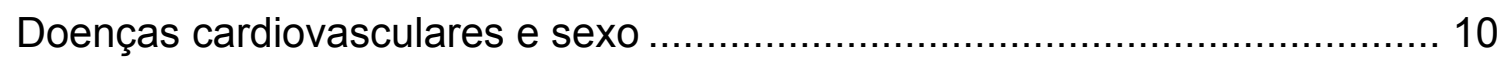

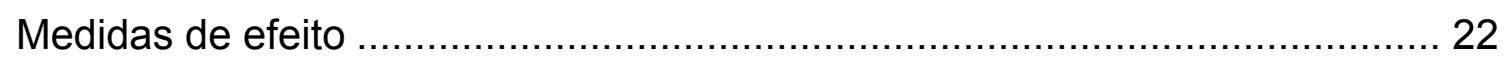

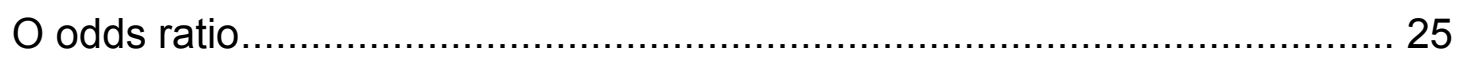

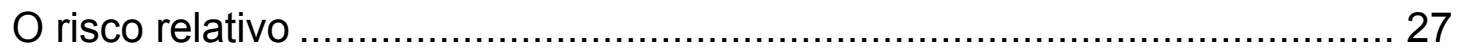

A razão de danos (hazard ratio) .................................................... 31

A razão de derivadas ............................................................................ 35

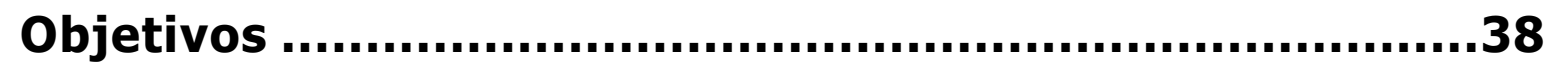

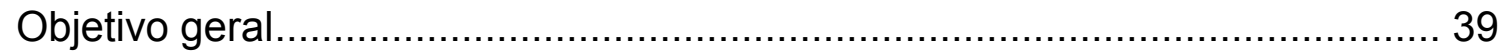

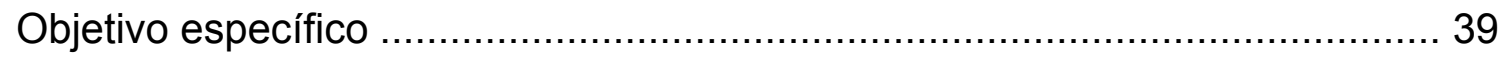

Material e métodos ...............................................40

O estudo AFIRMAR: pacientes estudados ............................................. 41

Efeitos relativos num espaço complementado: conceitos preliminares para introdução da razão de derivadas como medida de efeito ............................ 42

A razão de derivadas como medida de efeito ........................................ 47

Resultados .................................................................56

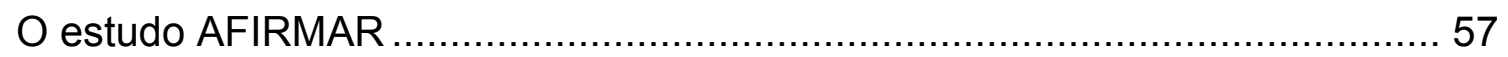

O efeito do sexo sobre a ocorrência de infarto agudo do miocárdio no estudo

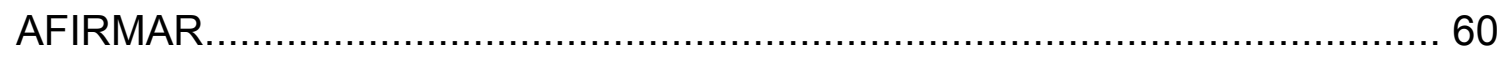

Comentários...................................................69

Conclusão ..................................................................88 


\section{Índice de Figuras}

Figura 1 - Causas de Óbitos SEgundo o Capítulo da CID-10, BRASIL , 2001...... 11

FIgURA 2 - ÓBITOS POR DOENÇAS DO APARELHO CIRCULATÓRIO SEGUNDO O SEXO,

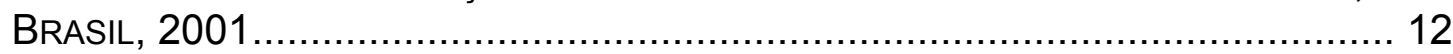

FIgURA 3 - NÚMERO DE ÓBITOS POR DOENÇAS CARDIOVASCULARES NO BRASIL, 1980 A 2001, E LINHAS DE TENDÊNCIA LINEAR ....

FIGURA 4 - NÚMERO DE ÓBITOS POR DOENÇAS CARDIOVASCULARES NOS ESTADOS

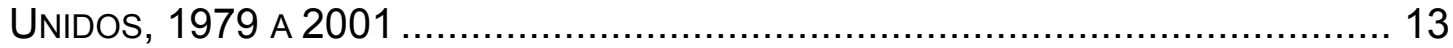

FIGURA 5 - EXEMPLO HIPOTÉTICO DE MEDIDA DE EFEITO EM SENTIDO GERAL ............... 22

FIGURA 6 - REPRESENTAÇÃO GRÁFICA DO CÁLCULO DO ODDS RATIO EM REGRESSÃO

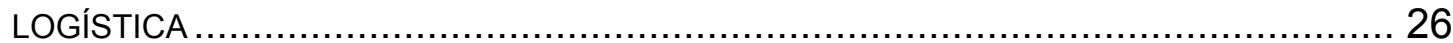

FIGURA 7 - EXEMPLO HIPOTÉTICO DE RISCO RELATIVO COMO RAZÃO DE FORÇAS DE MORBIDADE .

FIGURA 8 - EXEMPLO HIPOTÉTICO DE RISCO RELATIVO COMO RAZÃO DE FUNÇÕES DE DANO

FIGURA 9 - ESPAÇO COMPLEMENTADO EM REPRESENTAÇÃO DE ESCHER, 1943

FIGURA 10 - CURVAS HIPOTÉTICAS DE INCIDÊNCIA ACUMULADA E DENSIDADE DE INCIDÊNCIA ENTRE HOMENS E MULHERES

FIGURA 11 - FIgURA 10 EM DETALHE

FIGURA 12 - CURVAS HIPOTÉTICAS DE INCIDÊNCIA ACUMULADA E DENSIDADE DE INCIDÊNCIA ENTRE HOMENS E MULHERES NUMA SITUAÇÃO ONDE A RAZÃO ENTRE AS

CATEGORIAS DE SEXO NÃO SE APLICA ................................................ 46

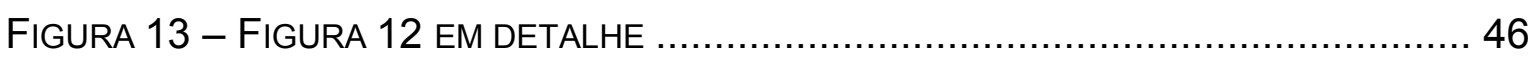

FIGURA 14 - COMPORTAMENTO DE UM GRUPO DE PESSOAS ACUMULANDO OCORRÊNCIAS DE DOENÇA AO LONGO DO TEMPO.

FIGURA 15 - MODELO DINÂMICO DE TRANSIÇÃO DE SADIOS PARA DOENTES SEGUNDO UMA TAXA DE INCIDÊNCIA DE DOENÇA

FIGURA 16 - COMPORTAMENTO DE UM GRUPO DE PESSOAS QUE SE CONSTITUI CONFORME ACUMULA OCORRÊNCIAS DE DOENÇA AO LONGO DO TEMPO

FIGURA 17 - FREQÜÊNCIAS ACUMULADAS E CORRESPONDENTES FUNÇÕES DE DISTRIBUIÇÃO ACUMULADA DE PROBABILIDADE NORMAL ENTRE CASOS E CONTROLES

FIGURA 18 - DISTRIBUIÇÃO DE FREQÜÊNCIAS E CORRESPONDENTES FUNÇÕES DE DENSIDADE DE PROBABILIDADE NORMAL ENTRE CASOS E CONTROLES

FIGURA 19 - COMPARAÇÃO DO EFEITO DE LDL SOBRE A OCORRÊNCIA DE INFARTO AGUDO DO MIOCÁRDIO POR REGRESSÃO LOGÍSTICA E POR RAZÃO DE DERIVADAS

FIGURA 20 - DISTRIBUIÇÃO DE SEXO ENTRE OS GRUPOS DE PACIENTES DO ESTUDO AFIRMAR. 
FIGURA 21 - PARTICIPAÇÃO PROPORCIONAL DAS REGIÕES BRASILEIRAS NO ESTUDO AFIRMAR

FIGURA 22- CURVAS DE FUNÇÃO DE DANO [HAZARD FUNCTION = -LG(SOBREVIDA)] PARA CADA SEXO ENTRE PESSOAS INFARTADAS ....

FIGURA 23 - HISTOGRAMA DE FREQÜÊNCIA ACUMULADA DE IDADE E CORRESPONDENTE FUNÇÃO DE DISTRIBUIÇÃO AJUSTADA PARA PACIENTES INFARTADOS DO SEXO MASCULINO E FEMININO

FIGURA 24 - CURVAS DE FUNÇÕES DE DISTRIBUIÇÃO DE PROBABILIDADE DE IDADE AJUSTADAS AOS DADOS EMPÍRICOS DE HOMENS E MULHERES

FIGURA 25 - HISTOGRAMA DE FREQÜÊNCIAS DE IDADE E CORRESPONDENTE FUNÇÃO DE DENSIDADE DE PROBABILIDADE AJUSTADA PARA PACIENTES INFARTADOS DO SEXO MASCULINO E FEMININO

FIGURA 26 - AJUSTE DAS OCORRÊNCIAS DE INFARTO AO LONGO DOS VALORES DE IDADE A UMA FUNÇÃO DE DISTRIBUIÇÃO NORMAL

FIGURA 27 - COMPARAÇÃO DA FUNÇÃO DENSIDADE DE PROBABILIDADE (FDP) NORMAL (5) E DERIVADA DA FUNÇÃO LOGíSTICA AJUSTADA AOS DADOS EMPÍRICOS (3) EM HOMENS.

FIGURA 28 - COMPARAÇÃO DA FUNÇÃO DENSIDADE DE PROBABILIDADE (FDP) NORMAL (6) E DERIVADA DA FUNÇÃO LOGíSTICA AJUSTADA AOS DADOS EMPÍRICOS (4) EM MULHERES

FIGURA 29 - DERIVADAS DAS FUNÇÕES DISTRIBUIÇÃO DE IDADES EM CADA SEXO E A RAZÃO DE DERIVADAS HOMENS : MULHERES*

FIGURA 30 - NÚMERO DE ARTIGOS BRASILEIROS DO CAMPO DA SAÚDE REGISTRADO NAS BASES DO ISI ENTRE 1990 E 2002.

FIGURA 31 - GRÁFICOS DE FUNÇÕES TESTADAS PARA AJUSTE ÀS OBSERVAÇÕES EMPÍRICAS DE NÚMERO DE ARTIGOS BRASILEIROS EM CIÊNCIAS DA SAÚDE REGISTRADO NO ISI ENTRE 1990 E 2002

FIGURA 32 - GRÁFICO DA FUNÇÃO EXPONENCIAL AJUSTADA E SUA DERIVADA 78

FIGURA 33 - FORÇA DE EXPRESSÃO DOS RISCOS AVALIADOS PELA RAZÃO DE DERIVADAS DA FUNÇÃO (8) NAS IDADES DE 25 E 50 ANOS 83

FIGURA 34 - HIPOTÉTICA FUNÇÃO DE RAZÃO DE DERIVADAS E SUA DERIVADA $\left(2^{\mathrm{a}}\right.$ DERIVADA EM RELAÇÃO AO FENÔMENO ESTUDADO)... 


\section{Índice de Tabelas}

TABELA 1 - EXEMPLOS DE ESTUDOS ESTIMANDO O EFEITO DO SEXO EM DIFERENTES

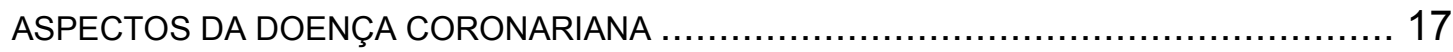

TABELA 2 - FATALIDADE EM 30 DIAS PARA PACIENTES ADMITIDOS PARA TRATAMENTO

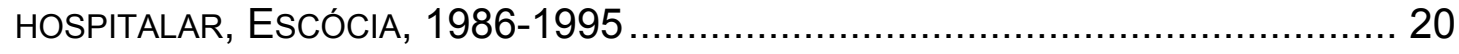

TABELA 3 - EFEITO DE LDL-COLESTEROL SOBRE A OCORRÊNCIA DE INFARTO EM ESTIMATIVA POR REGRESSÃO LOGÍSTICA ............................................. 54

TABELA 4 - NÚMERO E IDADE DE PACIENTES ESTUDADOS NO PROJETO AFIRMAR,

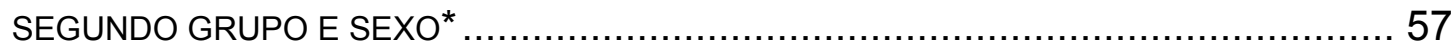

TABELA 5 - NÚMERO DE PACIENTES ESTUDADOS NO PROJETO AFIRMAR, SEGUNDO A

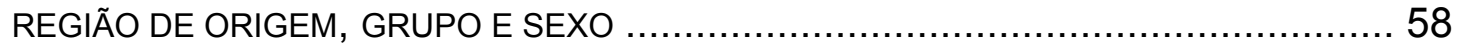

TABELA 6 - ORIGEM DOS PACIENTES DO ESTUdO AFIRMAR POR ESTADO .................. 59

TABELA 7 - EFEITO DO SEXO MASCULINO EM CONTRASTE COM O FEMININO PARA A CONDIÇÃO PRESENÇA DE INFARTO (CASO) COM CONTROLE DE IDADE, EM ANÁLISE POR REGRESSÃO LOGÍSTICA

TABELA 8 - EFEITO DO SEXO MASCULINO EM CONTRASTE COM O FEMININO PARA CHANCES DE INFARTO AO LONGO DAS IDADES ENTRE PESSOAS INFARTADAS (CASOS), EM MODELO DE RISCOS PROPORCIONAIS DE COX. 
Introdução 
Doenças cardiovasculares e sexo

As doenças cardiovasculares são atualmente as principais causas de morbidade e mortalidade em todo o mundo, sendo matéria de interesse tanto para a Clínica quanto para a Saúde Pública. Em 2001, Robert Beaglehole $^{1}$, através da prestigiosa revista Lancet, lançou apelo para um engajamento global no controle destas doenças. Estimando que naquele ano houvessem 56 milhões de mortes em todo o mundo, ele esperava que 12,5 milhões delas fossem atribuíveis à doença coronariana e aos acidentes vasculares cerebrais, com ocorrências afetando todos os tipos de paises. A despeito de reconhecer uma liderança responsável por parte da Organização Mundial da Saúde (OMS), Beaglehole deu ênfase à necessidade de adesão da sociedade através de organizações nãogovernamentais, bem como sugeriu que agências de financiamento à pesquisa e revistas científicas devessem dar prioridade a estudos de estratégias de controle à exposição a fatores de risco.

De fato, o reconhecimento pela OMS deste desafio como um problema de Saúde Pública é inequívoco. Já em 1979, a OMS criou o projeto MONICA ${ }^{2}$ (Multinational MONItoring of trends and determinants in CArdiovascular disease) que reuniu 32 centros colaboradores em 21 paises para acompanhar uma população de 10 milhões de homens e mulheres com idades entre 25 e 64 anos e cujos dados de acompanhamento têm gerado inúmeros estudos sobre a epidemiologia das doenças cardiovasculares. Lotufo $^{3}$, em 1998, estudou óbitos por doenças do coração em diferentes capitais brasileiras e encontrou que, já para o período 1984 a 1987, na faixa etária de 45 a 64 anos, o comportamento destas doenças no Brasil era semelhante ao de paises europeus e Estados Unidos, com taxas de mortalidade elevadas e ônus especial para as mulheres. Lessa ${ }^{4}$, estudando especificamente os óbitos por doença coronariana no Brasil para idades entre 20 e 59 anos no período de 1979 a 1998, encontrou que o número de óbitos registrados para mulheres havia sido $43,3 \%$ maior que o dos 
homens, embora as taxas de mortalidade tivessem se mantido estáveis, dado um concomitante maior crescimento da população feminina.

Consultando-se os dados oficiais de mortalidade no Brasil ${ }^{5}$, encontra-se que 2001 é o mais recente ano com informações disponíveis. A figura 1 mostra a distribuição de freqüência destes óbitos segundo as causas agrupadas por capítulos da CID-10 (10ª versão da Classificação Internacional de Doenças). As doenças do aparelho circulatório são destacadamente as mais importantes: primeiro lugar, com freqüência quase duas vezes superior à segunda causa.

Figura 1 - Causas de óbitos segundo o capítulo da CID-10, Brasil , 2001

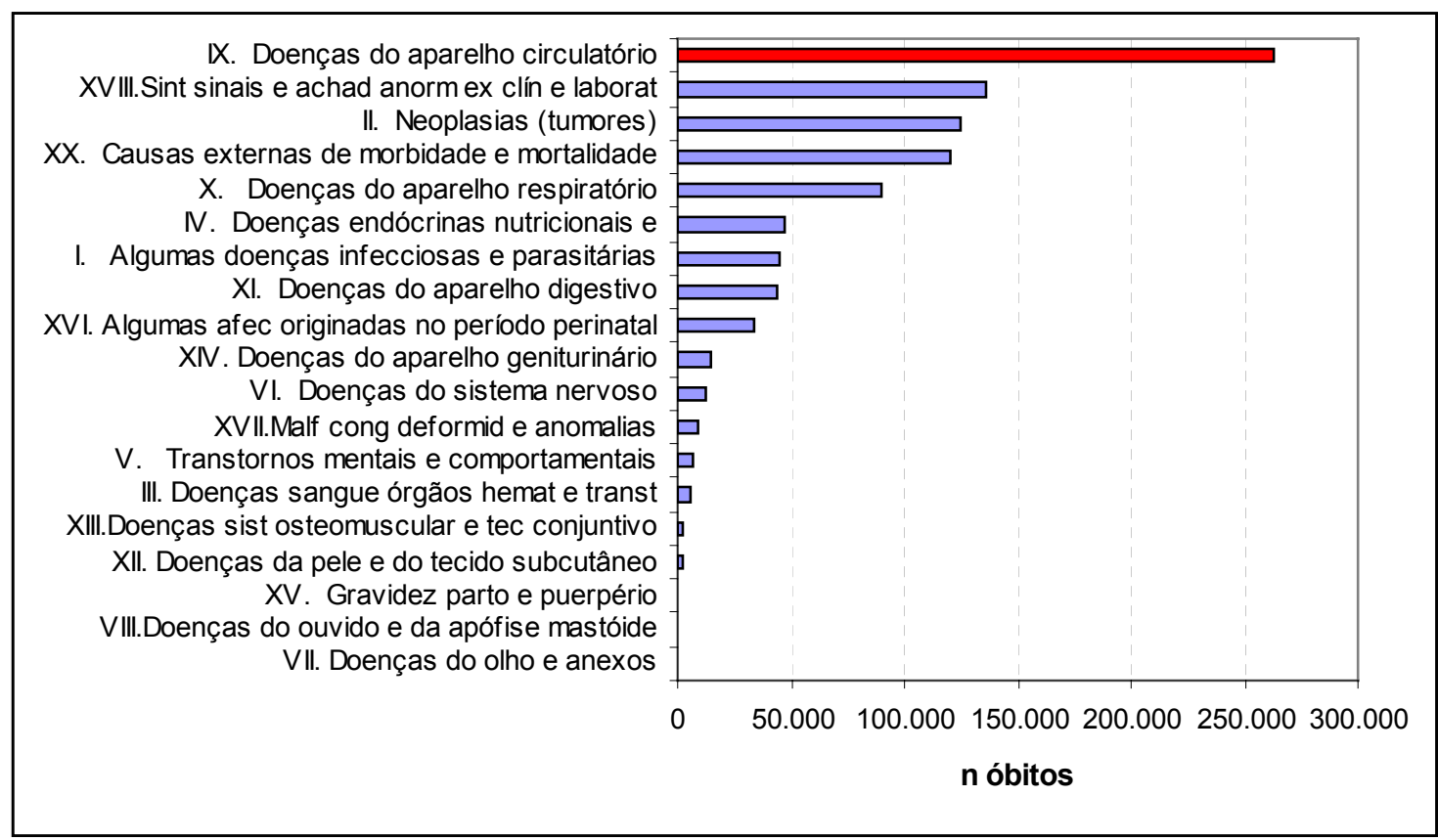

Esta posição tem sido a mesma desde 1979, menor ano para o qual o DATASUS oferece acesso a informações. Da mesma forma tem sido estável a discreta superioridade do sexo masculino entre os óbitos por doenças cardiovasculares (Figura 2). Para ambos os sexos, as taxas de mortalidade parecem mostrar uma discreta tendência de decréscimo, como sugeriu De Lolio et al. ${ }^{6}$ em estudo de 1995, onde apenas as capitais Recife e Rio de Janeiro mostravam tendências de crescimento. Tanto a tendência de decréscimo quanto as diferenças regionais foram recentemente confirmadas por Mansur et al. ${ }^{7}$. 
Figura 2 - Óbitos por Doenças do Aparelho Circulatório segundo o sexo, Brasil, 2001

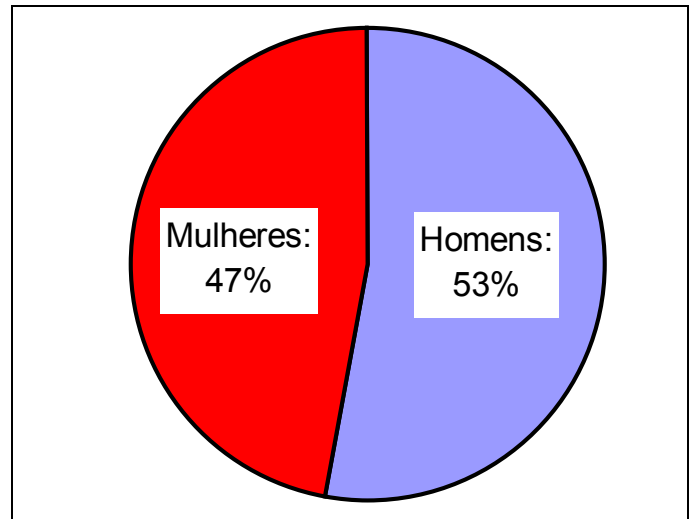

Além dos registros de mortalidade, o DATASUS oferece também informações demográficas com as quais se pode calcular coeficientes de mortalidade a partir de 1980. No gráfico abaixo (Figura 3) pode-se ver o comportamento da mortalidade por doenças cardiovasculares no Brasil para os últimos anos.

Figura 3 - Número de óbitos por Doenças Cardiovasculares no Brasil, 1980 a 2001, e linhas de tendência linear

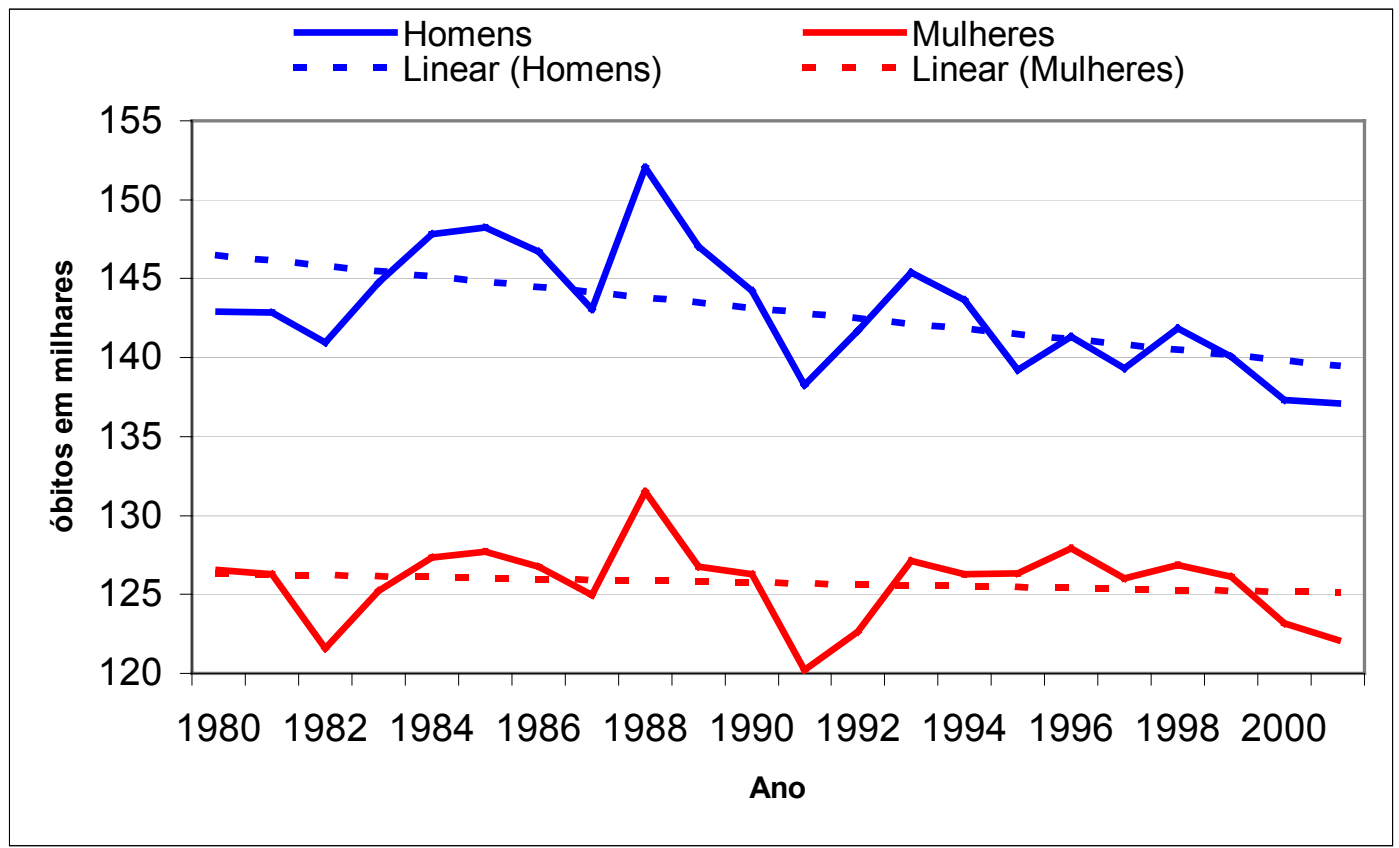

Nota: Doenças do Aparelho Circulatório, CID IX até 1995 e CID X de 1996 a 2001 Coeficientes de mortalidade por 100.000 para população padrão em 2000

Pode-se notar que, embora uma função linear possa ser uma representação modesta do comportamento da mortalidade, parece de fato haver uma discreta tendência de decréscimo, menos acentuada para as mulheres, 
como que sugerindo que a um tempo as curvas de ocorrências de homens e mulheres se cruzariam e progressivamente trocariam de lugar. As estatísticas da American Heart Association revelam que, de fato, nos Estados Unidos o número de óbitos por doenças cardiovasculares em mulheres já ultrapassou, desde a década de 1980, o número em homens, como mostra a Figura 4, abaixo:

Figura 4 - Número de óbitos por Doenças Cardiovasculares nos Estados Unidos, 1979 a 2001

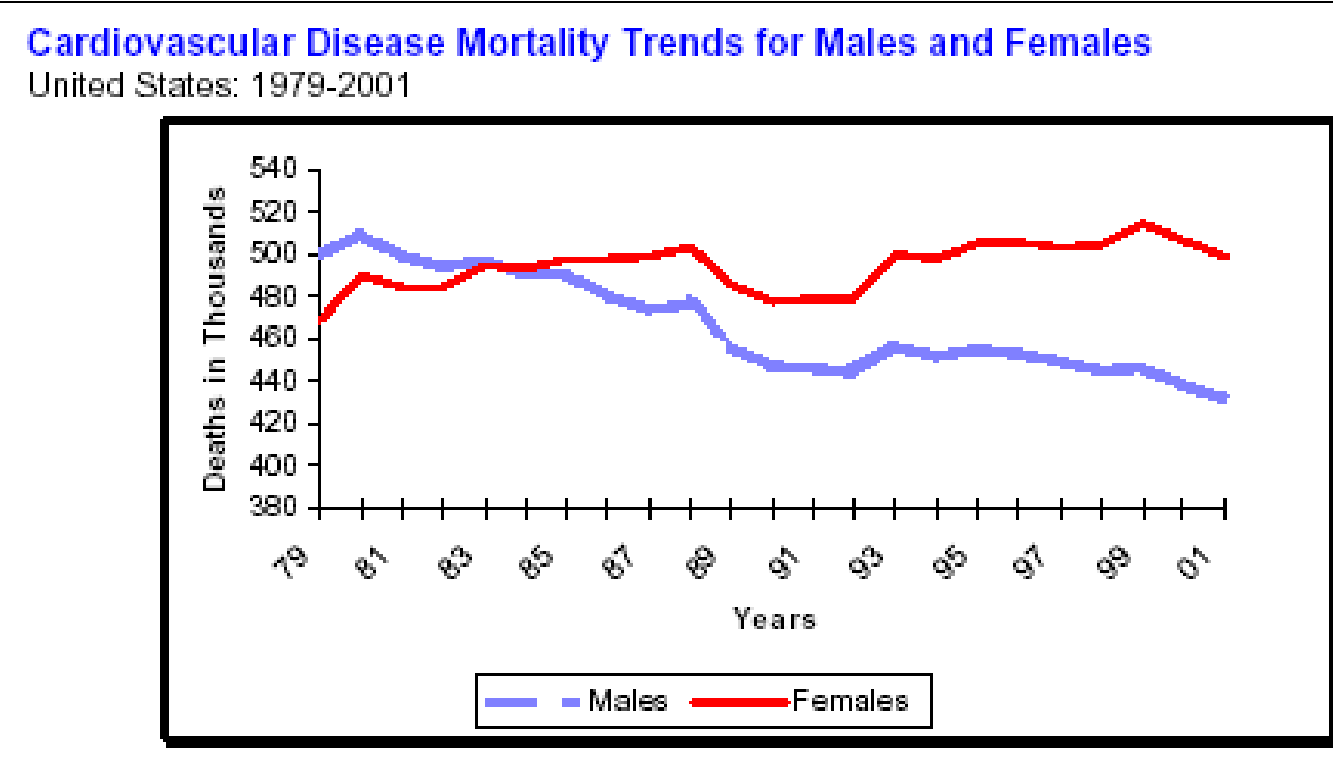

Source: $\mathrm{CDC} / \mathrm{NCHS}$.

Note: Death rates are age-adjusted per 100,000 population, based on the 2000 U.S. standard Some data are reported according to ICD/9 codes and some use ICD/10 codes.

Esta tendência de decréscimo, bem como a oposição de comportamentos entre homens e mulheres, parece ser generalizada, passível de observação em diferentes paises do globo e interessando tanto mortalidade quanto morbidade. Estudo sobre as ocorrências de novos casos de primeiro infarto do miocárdio na população de Estocolmo ${ }^{8}$ para pessoas entre 30 e 89 anos no período de 1984 a 1986, mostrou um declínio médio de $2 \%$ para homens e de apenas 1,4\% para mulheres. Estudo mais recente no norte da Suécia ${ }^{9}$, região participante do projeto MONICA, também encontrou que tanto morbidade quanto fatalidade por infarto do miocárdio têm tendência decrescente, mas que ela é menos pronunciada nas mulheres. 
Na Espanha um estudo recente ${ }^{10}$ sugere que em casos de infarto do miocárdio a taxa de fatalidade seja maior para mulheres, enquanto que estudo no Canadá ${ }^{11}$ mostra que a despeito de uma taxa de mortalidade maior para homens, as incapacidades são maiores para as mulheres (21\% contra 7\% com dificuldade de movimentação seis vezes maior que pessoas não doentes). Para se entender este estado de coisas, deve-se levar em conta que o aumento de longevidade das populações tem aumentado as chances de ocorrência de doenças cardiovasculares em mulheres ${ }^{12}$ e que, particularmente no infarto do miocárdio, as mulheres tendem a ser mais velhas, terem mais diabetes e mais hipertensão como agravantes do problema cardíaco ${ }^{13}$. Na França ${ }^{14}$, em estudo participante do projeto MONICA, encontrou-se que tabagismo e diabetes foram fatores de risco que aumentaram mais entre as mulheres e que, embora a hipercolesterolemia tivesse se mantido estável para ambos os sexos, as medidas de prevenção melhoraram apenas entre os homens.

As diferenças de sexo na doença coronariana são reconhecidas de longa data. Já no século XIX, Moynac ${ }^{15}$ escrevia que a angina pectoris era mais freqüente entre homens do que entre mulheres. William Osler, que descrevia a doença coronariana como aquela que começa onde as outras terminam ("it begins where other diseases end - in death") ${ }^{16}$, dava a Morgagni o crédito de pioneiro na descrição da doença. Em seu livro "The evolution of modern medicine" ele escreveu ${ }^{17}$ :

What could be more correct than this account of angina pectoris-probably the first in the literature? "A lady forty-two years of age, who for a long time, had been a valetudinarian, and within the same period, on using pretty quick exercise of body, she was subject to attacks of violent anguish in the upper part of the chest on the left side, accompanied with a difficulty of breathing, and numbness of the left arm; but these paroxysms soon subsided when she ceased from exertion. In these circumstances, but with cheerfulness of mind, she undertook a journey from Venice, purposing to travel along the continent, when she was seized with a paroxysm, and died on the spot. I examined the body on the following day.... The aorta was considerably dilated at its curvature; and, in places, through its whole tract, the inner surface was unequal and ossified. These appearances 
were propagated into the arteria innominata. The aortic valves were indurated...." He remarks, "The delay of blood in the aorta, in the heart, in the pulmonary vessels, and in the vena cave, would occasion the symptoms of which the woman complained during life; namely, the violent uneasiness, the difficulty of breathing, and the numbness of the arm."

Paradoxalmente, teria então sido feminino o primeiro caso de doença coronariana relatado na literatura. Mais paradoxal ainda, teria sido o caso de uma mulher de apenas 42 anos, supostamente então em pleno menacma, período em que as mulheres teriam uma suposta proteção hormonal para as doenças cardiovasculares. De fato, as doenças cardiovasculares tendem a ocorrer nas mulheres principalmente após a menopausa, o que sugeriu que talvez uma terapia de reposição hormonal pudesse devolver-Ihes a proteção perdida. Em 1991, depois de uma controvérsia entre seus primeiros resultados e algumas evidências em contrário na coorte de Framingham, o "Nurses' Health Study"18, sediado na Harvard School of Public Health, tendo acompanhado 48.470 mulheres menopausadas por 10 anos, concluiu que mulheres sob reposição hormonal com estrógenos tinham um risco relativo de 0,56 para doença coronariana, ou por outra, a reposição hormonal teria efeito protetor para a doença. Este mesmo estudo mostrou efeitos semelhantes para a reposição hormonal combinada de estrógenos e progesterona em $1996^{19}$, depois de 16 anos de acompanhamento de mais de 50 mil mulheres.

Durante a década de 1990, esta matéria ganhou grande atenção dos cardiologistas. Em 1991, o NIH - National Institutes of Health, dos Estados Unidos, iniciaram o planejamento do WHI (Women's Health Initiative) que, entre 1993 e 1998 recrutou 161.809 mulheres em menopausa com idades entre 50 e 79 anos para uma série de diferentes estudos. Em 2002, o WHI publicou as conclusões de seu ensaio clínico de terapia hormonal combinada de estrógeno e progesterona ${ }^{20}$ : tendo seguido 8.506 mulheres num grupo tratado e 8.102 mulheres num grupo placebo, o estudo foi descontinuado no $5^{\circ}$ ano de seguimento, 3 anos antes do planejado, dada 
a constatação de alta incidência de câncer de mama no grupo tratado (sabe-se que o estrógeno predispõe ao $\mathrm{Ca}$ de endométrio - 47 casos registrados no estudo - e a progesterona predispõe ao Ca de mama - 290 casos registrados no estudo). Até o ponto em que o estudo foi conduzido, as conclusões foram que, ao contrário de proteção, a reposição hormonal seria fator de risco para a doença coronariana (evento coronariano definido como infarto do miocárdio, revascularização ou morte).

Em 1998, os resultados do estudo HERS - The Heart and estrogen/ progestin Replacement Study ${ }^{21}$ já sugeriam que a reposição hormonal combinada não teria efeito (risco relativo -hazard ratio- calculado em 0,99, intervalo de confiança de $95 \%$ entre 0,80 e 1,22). O HERS foi também um ensaio clínico do NIH, executado pelo National Heart, Lung, and Blood Institute, com financiamento do Wyeth-Ayerst Laboratories, tendo observado 1.380 mulheres no grupo tratado e 1.383 no grupo placebo por 52 meses. As mulheres estavam em menopausa com idades entre 44 e 79 anos e todas tinham um antecedente estabelecido de doença coronariana, ou seja, avaliava-se o efeito da reposição hormonal como estratégia de tratamento de pacientes coronarianos. Estudo semelhante, mas dirigido para a reposição hormonal restrita a estrógenos, foi ainda recentemente conduzido no Reino Unido, o ESPRIT (oEStrogen in the Prevention of ReInfarction Tria). Suas conclusões ${ }^{22}$ foram as mesmas: comparando 513 mulheres em grupo de tratamento com 504 em grupo placebo numa evolução de dois anos, conclui-se que o estrógeno em nada contribuía para evitar novo infarto ou morte cardíaca em mulheres coronariopatas sob tratamento (hazard ratio ou razão de dano $=0,99$, intervalo de confiança de $95 \%$ entre 0,70 e 1,41$)$.

Embora o efeito do estrógeno em relaxar a musculatura lisa das artérias e de inibir o desenvolvimento da aterosclerose estejam bem estabelecidos ${ }^{23}$, a efetividade destas propriedades na prevenção primária ou secundária da doença coronariana não pôde ser comprovada. Editoriais das grandes revistas médicas dão esta questão como encerrada ${ }^{24 ; 25}$ e a reposição 
hormonal deixa de interessar os cardiologistas para restringir-se aos campos da geriatria e da ginecologia.

Dr. Noel Bairey Merz, 'scientific chair' do estudo Women's Ischemia Syndrome Evaluation (WISE), que desde 1996 vem acompanhando 1.000 mulheres com idades entre 20 e 60 anos (jovens) e cujos resultados orientaram recente Scientific Statement da American Heart Association ${ }^{26}$, afirma que

\begin{abstract}
"Studies of women's health should look at women comprehensively and ask: - 'Is it important to take the sex of the subject into consideration when it comes to screening, diagnosis, and treatment of disease?' Pretty much everywhere we've looked, the answer has been yes."
\end{abstract}

Ao estudar mulheres jovens - o WISE tem estudado como deficiências hormonais em mulheres na menacma aumentam o risco de doença cardiovascular -, este estudo ratifica a importância tanto do sexo quanto da idade no julgamento clínico destas doenças. Para dar conta do efeito sexo, os estudos de doenças cardiovasculares geralmente fazem análises de risco de forma separada para cada sexo e a razão de dano (hazard ratio), risco relativo, razão de incidência ou o odds ratio são utilizados para avaliar o efeito de uma categoria de sexo em relação a outra. Na tabela 1 são apresentados alguns estudos recentes que servem de exemplo para alguns aspectos da doença coronariana onde interessa aferir a influência do sexo, bem como suas diferentes estratégias para medida de efeito.

Tabela 1 - Exemplos de estudos estimando o efeito do sexo em diferentes aspectos da doença coronariana

\begin{tabular}{|c|c|c|c|}
\hline Estudo & $\begin{array}{l}\text { Local, data } \\
\text { publicação }\end{array}$ & $\begin{array}{c}\text { Tipo de Medida de } \\
\text { efeito }\end{array}$ & Efeito encontrado \\
\hline $\begin{array}{l}\text { Risco para cirurgia de } \\
\text { revascularização e para intervenção } \\
\text { percutânea, em seguimento de } \\
\text { coorte }(1995-2000) \text { de } 37.401 \\
\text { pacientes submetidos a } \\
\text { cateterismo }{ }^{27} \text {. }\end{array}$ & $\begin{array}{l}\text { Alberta, } \\
\text { Canadá, } \\
2004\end{array}$ & $\begin{array}{l}\text { Risco relativo, } \\
\text { mulheres : homens }\end{array}$ & $\begin{array}{l}3,48(1,95-6,24) \text { para } \\
\text { revascularização e } 2,38 \\
(1,48-3,83) \text { para } \\
\text { intervenção percutânea }\end{array}$ \\
\hline $\begin{array}{l}\text { Prevalência de infarto do miocárdio } \\
\text { em doentes coronarianos sob } \\
\text { acompanhamento em nível } \\
\text { primário. Corte transversal de } \\
\text { população com } 103.613 \text { com idade }\end{array}$ & $\begin{array}{l}\text { Londres, } \\
\text { Reino Unido, } \\
2003\end{array}$ & $\begin{array}{l}\text { Risco relativo com } \\
\text { ajuste para idade, } \\
\text { homens : mulheres }\end{array}$ & $1,57(1,37-1,81)$ \\
\hline
\end{tabular}


Tabela 1 - Exemplos de estudos estimando o efeito do sexo em diferentes aspectos da doença coronariana

\begin{tabular}{|c|c|c|c|}
\hline Estudo & $\begin{array}{l}\text { Local, data } \\
\text { publicação }\end{array}$ & $\begin{array}{c}\text { Tipo de Medida de } \\
\text { efeito }\end{array}$ & Efeito encontrado \\
\hline \multicolumn{4}{|l|}{ acima de $44 \operatorname{anos}^{28}$. } \\
\hline $\begin{array}{l}\text { Risco de óbito em } 5 \text { anos de } \\
\text { seguimento de } 2 \text { coortes: } 22.967 \\
\text { pacientes infartados e } 8.441 \\
\text { pacientes com angina instável }{ }^{29}\end{array}$ & $\begin{array}{l}\text { Alberta, } \\
\text { Canadá, } \\
2003\end{array}$ & $\begin{array}{l}\text { Razão de danos } \\
\text { ( hazard ratio) } \\
\text { ajustada para } \\
\text { condições clínicas } \\
\text { de entrada, mulheres } \\
\text { : homens }\end{array}$ & $\begin{array}{l}0,81(0,72-0,92) \text { entre } \\
\text { anginosos e } 0,99(0,93- \\
1,05) \text { entre infartados, } \\
\text { idades menores que } 65 \\
\text { anos }\end{array}$ \\
\hline $\begin{array}{l}\text { Registros de alta hospitalar de } 19 \\
\text { municípios com população média } \\
\text { de } 4,8 \text { a } 5,1 \text { milhões no período } \\
\text { estudado (1984-1999) }\end{array}$ & Suécia, 2003 & $\begin{array}{l}\text { Razão de incidência } \\
\text { de infarto, homens : } \\
\text { mulheres entre } 25 \text { e } \\
44 \text { anos }\end{array}$ & $\begin{array}{l}5,63(4,96-6,39) \text { no } \\
\text { período } 1984-87 \\
3,72(3,28-4,21) \text { no } \\
\text { período } 1996-99\end{array}$ \\
\hline $\begin{array}{l}\text { Ocorrência de doença } \\
\text { cardiovascular em coorte } 1.091 \\
\text { pessoas com idade } 42.86 \pm 16.9 \mathrm{DP}, \\
\text { selecionadas por amostra } \\
\text { probabilística em Porto Alegre, RS, } \\
\text { seguidos por } 6 \text { anos em média }{ }^{31} \text {. }\end{array}$ & $\begin{array}{l}\text { Porto Alegre, } \\
\text { Brasil, } 2003\end{array}$ & $\begin{array}{l}\text { Razão de danos } \\
\text { (hazard ratio), } \\
\text { homens : mulheres }\end{array}$ & $2,01(1,03-3,91)$ \\
\hline $\begin{array}{l}\text { Registros de } 54 \text { hospitais com } \\
6.067 \text { pacientes infartados entre } \\
1994-97^{32}\end{array}$ & $\begin{array}{l}\text { Alemanha, } \\
2002\end{array}$ & $\begin{array}{l}\text { Odds ratio para } \\
\text { óbito hospitalar } \\
\text { ajustado para idade, } \\
\text { mulheres : homens }\end{array}$ & $1,16(0,99-1,35)$ \\
\hline $\begin{array}{l}\text { Acompanhamento de } 1937 \\
\text { pacientes tratados de infarto em } \\
\text { hospital de referencia entre } 1995 \text { e } \\
2000 \text { para examinar mortalidade } \\
\text { após um ano }\end{array}$ & $\begin{array}{l}\text { Munique, } \\
\text { Alemanha, } \\
2002\end{array}$ & $\begin{array}{l}\text { Razão de danos } \\
\text { (hazard ratio) } \\
\text { ajustada para idade, } \\
\text { mulheres : homens }\end{array}$ & $0,65(0,49-0,87)$ \\
\hline 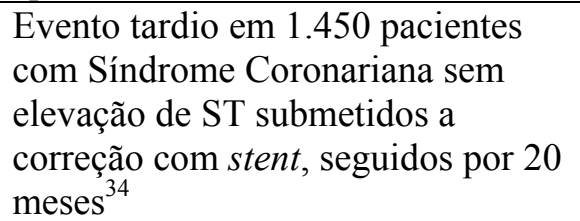 & $\begin{array}{l}\text { Basiléia, } \\
\text { Suíça, } 2002\end{array}$ & $\begin{array}{l}\text { Razão de danos } \\
\text { (hazard ratio) com } \\
\text { ajuste multivariado, } \\
\text { mulheres : homens }\end{array}$ & $0,51(0,28-0,92)$ \\
\hline $\begin{array}{l}\text { Estudo retrospectivo de } 236 \\
\text { pacientes infartados ( } 54 \text { mulheres e } \\
182 \text { homens) tratados no Instituto } \\
\text { do Coração, para avaliar risco de } \\
\text { re-infarto ou morte }{ }^{35} \text {. }\end{array}$ & $\begin{array}{l}\text { São Paulo, } \\
\text { Brasil, } 2002\end{array}$ & $\begin{array}{l}\text { Odds ratio, mulheres } \\
: \text { homens }\end{array}$ & $5,98(1,12-31,97)$ \\
\hline $\begin{array}{l}\text { Seguimento de } 7,5 \text { a } 10 \text { anos de } \\
2.276 \text { homens e } 1.270 \text { mulheres } \\
\text { submetidos a teste de stress para } \\
\text { diagnóstico de coronariopatia }^{36}\end{array}$ & $\begin{array}{l}\text { Olmsted, } \\
\text { Minnesota, } \\
\text { EEUU, } 2002\end{array}$ & $\begin{array}{l}\text { Risco relativo, } \\
\text { homens : mulheres }\end{array}$ & $\begin{array}{l}1,40(1,05-1,86) \text { para } \\
\text { óbito; } \\
1,67(1,24-2,26) \text { para } \\
\text { evento cardíaco } \\
\end{array}$ \\
\hline $\begin{array}{l}\text { Óbito de curto prazo depois de } 1^{\circ} \\
\text { infarto. } 201.114 \text { casos entre } 1986- \\
1995^{37} \text {. }\end{array}$ & $\begin{array}{l}\text { Escócia, } \\
\text { Reino Unido, } \\
2001\end{array}$ & $\begin{array}{l}\text { Odds ratio ajustado } \\
\text { (Mantel-Haenszel), } \\
\text { homens : mulheres }\end{array}$ & $\begin{array}{l}1,25(1,07-1,46) \text { para } \\
\text { idade }<55 \text { anos, } \\
\text { pacientes } \\
\text { hospitalizados } \\
\end{array}$ \\
\hline $\begin{array}{l}4.900 \text { homens e mulheres de } 25 \text { a } \\
64 \text { anos que sobreviveram } 1^{\circ} \\
\text { infarto, seguidos por } 5,9 \text { anos em } \\
\text { média }^{38} \text {. }\end{array}$ & $\begin{array}{l}\text { Finlândia, } \\
2001\end{array}$ & $\begin{array}{l}\text { Razão de danos } \\
\text { (hazard ratio), } \\
\text { homens : mulheres }\end{array}$ & $\begin{array}{l}1,74(1,45-2,09) \text { para } \\
\text { infarto definitivo ou } \\
\text { provável }\end{array}$ \\
\hline Coorte representativa de 1.567 & Beirute, & Razão de incidência, & $2,24(1,62-3,12)$ \\
\hline
\end{tabular}


Tabela 1 - Exemplos de estudos estimando o efeito do sexo em diferentes aspectos da doença coronariana

\begin{tabular}{lccc}
\hline \multicolumn{1}{c}{ Estudo } & $\begin{array}{c}\text { Local, data } \\
\text { publicação }\end{array}$ & $\begin{array}{c}\text { Tipo de Medida de } \\
\text { efeito }\end{array}$ & Efeito encontrado \\
\hline $\begin{array}{l}\text { homens e mulheres com 50 anos ou } \\
\text { mais que participaram de estudo }\end{array}$ & Líbano, 2001 & homens : mulheres & \\
transversal em 1983, seguidos por & & & \\
10 anos, avaliando-se estado vital e & & & \\
causa de morte em autópsia & & & \\
verbal $^{39}$. & & & \\
\hline
\end{tabular}

Dentro desta ampla diversidade de aspectos estudados, o que parece sempre emergir como padrão é que homens adoecem em idade mais jovem e que mulheres tendem a ter quadros clínicos mais graves, embora quando controlado o efeito da idade isto nem sempre subsista. Portanto, seja por força de alterações hormonais, susceptíveis ou não de correção medicamentosa, ou seja por força de outras características clínicas da mulher coronariopata, o que resta inequívoco é que dependendo da idade o sexo tem efeitos diversos. Neste sentido, as medidas de efeito do sexo baseadas em medidas resumo como as exemplificadas acima, não esclarecem qual seria a idade de inflexão para a influência do sexo sobre a doença coronariana.

Para buscar a identificação deste ponto de inflexão, geralmente os autores recorrem a estratificar efeitos em categorias de idade, de forma a sugerir em qual faixa etária as mulheres superam os homens em risco para a doença coronariana. No estudo escocês já citado na tabela $1^{37}$, os autores apresentam uma tabela onde se lê 
Tabela 2 - Fatalidade em 30 dias para pacientes admitidos para tratamento hospitalar, Escócia, 1986-1995

\begin{tabular}{|l|l|}
\hline \multicolumn{1}{|c|}{ Grupo etário } & \multicolumn{1}{c|}{ Odds ratio } \\
\hline$<55$ anos & $1,25(1,07-1,46)$ \\
\hline $55-64$ anos & $1,16(1,07-1,25)$ \\
\hline $65-74$ anos & $1,08(1,03-1,14)$ \\
\hline $75-84$ anos & $1,00(0,95-1,06)$ \\
\hline$>84$ anos & $0,98(0,88-1,10)$ \\
\hline
\end{tabular}

Fonte: MacIntyre K, Stewart S, Capewell S, Chalmers JWT, Pell JP, Boyd J et al. Gender and survival: A population-based study of 201,114 men and women following a first acute myocardial infarction. Journal of the American College of Cardiology 2001; 38:729-35.

Neste estudo, os dados sugerem que seria após os 75 anos que, no grupo particular de doentes hospitalizados (excluídos óbitos antes de chegar ao hospital), as mulheres passariam a ter iguais chances de óbito. No estudo de Chang et al. no Canadá $^{29}$, em seguimento populacional de pacientes após alta hospitalar, as diferenças entre sexos para risco de óbito desapareciam aos 65 anos. Nas recomendações da American Heart Association e American College of Cardiologists ${ }^{40 ; 41}$ para avaliação de risco cardiovascular, o valor do escore atribuído ao sexo feminino passa a ser maior que o atribuído ao sexo masculino a partir da faixa etária 45-49 anos. A grande variabilidade de abordagens, em diferentes aspectos estudados e diferentes medidas de efeito utilizadas, levou Witt e Roger ${ }^{12}$ a concluírem em recente revisão que "While attention has been recently directed at coronary disease in women, there is relatively limited information on the incidence and prevalence of coronary disease in women and how it may have changed over time; few studies include sufficient numbers of women to draw appropriate inference". De fato, embora abundem estudos sobre mortalidade, complicações e fatores de risco, ainda se demanda um conhecimento sobre os padrões de ocorrência da doença coronariana segundo sexo e idade, e em relação a esta, um tratamento que exceda a estratificação que categoriza suas medidas originalmente contínuas, parece ser de todo pertinente. 
A historia natural da doença coronariana se redefine para cada ambiente epidemiológico. Uma recente avaliação do projeto MONICA ${ }^{42}$ (15 diferentes populações em 9 diferentes paises) encontrou diferenças significativas entre paises e mesmo entre populações de um mesmo país após examinar 60.763 eventos por doença coronariana (definidos literalmente como: nonfatal and fatal events of definite myocardial infarction, possible coronary deaths, and unclassifiable coronary deaths). Na Escócia, regiões a pequena distância como Inverness e Edinburgh mostraram diferentes padrões de fatores de risco ${ }^{43}$. Na Bélgica, as cidades de Ghent (em Flanders) and Charleroi (na Walloonia) mostraram diferentes tendências de prevalência de fatores de risco examinados para o período de 1985 a $1992^{44}$. Com este mesmo sentido de diversidade epidemiológica, as estimativas de risco baseadas em parâmetros do estudo de Framingham, têm se mostrado inadequadas (predição de ocorrência de infarto agudo do miocárdio por equações de risco derivadas de Framingham superestimaram ocorrências), como registrou um estudo para duas coortes alemãs ${ }^{45}$, uma em Augsburg (MONICA) e outra em Muenster (PROCAM), e outro para a população de uma cidade da Dinamarca ${ }^{46}$ (escores de risco de Framingham superestimavam ocorrência de doença coronariana na Dinamarca e escores da Dinamarca subestimavam ocorrências em Framingham).

No Brasil, o AFIRMAR ${ }^{47}$ (Avaliação dos Fatores de Risco para o Infarto do Miocárdio) foi um estudo caso-controle multicêntrico levado a efeito entre outubro de 1997 e novembro de 2000, que reuniu informações de 3.350 pacientes de infarto agudo do miocárdio atendidos em 104 hospitais de 51 cidades. Em análise de regressão logística condicional para 1.279 pares de caso e controle de mesmo sexo e faixa etária, este estudo proveu estimativas acuradas de fatores de risco para o infarto no Brasil e teve importante repercussão no meio acadêmico ${ }^{48}$, particularmente por ter apontado o elevado risco de infarto para fumantes e por ter encontrado papel protetor para a ingestão de bebidas alcoólicas. No presente estudo se buscará estudar o efeito do sexo para a ocorrência do infarto agudo do miocárdio no Brasil a partir da análise dos dados do projeto AFIRMAR. 


\section{Medidas de efeito}

Medida de efeito tem dois sentidos para o epidemiologista, como adverte Rothman ${ }^{49}$. Num sentido geral é o efeito de uma causa sobre uma situação de doença. Por exemplo, se insuficiência renal leva a anemia, interessa saber o efeito da primeira sobre a segunda. Representando-se a insuficiência renal por uma dosagem sérica de creatinina e anemia por dosagem de hemoglobina no sangue total, o efeito poderia ser aferido por uma regressão linear, como sugere a figura abaixo construída com dados hipotéticos a título de exemplo.

Figura 5 - Exemplo hipotético de medida de efeito em sentido geral

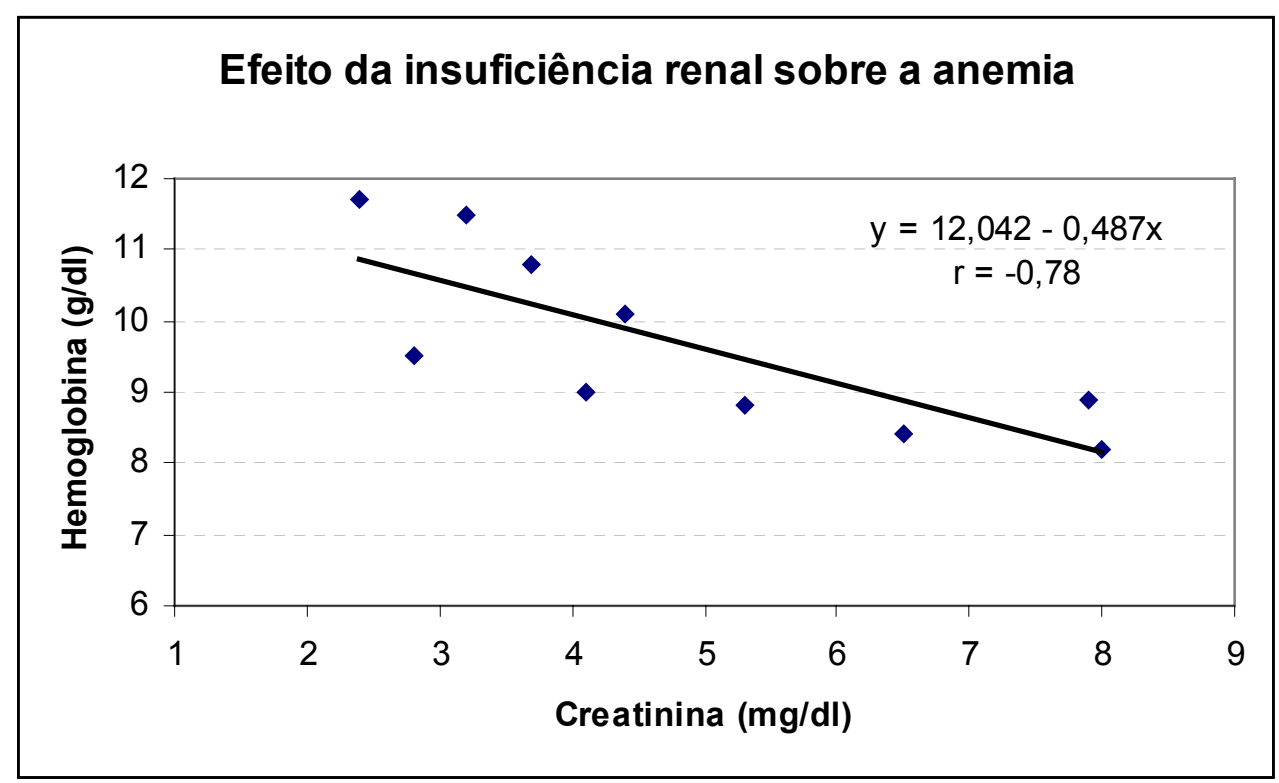

Nesta regressão, a intensidade da associação entre os dois fenômenos representados (insuficiência renal e anemia) é medida pelo coeficiente de regressão $(-0,78)$ e o efeito de um sobre o outro é medido pela inclinação da reta: $-0,487$, que sugere que cada agravamento de insuficiência renal, representado pelo aumento de um (1) mg de creatinina por dl, tem o efeito de agravamento da anemia por uma correspondente diminuição de 0,487 $\mathrm{g} / \mathrm{dl}$ de hemoglobina.

Em sentido mais estrito, medida de efeito é uma diferença de ocorrências de doença entre dois grupos de pessoas separadas por algum atributo cuja presença é interpretada como exposição, supondo-se que o atributo 
contribua para a doença como um componente causal. É neste sentido mais estrito que Rothman ${ }^{49}$ descreve efeito como:

$$
\text { Efeito }=I_{1}-I_{0}
$$

com I representando uma medida de ocorrência e os subscritos 1 e 0 representando grupo com o atributo e grupo sem o atributo. Na verdade, com vistas a uma generalização, a função efeito poderia ser re-escrita para um operador genérico " $\mathrm{g}$ " como

$$
\text { Efeito }=\mathrm{I}_{1} \mathrm{~g} \mathrm{I}_{0}
$$

De fato, 'I', a medida de ocorrência de doença, inclui diferentes estratégias de cálculo para incidência, prevalência ou contraste sim/não (odds), e 'g' diferentes estratégias de comparação destas ocorrências, seja em diferenças absolutas ou relativas.

Estas medidas de efeito, como sugere Leon $\mathrm{Gordis}^{50}$, são realizadas com o intuito de se estabelecer relações de associação e, em última instância, inferência de causalidade. Gordis sugere que sejam indicadores de risco

1. o risco absoluto, a inferência de probabilidade de evento a partir de uma medida de ocorrência, v.g. sua incidência. Não mede efeito, relações de associação, mas é elemento de seu cálculo;

2. o risco relativo, a estimativa de quantas vezes o risco de doença (estimativa de probabilidade de doença) de um grupo (v.g. expostos) é superior (ou inferior) ao risco de outro grupo (v.g. não expostos);

3. o odds ratio, a estimativa de quantas vezes o odds para doença (estimativa de chances para doença) de um grupo é maior (ou menor) que o odds de outro grupo;

4. a razão de mortalidade padronizada (SMR), a estimativa de quão relativamente maior (ou menor) é o número de óbitos numa população em contraste com o número que seria esperado numa 
população padrão que experimentasse o mesmo perfil de mortalidade;

5. a razão de mortalidade proporcional, que estima quantas vezes maior é a mortalidade proporcional por uma dada causa numa população (v.g. exposta) contra outra tomada como referente (v.g. não exposta);

6. o risco atribuível, que é a diferença entre medidas de ocorrência, podendo ser expressa de forma bruta ou proporcional, neste caso para sugerir acréscimo proporcional de ocorrências.

Estas sugestões não esgotam as possibilidades de definição de ' $g$ ', que se redefine em cada autor segundo a natureza da medida de ocorrência de doença e a natureza da comparação que se busca.

Nestas definições de medida de efeito, o uso de duas palavras - risco e razão - com diferentes sentidos não raro gera dificuldade de entendimento sobre o que se fala.

Risco pode ser entendido como risco do indivíduo adoecer e neste caso refere-se a uma probabilidade de adoecer como inferência direta da medida de ocorrência da doença; ou pode ainda ser entendido como acréscimo de chances para doença, quantas vezes o risco, a probabilidade de adoecer, é maior ou menor num ou noutro grupo de pessoas considerado. Destaquese na diferença que o primeiro se realiza no espaço das pessoas enquanto que o segundo se realiza no espaço de populações.

No caso de razão, na língua inglesa diferencia-se 'rate' (quanto de uma coisa por unidade de outra) de 'ratio' (quantas vezes uma coisa maior/ menor que outra), mas em português, 'razão' acumula os dois significados. A medida de ocorrência de doença é rate (v.g. incidence rate) e a medida de efeito, efeito relativo, é ratio (v.g. incidence rate ratio). Estas medidas de razão (ratio) indicam tanto associação quanto efeito. Não há associação quando a razão é um (=1); há efeito positivo, de acréscimo, quando a razão é maior 
que um (>1); há efeito negativo, de proteção, quando a razão é menor que $1(<1)$.

Para o escopo do presente estudo, será pertinente rever três estratégias de medida cujos conceitos estão subjacentes na medida de efeito a ser proposta, a razão de derivadas.

\section{O odds ratio}

O odds, ou chance, é uma medida de ocorrência que substitui a proporção onde ela não se aplica, como nas situações onde os denominadores não são conhecidos. O odds ratio, ou razão de chances, é uma medida de efeito que substitui a razão entre riscos absolutos (risco relativo) e estima quantas vezes as chances de doença são maiores ou menores num grupo em relação a outro. Dados dois grupos separados, por exemplo segundo a presença/ ausência de uma característica (v.g. $A_{1}$ e $A_{0}$ ), as ocorrências de doença são comparadas pela razão das chances de doença em $A_{1}$ contra as chances de doença em $A_{0}$. Designando por ' $p$ ' a proporção de doentes e por ' $q$ ' a proporção de não doentes, o odds ratio (OR) é

$$
O R=\frac{\mathrm{p}_{1} / \mathrm{q}_{1}}{\mathrm{p}_{0} / \mathrm{q}_{0}} \text { ou } O R=\frac{p_{1} q_{0}}{p_{0} q_{1}}
$$

pelo que numa apresentação tabular de dados, o odds ratio é também referido como razão dos produtos cruzados.

Tratando o odds como uma medida contínua dependente de variações de uma outra medida contínua, a regressão do odds por esta independente contínua segue um modelo logístico ${ }^{51}$ onde:

$$
O d d s=e^{b_{0}+b_{i} x_{i}}
$$

onde $b_{0}$ é uma constante, $b_{i}$ são coeficientes e $x_{i}$ são valores assumidos pela $i$ éssima variável independente $(\mathrm{X})$ que indica mudança de algum atributo.

Assim formalizado o odds, o odds ratio para uma variação de atributo $\Delta x$ resulta em 


$$
O R=\frac{e^{b_{0}+b_{i}\left(x_{i}+\Delta x\right)}}{e^{b_{0}+b_{i}\left(x_{i}\right)}}=e^{b_{i} \Delta x}
$$

ou seja, o OR é a exponencial do produto do coeficiente de regressão pela variação da variável independente.

$\mathrm{Na}$ figura abaixo se encontra uma representação gráfica do cálculo do odds ratio que permite uma visualização do procedimento.

Figura 6 - Representação gráfica do cálculo do odds ratio em regressão logística

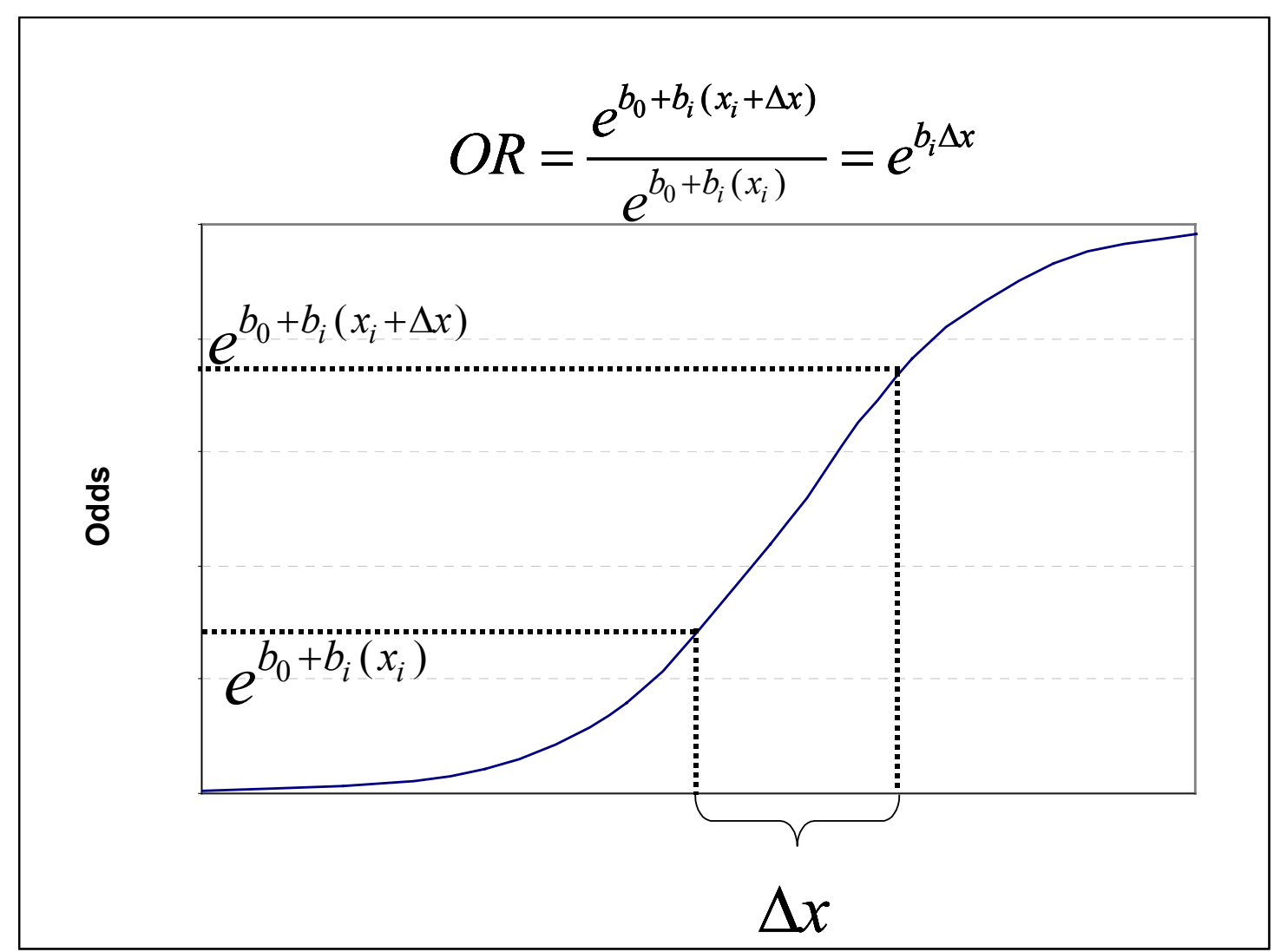

No caso particular de uma variável independente categórica do tipo presença / ausência de um atributo, a exponencial do coeficiente mede o efeito da presença do atributo, quantas vezes as chances de ocorrência de doença (odds para doença) estão aumentadas/ diminuidas na presença do atributo (odds ratio). Em seu artigo seminal de 1976 (1.487 citações! registradas até a presente data - Abr/2004), Miettinen ${ }^{52}$ demonstra que numa população estável, onde entrada e saída de pessoas são compensadas (steady state population) o odds ratio equivale ao risco relativo. 


\section{0 risco relativo}

Embora em tese o risco relativo seja uma razão de proporções que estimam probabilidades a partir de freqüências empíricas e expresse em quanto a probabilidade de doença para um indivíduo de um grupo é superior (ou inferior) à probabilidade de doença para um individuo em outro grupo, não raro o tempo em que as pessoas estão sujeitas a contrair doença precisa ser levado em conta. Por issso, Miettinen distingue dois tipos de medida de incidência:

1. Coeficiente de incidência numa população estável, como uma coorte acompanhada no tempo, que é uma proporção (numerador e denominador pertencem à mesma dimensão):

$$
C I=\frac{P_{0}-P_{t}}{P_{0}}
$$

Como no numerador estão todos os casos de pessoas que apresentaram o evento e no denominador todas as pessoas consideradas, o que se tem é uma proporção acumulada até o tempo ' $t$ ', pelo que esta medida de incidência é também chamada de Incidência Acumulada (CI é usado para designar Cumulative Incidence).

2. Coeficiente de incidência numa população dinâmica, que é uma taxa de ocorrências no tempo: casos de pessoas que apresentaram o evento por unidade de tempo, na notação de Miettinen

$$
I D=\frac{c}{\Delta t}
$$

Como numerador e denominador pertencem a dimensões distintas, o que se tem é uma densidade de casos (c) por intervalo de tempo $(\Delta \mathrm{t})$, pelo que esta medida de incidência é chamada Densidade de Incidência ( $I D=$ Incidence density) 
Numa população dinâmica, indivíduos entram e deixam a população por diferentes razões, v.g. nascimento e morte, e por isso o coeficiente ID passa a ser expresso como um quociente do número total de pessoas com doença $(c)$ pelo número total de pessoas do grupo ponderado pelo tempo total destas pessoas no grupo (pessoas-tempo, $v . g$. pessoas-ano). Sendo ' $C$ ' o número de pessoas que apresentaram o evento, a dimensão 'pessoa' se anula no quociente, resultando que a dimensão de ID é o inverso do tempo $\left(t^{-1}\right)$ :

Densidade de incidência $=\Sigma$ pessoas que adoecem $/ \Sigma$ pessoas-tempo A cada dado tempo, esta medida de ocorrência de doença é o quociente entre o acumulado de eventos de doença e o acumulado de pessoas-tempo de observação. A força com que a doença se expressa num ponto singular (limite da razão quando o denominador tende a um valor específico, pontual) é uma densidade de incidência ou, alternativamente designada uma força de morbidade.

Miettinen ${ }^{52}$, tratando tempo como uma medida contínua, estabelece a relação entre incidência acumulada (CI) e densidade de incidência (ID) através da seguinte função:

$$
\begin{aligned}
& \mathrm{CI}_{t_{0}, t_{1}}=1-e^{\left(-\int_{t_{0}}^{t_{1}}\left(\mathrm{ID}_{t}\right) d t\right)} \\
& \text { onde } \mathrm{CI}=\text { incidência acumulada } \\
& \mathrm{ID}=\text { densidade de incidência } \\
& \text { e os subscritos } 0 \text { e } 1 \text { sugerem tempos } 0 \text { e } 1
\end{aligned}
$$

Rodrigues e Kirkwood ${ }^{53}$ preferem chamar esta medida de ocorrência "risco de incidência" e interpretam-na como uma estimativa de probabilidade de uma pessoa adoecer: - "Incidence risk (alternatively called cumulative incidence) is the probability that a person initially free from disease develops it at some time during the period of observation". Sobre a densidade de incidência, que chamam de "incidence rate", anotam: - 
"Incidence rate (alternatively called incidence density) is the rate of contracting the disease among those still at risk".

Note-se que até aqui, 'risco' está sendo usado no sentido de probabilidade, quer diretamente medido pelo CI (veja que Rodrigues e Kirkwood preferem 'incidence risk' para lembrar que se trata de uma medida de risco de individuo apresentar evento) quer indiretamente pelo ID com o uso da função (1). Para tratar de 'risco' como variação de chances para apresentar doença na comparação entre dois grupos, há que se recorrer a uma razão (ratio) de riscos, que expresse um risco relativo: risco de um grupo em relação a outro grupo. Miettinen ${ }^{52}$ adverte que a razão de riscos instantâneos (pontuais) é igual à razão de densidades de incidência: - "The ratio of instantaneous risk ( $\mathrm{Cl}$ num ponto) is identical to the ratio of the corresponding incidence densities (ID)", o que de fato é verdadeiro por uma regra de Cálculo, enunciada por Leibniz e chamada de regra da cadeia ${ }^{54}$ :

$$
\frac{d y}{d x}=\left(\frac{d y}{d u}\right)\left(\frac{d u}{d x}\right)
$$

No caso das forças de morbidade - derivadas em relação ao tempo -, a comparação de dois grupos ( $x$ e y), na forma de uma razão - razão de derivadas - ou risco relativo de um grupo em relação ao outro, tem-se que

$$
\frac{\frac{d y}{d t}}{\frac{d x}{d t}}=\left(\frac{d y}{d t}\right)\left(\frac{d t}{d x}\right)=\frac{d y}{d x}
$$

Desta forma, tanto a razão de incidências acumuladas quanto a razão de densidades de incidência, informam um risco relativo, uma medida de efeito de quantas vezes a incidência (CI ou ID) é maior num grupo em contraste com outro. Nesta abordagem, embora se possa calcular o risco relativo por intervalos de tempo, v.g. todo o tempo da observação como 
um risco médio, pode-se também ainda calculá-lo para qualquer ponto no tempo. Isto parece de todo interessante já que, ainda que um grupo possa ter risco (CI) maior que outro, não necessariamente esta superioridade está presente todo o tempo (ID).

A figura abaixo, num exemplo hipotético, sugere dois grupos putativos que diminuem progressivamente conforme pessoas afetadas progressivamente deixam o grupo. Os grupos vermelho e azul exibem diferentes comportamentos, embora ao fim da observação ambos sejam reduzidos a zero, ou seja, todas as pessoas acabem apresentando o evento. A força com que o evento, v.g. doença, se expressa em cada grupo não é regular em todos os momentos do tempo, v.g. idade.

Figura 7 - Exemplo hipotético de risco relativo como razão de forças de morbidade

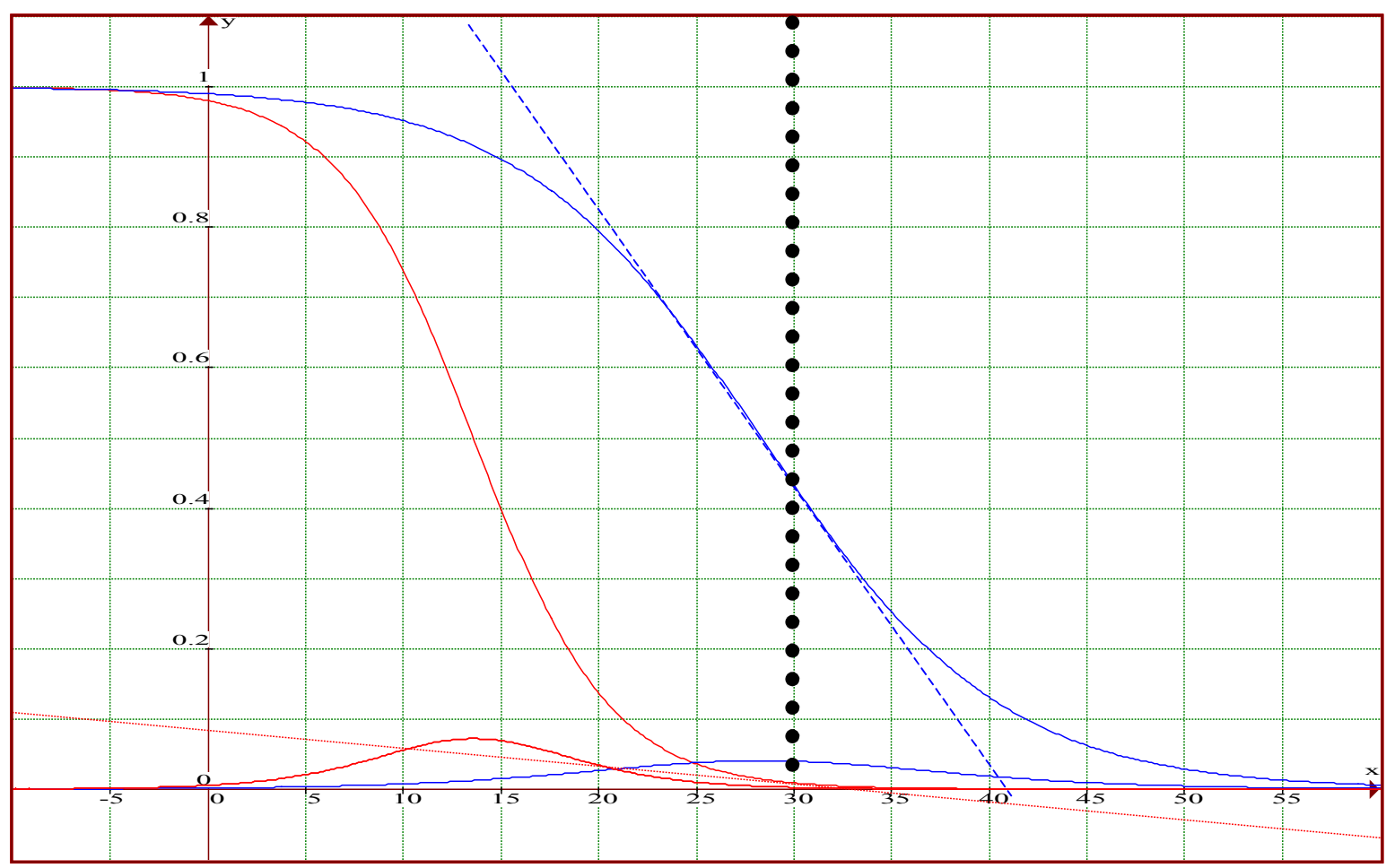

Nota-se no destaque que para o valor 30 na abcissa, a força de morbidade, representada pela tangente ou derivada no ponto 30 , é muito mais inclinada no grupo azul do que no grupo vermelho. De fato, a inclinação da tangente azul é -0,04 e a da tangente vermelha -0,002, ou seja no suposto tempo 30, azuis são 20 vezes maiores que os vermelhos em força de doença, têm risco relativo instantâneo de 20 , em relação aos vermelhos. 
No entanto, os vermelhos já têm $99 \%$ de seus membros afetados, enquanto que os azuis têm apenas $56 \%$ de seus membros afetados: no gráfico vê-se as densidades de incidência (ID) das curvas azul e vermelha. Note-se que neste exemplo, ambos os grupos sugeridos, azul e vermelho, ao fim da observação têm $100 \%$ dos indivíduos afetados. Neste caso, o risco relativo para o período todo é 1 , ou seja tanto num grupo quanto no outro a incidência acumulada é 1 . No ponto 30 tomado como exemplo, para aplicação da fórmula de Miettinen (1) tem-se os seguintes cálculos:

$$
\begin{aligned}
& \begin{array}{lccc}
\text { curva } & \text { - integral da ID } & \exp (\text {-integral) } & \text { 1-exp(-integral) } \\
\hline \text { vermelha } & -0,99 & 0,371576691 & 0,628423309 \\
\text { azul } & -0,5635 & 0,569213327 & 0,430786673
\end{array} \\
& \mathrm{CI}_{\text {vermelho }_{t_{0}, t_{30}}}=1-e^{(-0,99)}=0,63 \mathrm{e}
\end{aligned}
$$

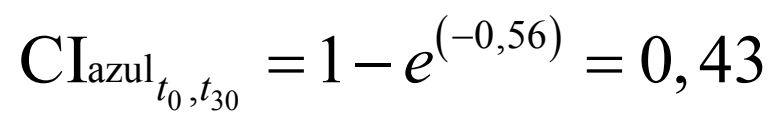

de forma que o risco relativo é 1,46 para vermelho. Desta forma tem-se que, embora o risco relativo da incidência acumulada até o tempo 30 sugira que vermelhos tenham risco aumentado em $46 \%$, o risco relativo da força de incidência no tempo 30 (risco instantâneo em 30) é 20 vezes maior para azuis do que para vermelhos. Para uma situação como a sugerida na figura 7, onde ao fim de todo o tempo de observação todos os indivíduos tanto de um grupo quanto de outro acabarão por apresentar o evento estudado, parece irrecorrível que as comparações aptas sejam entre forças de morbidade e não morbidade acumulada, sob pena de arbítrio na escolha do valor de tempo para estimação de efeito: para tempo 30 o risco de vermelhos é 1,4 mas ao tempo 60 é 1,0 .

\section{A razão de danos (hazard ratio)}

A razão de danos (hazard ratio) é uma medida de efeito que examina quantas vezes uma taxa de dano (hazard rate) é maior ou menor que outra. Taxa de dano é uma medida de velocidade de ocorrência de eventos 
que guarda uma analogia com a densidade de incidência na medida em que ambas são funções cujas acumuladas representam um risco. Da mesma forma que a razão de duas incidências acumuladas mede um risco relativo, a razão de duas taxas de dano acumuladas também representa um risco relativo.

A taxa de dano é uma medida concebida para estudos de sobrevivência, onde os eventos são óbitos, circunstância na qual o denominador de candidatos ao evento são os ainda vivos, ou os ainda por morrer, como na densidade de incidência o denominador são as pessoas-tempo ainda livres de evento, ainda por adoecer.

Esta taxa de dano variando no tempo é geralmente denotada por $\lambda(\mathrm{t}) \mathrm{e}$ designada função hazard (dano). Armitage ${ }^{55}$, designando $f(t)$ a função densidade de probabilidade de eventos no tempo e $F(t)$ a correspondente função distribuição, define $\lambda(t)$ como:

$$
\lambda(t)=\frac{f(t)}{1-F(t)}
$$

ou seja, a razão entre a velocidade de ocorrência e a proporção de pessoas sobrevivendo, o complemento da função distribuição, o que caracteriza uma medida de risco: eventos por pessoas sob risco de apresentar evento. O denominador desta razão $[1-\mathrm{F}(\mathrm{t})]$, a proporção de sobreviventes, é designado função sobrevivência e denotada por $S(t)$, permitindo que $\lambda(t)$ seja re-escrito como:

$$
\lambda(t)=\frac{f(t)}{S(t)}
$$

Lembrando que a função densidade $[f(t)]$ é a derivada da função distribuição $[F(t)]$, pode-se concluir que $f(t)$ é o negativo da derivada da função sobrevivência $[S(t)]$ : 


$$
\begin{aligned}
& S(t)=1-F(t) \\
& \frac{d S(t)}{d t}=\frac{d[1-F(t)]}{d t} \\
& \frac{d S(t)}{d t}=-f(t) \text { ou } f(t)=-\frac{d S(t)}{d t}
\end{aligned}
$$

Assumindo-se que

1. a velocidade de ocorrência de eventos seja constante e lembrando

2. que a derivada do logaritmo de uma função é igual à razão entre sua derivada e ela mesma

3. e que em $S(t)$, t varia entre 0 e $t[S(t)-S(0)]$ e que $S(0)=1$ (no início todos estão vivos)

integrando-se a função $\lambda(t)$ com relação a tempo obtém-se que $\lambda(t)$ é o negativo do logaritmo da função sobrevivência:

$$
\int_{0}^{t} \lambda(t) d t=\int_{0}^{t} \frac{f(t)}{S(t)} d t \text { ou } \int_{0}^{t} \lambda(t) d t=\int_{0}^{t} \frac{d S(t)}{S(t)} d t \text { ou } \lambda \mathrm{t}=-\ln \left(\frac{\mathrm{S}(\mathrm{t})}{\mathrm{S}(0)}\right)=-\ln [\mathrm{S}(\mathrm{t})]
$$

Desta forma, a função sobrevivência resulta no antilog

$$
S(t)=e^{-\lambda t}
$$

Nesta forma, $\lambda$ pode então ser interpretado como o risco de efeito multiplicativo sobre a redução de sobrevida, pelo que dano ou hazard. Um valor da função de dano $(\lambda)$ é um rate (uma taxa) e a razão entre dois valores característicos de dois grupos a serem comparados é um ratio (uma razão), um hazard rate ratio, geralmente referido simplesmente como hazard ratio.

Para a comparação entre dois grupos de pessoas, v.g. expostos e não expostos a um fator relacionado à doença, a função de dano $\lambda(t)$ pode ser 
reconsiderada como um $\lambda(t, x)$, ou seja, um função dependente tanto do tempo quanto de um fator ' $X$ ' considerado. A razão entre dois $\lambda(t, x)$ segundo, por exemplo, categorias de $X$, é uma medida de risco relativo, de efeito de um x sobre outro. Num modelo de regressão de Cox, esta razão de riscos é assumida como regular, ou seja assume-se que as diferenças de dano em qualquer ponto do tempo guardem uma relação de proporcionalidade. Na regressão de Cox, os expoentes da exponencial que caracteriza a função sobrevivência vão ser comparados de maneira semelhante ao que é feito na regressão logística (Figura 6), de forma que o antilog do coeficiente de regressão será uma estimativa de risco relativo. $\mathrm{Na}$ figura abaixo se apresenta um exemplo de dados hipotéticos onde são comparadas duas funções de dano num modelo de Cox.

Figura 8 - Exemplo hipotético de risco relativo como razão de funções de dano

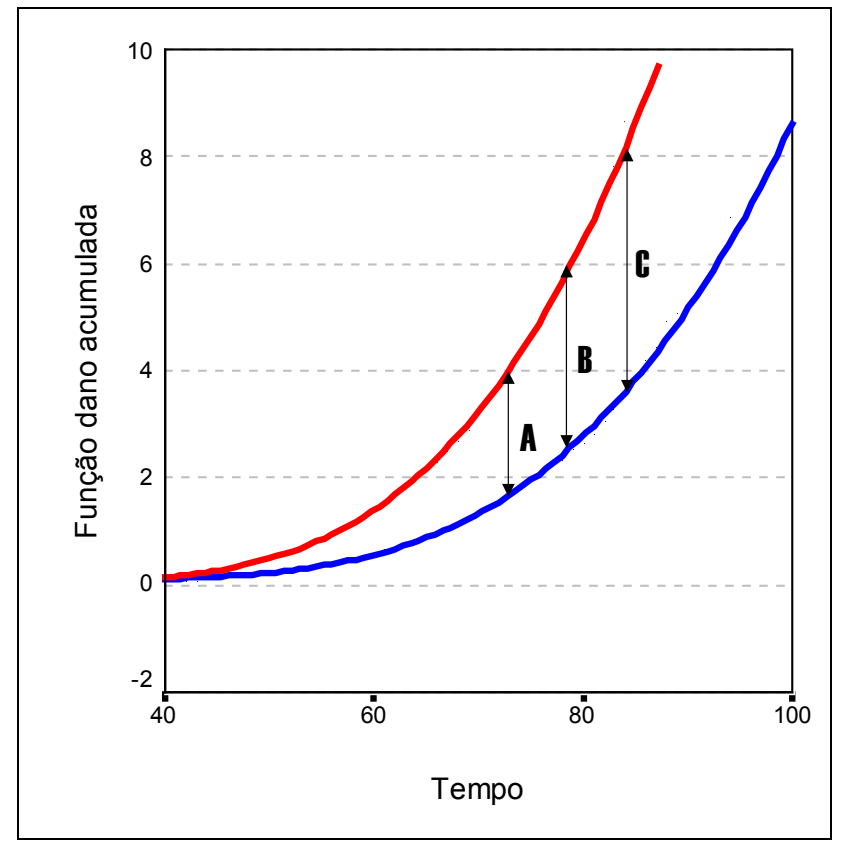

Note-se no gráfico que embora os segmentos A, B e C, que mostram as distâncias entre as funções, tenham tamanhos diferentes, a razão entre valores das duas funções é constante, de forma que $B / A=C / B$. Esta taxa de acréscimo é que é calculada na regressão de Cox, e para o exemplo da Figura 8 resulta em 2,3. Isto então sugere que a categoria vermelha tenha riscos de evento 2,3 vezes maiores que os da categoria azul. Este é um 
risco médio, já que as funções são ajustadas sob as premissas de velocidades constantes e razões proporcionais.

\section{A razão de derivadas}

A razão de derivadas é uma técnica de estimação de risco relativo que no presente estudo foi concebida para oferecer resposta à questão do efeito do sexo sobre a ocorrência de infarto agudo do miocárdio.

Guarda analogia tanto com a incidence rate ratio (razão de ID) quanto com a hazard rate ratio (razão de taxa de dano) enquanto medida de efeito. Em relação à primeira, é uma generalização do fato demonstrado de que a razão das funções densidades de incidência (derivadas) são equivalentes a uma razão de funções distribuição de probabilidade, portanto uma razão de riscos, um risco relativo. Em relação à segunda, é uma técnica de estimação de efeito que prescinde do contraste de ocorrências entre doentes e não doentes. De fato, na razão de dano e na regressão de Cox, pode-se considerar a entrada de informações sobre pessoas que não tenham apresentado o evento até um determinado ponto no tempo (dados censurados), mas a função não é um contraste entre casos SIM contra casos NÃO, como no odds ratio e na regressão logística. Considerando que esta situação em que a ocorrência de eventos entre não expostos pode ser desconsiderada é pouco usual em problemas das ciências da saúde, Armitage e Berry ${ }^{55}$ iniciam a apresentação do modelo de Cox de riscos proporcionais dando ênfase a esta característica:

\footnotetext{
"It would be unusual to analyse a single group of homogeneous subjects [v.g. todos doentes] but the basic method [função de dano definida no tempo: $\lambda(t)$ ] may be extended to cope with more realistic situations by modeling the hazard rate to represent dependence on variables recorded for each subject as well as on time [a função anteriormente sugerida: $\lambda(t, x)] . "$ Pg.435
}

O problema pouco usual que se coloca é analisar o efeito do sexo num grupo homogêneo de pessoas, as que tiveram infarto agudo do miocárdio. 
Usando-se o modelo de Cox, largamente usado como se viu nos exemplos da primeira parte desta introdução, obtém-se uma estimativa de efeito como razão de danos, mas paga-se tributo à premissa que supõe regularidade na relação. Os efeitos são assumidos como proporcionais e a medida de efeito é uma tendência média de efeito de um sexo sobre outro no condicionamento da ocorrência de infarto. Sob esta premissa supõe-se que as funções de dano nunca se cruzem, uma premissa imprópria para examinar-se a relação entre homens e mulheres todos doentes, pois, afinal, se em algum tempo um sexo supera o outro é porque, necessariamente, a outro tempo esta relação deva se inverter. A razão de derivadas será uma medida que não se expressará por um valor singular médio mas por uma função com a qual se poderá responder qual o efeito de um sexo em relação ao outro em qualquer momento do tempo que se tenha interesse. Naturalmente, como momento de interesse especial emerge o tempo em que a força de morbidade seja igual para os dois sexos, ou por outra, o momento em que a superioridade de um passe a dar lugar à superioridade complementar do outro.

Como comentado para o caso do cálculo do risco relativo como razão de densidades de incidência no exemplo da figura 7, quando ambos os grupos são de pessoas que apresentaram o evento em algum ponto do tempo, se a observação completa for analisada como razão das integrais (risk ratio) não haverá risco detectável já que ao fim ambos os grupos tiveram todos os seus membros afetados. Já a razão de derivadas (incidence rate ratio) para o período todo não oferecerá uma medida única, mas uma função que informará quanto a cada momento uma força de morbidade supera outra tomada como referência. Em epidemiologia, a busca de medidas sintéticas e singulares torna atrativa a informação resumida num único número como o risco relativo, o odds ratio e o hazard ratio. No entanto, estas medidas resumo fazem tabula rasa de variações cujo comportamento esconde informações importantes para um melhor conhecimento do fenômeno que se estude ${ }^{56}$. A razão de derivadas, informando o efeito na forma de uma 
função, frustra a expectativa de uma medida singular mas promove o alargamento da informação.

Para superar esta frustração mantendo-se a abordagem de medidas singulares e conseqüentemente as fortes premissas que ela impõe, a alternativa é examinar diferentes divisões de tempo e comparar as diferentes medidas singulares, como sugerem Armitage e Berry ${ }^{55}$, com base em Holford ${ }^{57}$, ao comentarem esta frustração na avaliação de risco pela função de dano:

"The main restriction of the exponential model is the assumption that the death rate is independent of time. It would usually be unreasonable to expect this assumption to hold except over short time intervals. One way of overcoming this restriction is to divide the period of follow-up into a number of shorter intervals, and assume that the hazard rate is constant within each interval but that it is different for the different intervals."

Esta tem sido a estratégia usada para esclarecer os efeitos do sexo sobre a ocorrência de doenças cardiovasculares, como se apresentou na tabela 2 . Para o presente estudo, define-se a razão de derivadas como método de estimação de efeito e com ela se avalia a influência do sexo na ocorrência do infarto agudo do miocárdio ao longo das idades. 
38

Objetivos 


\section{Objetivo geral}

O presente estudo busca examinar uma estratégia metodológica, a razão de derivadas, como instrumento de estimação de efeito em situações onde um grupo homogêneo definido por um atributo comum, v.g. presença de uma doença, é examinado com vistas a se conhecer os efeitos de um segundo atributo que se supõe condicionar a manifestação do primeiro em alguma dimensão específica, v.g. tempo, idade. Este segundo atributo, v.g. sexo, que divide o grupo original em subgrupos, terá seus efeitos aferidos de forma relativa pelo contraste entre os valores ou categorias que 0 caracterizam, v.g. masculino em contraste com feminino, segundo a dimensão em que o evento se manifeste, v.g. idade.

\section{Objetivo específico}

Identificar os efeitos do sexo sobre a idade de ocorrência de infarto agudo do miocárdio em pacientes brasileiros por contraste do sexo masculino com o feminino em relação à velocidade de incidência da doença pela idade. Identificar por este meio a idade onde homens e mulheres se igualam nesta medida de ocorrência, ou por outra, a idade em que a conhecida superioridade masculina passa a dar lugar à complementar superioridade feminina. 
Material e métodos 


\section{O estudo AFIRMAR: pacientes estudados}

O AFIRMAR foi realizado entre outubro de 1997 e novembro de 2000, como um estudo caso-controle multi-cêntrico que envolveu 104 hospitais em 51 cidades brasileiras. Foi idealizado e coordenado pelo Prof. Leopoldo S. Piegas, Diretor do Instituto Dante Pazzanese de Cardiologia, com vistas a identificar o perfil brasileiro de fatores de risco para o infarto agudo do miocárdio. Seus resultados foram publicados em agosto de 2003 no American Heart Journa ${ }^{47}$, um dos periódicos da American Heart Association. Os dados relativos à região metropolitana de São Paulo foram analisados em tese de doutorado apresentada à Faculdade de Medicina da USP ${ }^{58}$, em 2002.

No período de estudo, 3.350 pacientes (casos e controles) foram recrutados, dos quais 2.558 preencheram as condições necessárias para uma análise pareada por sexo e idade, conduzida por regressão logística condicional. $O$ pareamento por idade foi feito pela identificação de controle com data de atendimento mais próxima ao caso e para o qual a idade não diferisse do caso para mais ou para menos do que 5 anos.

O total de registros de pacientes, sem pareamento, foi também analisado por regressão logística incondicional, considerando-se neste modelo os mesmo fatores de risco analisados sob pareamento. A variável sexo não foi então analisada dado o pareamento inicial e a coerência de manter-se o mesmo grupo de fatores de risco sob avaliação no modelo não pareado. Foram considerados casos de infarto aqueles em que os pacientes apresentassem as características clínicas padronizadas pela Organização Mundial da Saúde. Controles foram selecionados entre pacientes do mesmo hospital para os quais a presença de qualquer doença cardiovascular foi excluída. 
O recrutamento de hospitais para participação no estudo foi feito via Sociedade Brasileira de Cardiologia e a participação acompanhada em seus congressos anuais.

\section{Efeitos relativos num espaço complementado: conceitos preliminares para introdução da razão de derivadas como medida de efeito}

Um espaço complementado é aquele cujos subconjuntos segundo um dado predicado são uma divisão completa de seu estado original. Em outras palavras, tudo neste espaço é uma categoria de um predicado ou um complemento desta categoria. Sexo, por exemplo, é um predicado que divide as pessoas em subconjuntos complementares: cada pessoa é masculino ou feminino e o subconjunto de todos os homens é o complemento do subconjunto de todas as mulheres. Isto, em linguagem de conjuntos, poderia ser enunciado como:

$$
\begin{gathered}
A \cup B=U \text { a união dos subconjuntos é uma tautologia e } \\
A \bigcap B=\varnothing \text { a intersecção dos subconjuntos é uma contradição }
\end{gathered}
$$

Espaços deste tipo são típicos, têm propriedades matemáticas próprias e seu estudo pertence a uma disciplina da Matemática, a Topologia. Embora possa parecer intuitivo que o complemento de masculino seja feminino e que num espaço fechado tudo que não pertença a um subconjunto pertença a seu subconjunto complementar, a complementaridade é uma condição muito particular, talvez mesmo bizarra no aspecto. Mauritius Cornelius Escher (1898-1972), foi um pintor holandês que, a despeito de não ter tido nenhum estudo especial em matemática, ganhou grande reconhecimento entre os matemáticos por sua habilidade em retratar conceitos matemáticos em seus desenhos e pinturas. A figura 9 mostra um trabalho de Escher (ensaio para o quadro Reptiles, de 1943) representando um espaço fechado com subespaços complementados. 
Figura 9 - Espaço complementado em representação de Escher, 1943

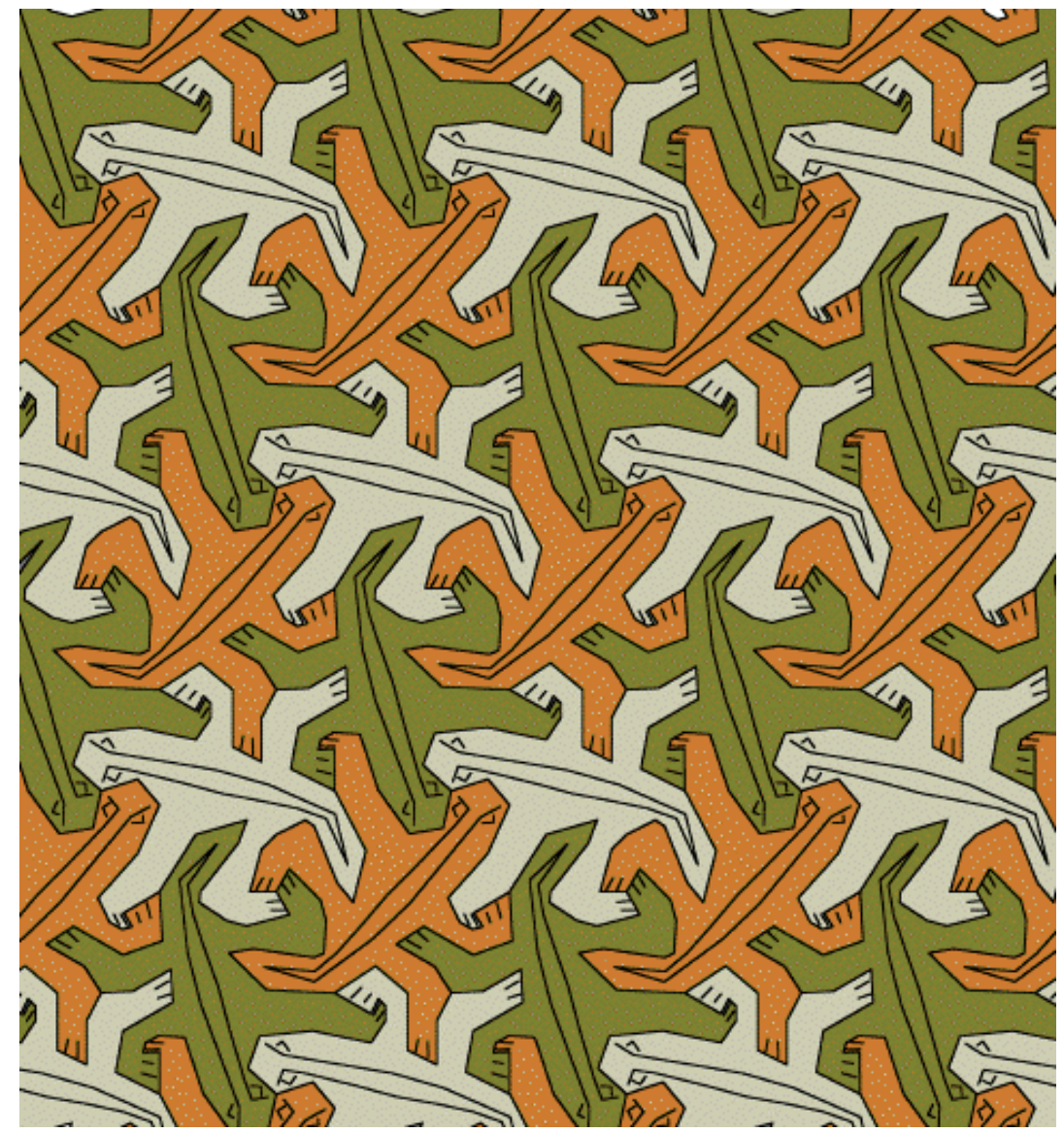

Neste espaço, em qualquer partição pode-se contrastar a proporção $\left(\mathrm{n}_{\mathrm{A}} / \mathrm{N}_{\mathrm{A}}\right)$ de lagartos de uma cor ( $\mathrm{n}_{\mathrm{A}}$ - lagartos de cor $A$ presentes na partição) em relação a todos os lagartos da mesma cor $\left(N_{A}\right.$ - todos os lagartos da cor $\left.A\right)$ contra a proporção $\left(n_{B} / N_{B}\right)$ de lagartos de outra cor $\left(n_{B}\right.$ - lagartos de cor $B$ presentes na partição) em relação a todos desta outra cor ( $\mathrm{N}_{B}$ - todos os lagartos da cor B), mas no espaço total, a proporção de lagartos de qualquer cor é $100 \%$ - todos os lagartos de uma cor estão no espaço total - e o contraste entre lagartos de diferentes cores não se aplica: a razão resulta em 1.

Pode-se ainda notar na figura que, embora em partições específicas a proporção de lagartos de uma cor possa superar a de lagartos de outra cor, sempre deverá haver um espaço complementar onde as superioridades se invertam - as superioridades são circunstanciais, já que se anulam no todo. Mais ainda, pode-se imaginar que se a transição entre subespaços for feita de uma maneira contínua, haverá sempre um ponto no espaço onde as 
proporções serão iguais, ou seja, o ponto de inflexão onde a superioridade de uma categoria cede lugar para a superioridade de outra categoria complementar.

Por fim, há que se destacar que o contraste entre duas categorias só será possível se a partição examinada contiver ambas as categorias, cada uma se expressando como uma proporção do total de seus pares.

De volta à ocorrência de doença, para se contrastar, por exemplo, duas categorias de sexo, masculino e feminino, ao longo do tempo, é preciso que para o valor de tempo que se queira aferir o efeito (partição do espaço total), ambas as categorias estejam presentes. A figura 10 abaixo hipoteticamente representa a ocorrência de uma doença nos subconjuntos homens e mulheres, azul e vermelho. Em ambas as categorias o fenômeno ao fim de algum tempo afeta todas pessoas. As densidades de incidência são apresentadas como funções derivadas da incidência acumulada em cada grupo, e são destacadas na figura 11 em seguida. Na abordagem mais comum em estudos de ocorrência de doença, toma-se a função densidade de incidência, que é interpretável como medidas instantâneas ou força de ocorrência em coortes dinâmicas, para analisar-se a incidência acumulada, que é a probabilidade de ocorrer doença num intervalo de tempo. Matematicamente, no entanto, é indiferente, uma vez que derivada e integral são funções isomórficas - de uma chega-se à outra. 
Figura 10 - Curvas hipotéticas de incidência acumulada e densidade de incidência entre homens e mulheres

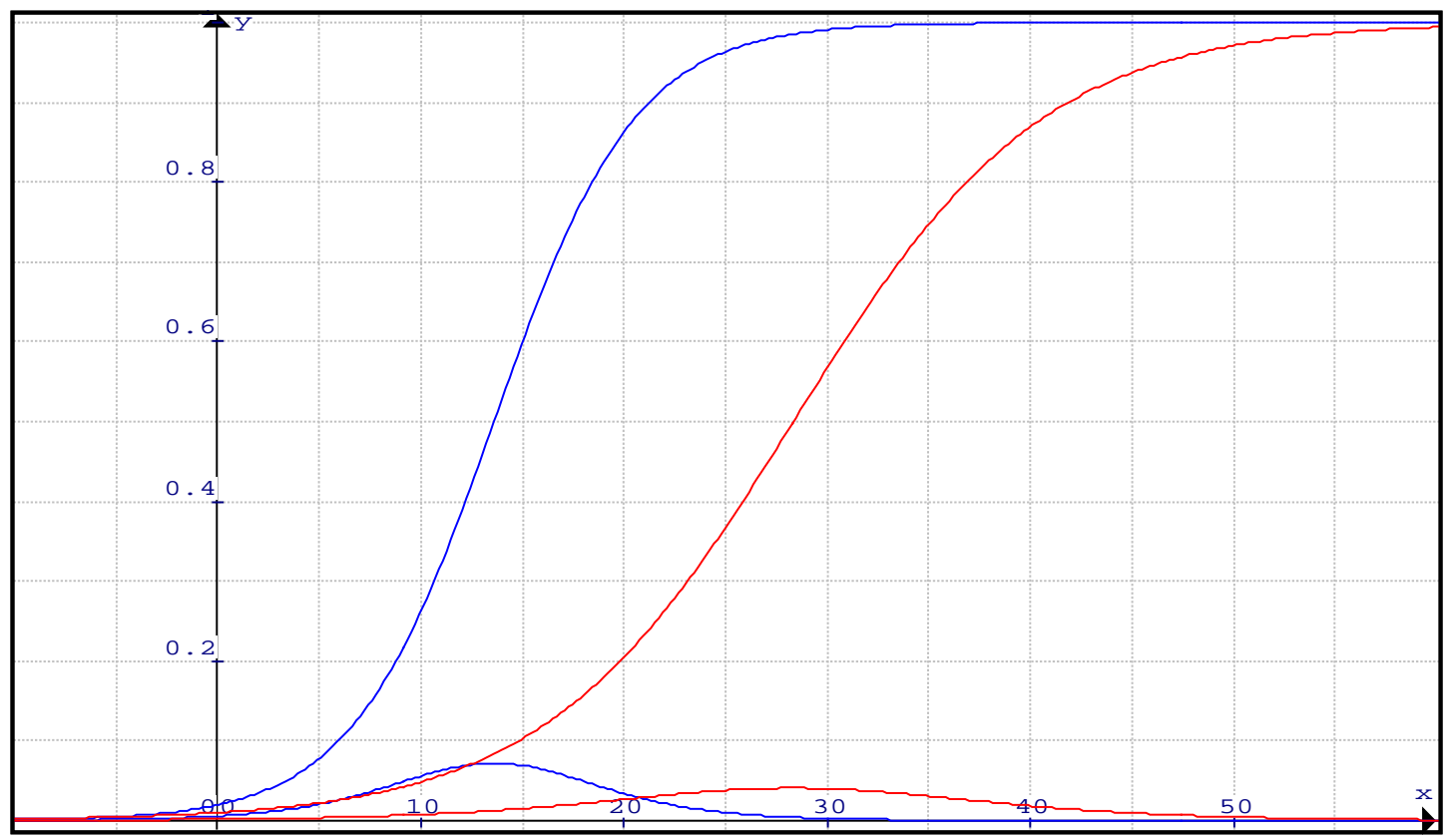

Figura 11 - Figura 10 em detalhe

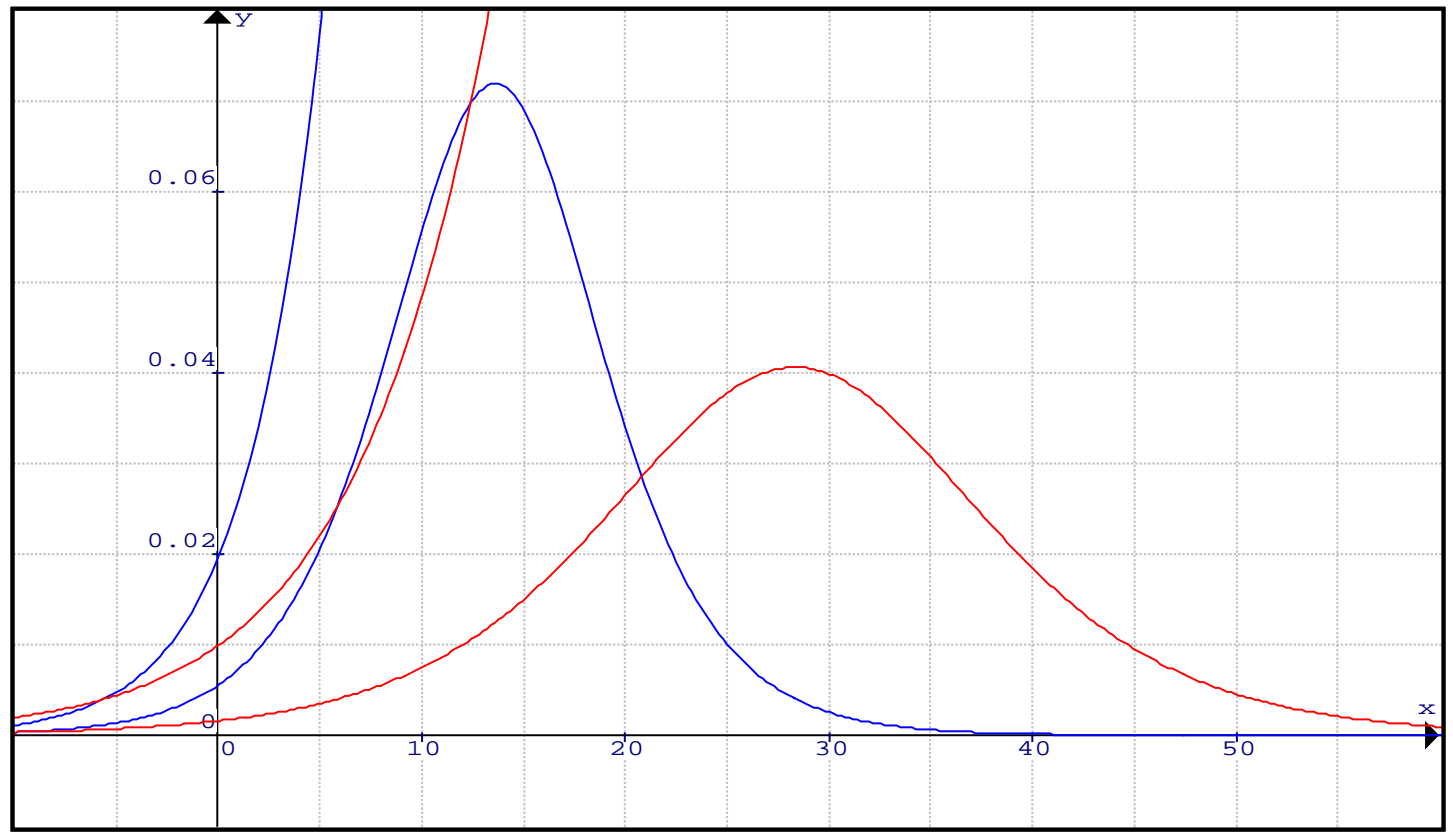

Nota-se que o efeito, que poderia ser medido como uma razão das funções derivadas não é possível para valores de tempo superiores a 40, quando a densidade de incidência para azul torna-se nula. Nota-se ainda que a superioridade do azul dá lugar a uma superioridade compensatória para o 
vermelho logo após o tempo 20 , sugerindo que o ponto de inflexão seja algo em torno de 21 ou 22.

As figuras seguintes mostram um exemplo semelhante onde o contraste na forma de razão não se aplicaria, dado que os tempos em que os eventos de uma categoria ocorrem são totalmente distintos dos tempos da outra.

Figura 12 - Curvas hipotéticas de incidência acumulada e densidade de incidência entre homens e mulheres numa situação onde a razão entre as categorias de sexo não se aplica

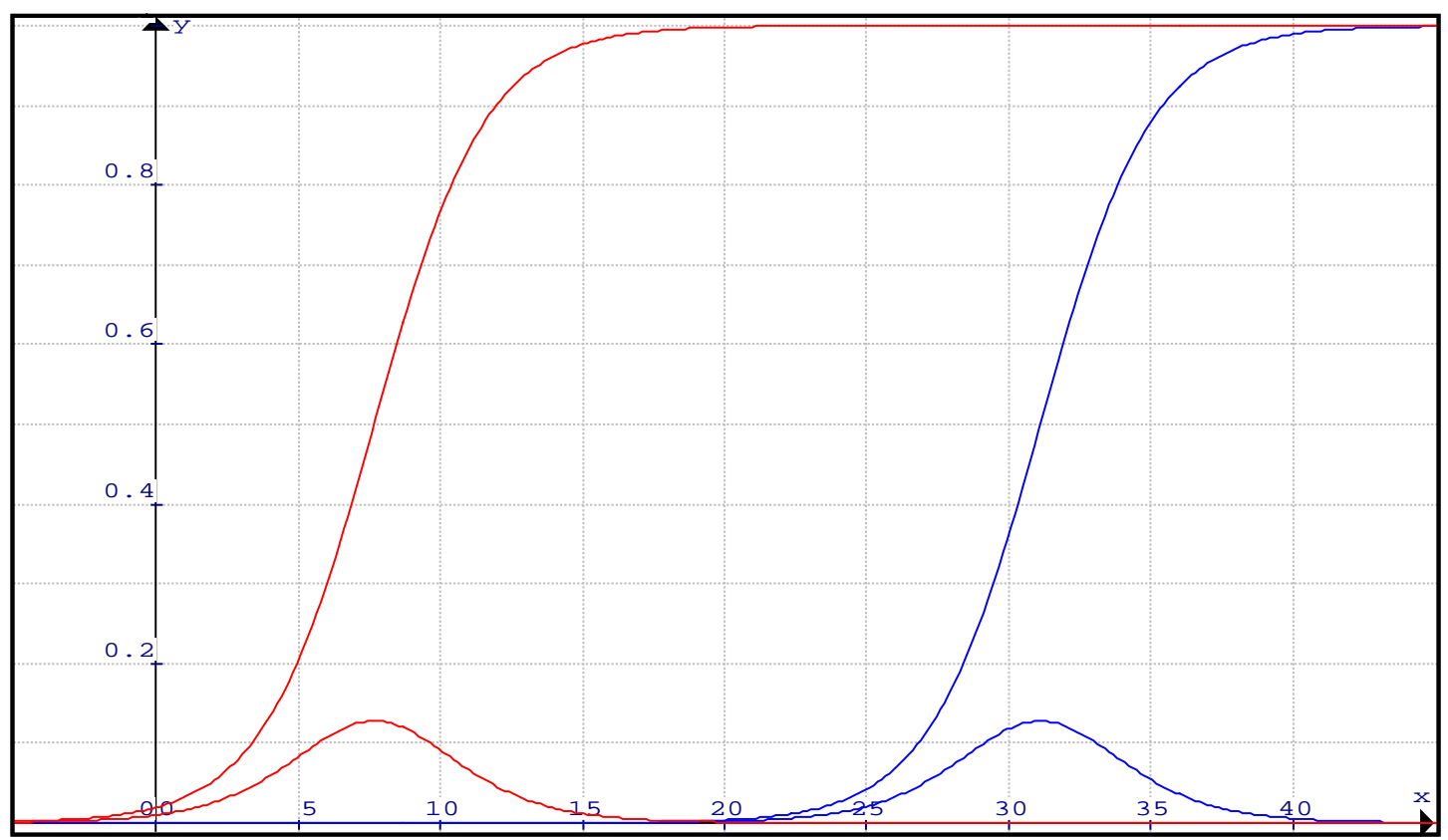

Figura 13 - Figura 12 em detalhe

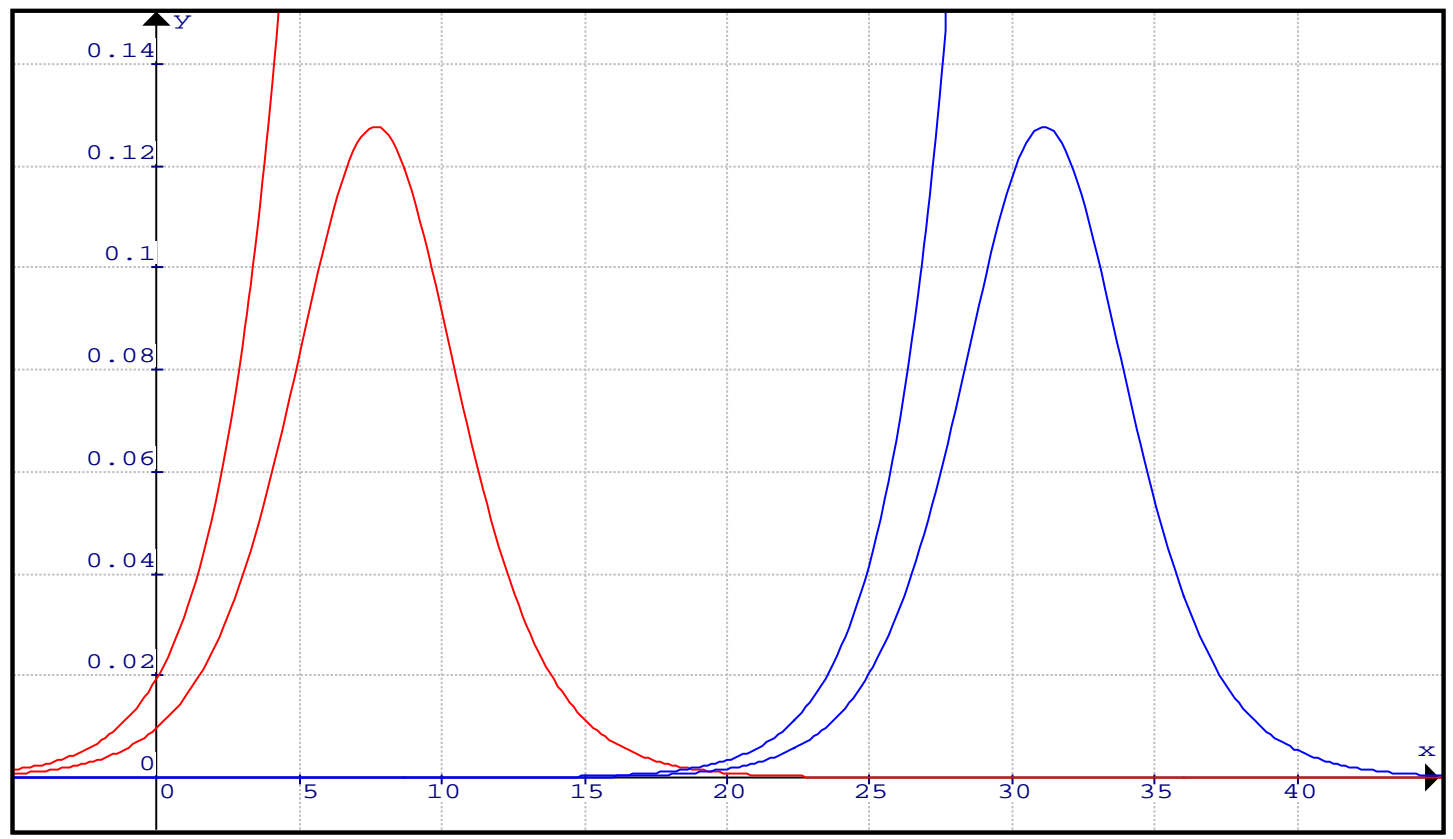




\section{A razão de derivadas como medida de efeito}

Como já ficou evidente dos comentários anteriores, a razão de derivadas é uma estratégia de estimação de risco relativo, ou efeito relativo. De fato, entendendo-se com Miettinen que o risco relativo seja uma razão de forças de morbidade, sendo estas as derivadas do risco acumulado, o que se tem como medida de risco relativo é uma razão de derivadas. Quando Miettinen define risco acumulado como

$$
\mathrm{CI}_{t_{0}, t_{1}}=1-e^{\left(-\int_{t_{0}}^{t_{1}}\left(\mathrm{ID}_{t}\right) d t\right)}
$$

ele está considerando um grupo de pessoas acompanhadas ao longo do tempo, uma coorte, que inicialmente é livre de doença e que progressivamente acumula ocorrências de doença. Se se considerar expressar o número de pessoas sob acompanhamento como uma proporção (normalizando $n$ para a unidade) e ainda se se considerar que ao final do acompanhamento todas as pessoas venham a ser afetadas, pode-se representar este modelo com uma figura como a sugerida abaixo:

Figura 14 - Comportamento de um grupo de pessoas acumulando ocorrências de doença ao longo do tempo

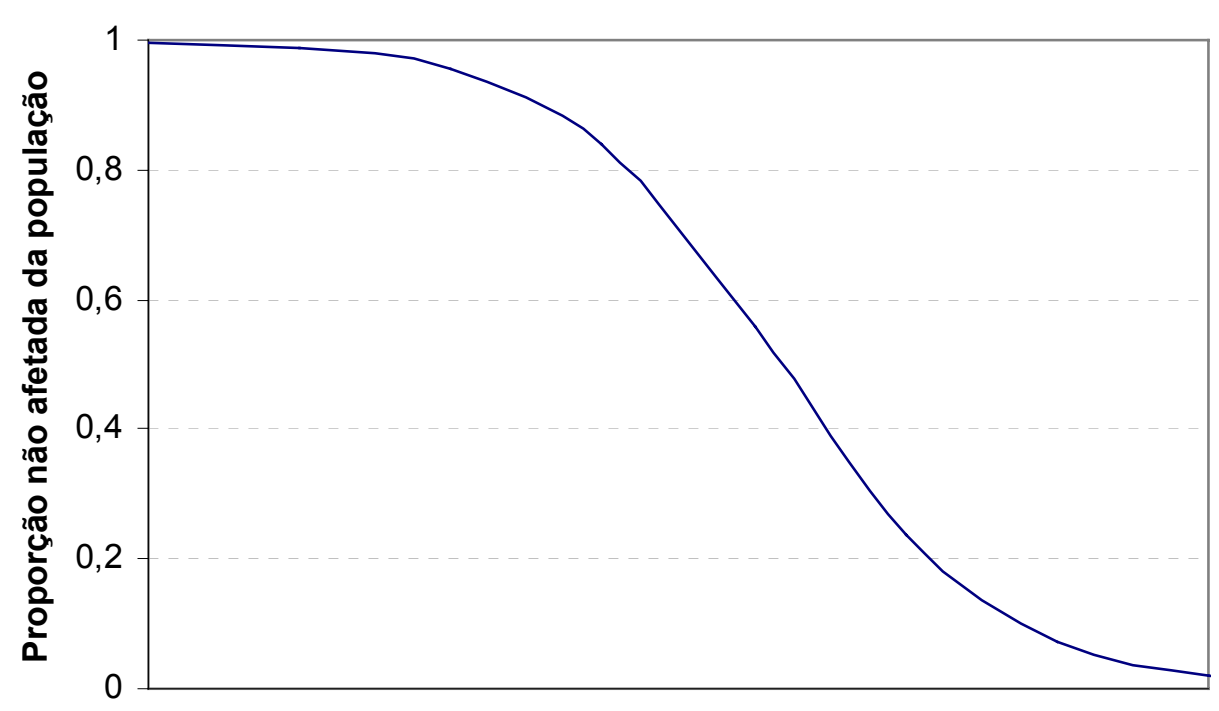


O modelo dinâmico que está sendo considerado é o da transição de pessoas sadias (S) para pessoas doentes (D) segundo uma taxa de incidência de doença que varia no tempo $\left(I_{t}\right)$, como na figura abaixo:

Figura 15 - Modelo dinâmico de transição de sadios para doentes segundo uma taxa de incidência de doença

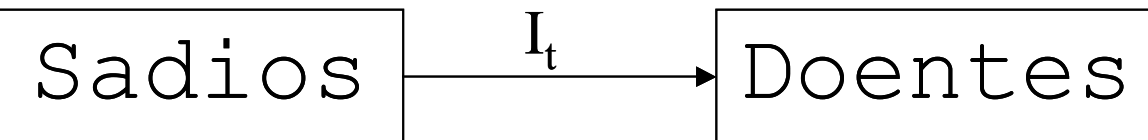

onde se define que

$\mathrm{D}_{0}=$ Proporção de doentes no tempo $\mathrm{t}=0$;

$\mathrm{S}_{0}=$ Proporção de sadios no tempo $\mathrm{t}=0$;

$D_{t}=$ Proporção de doentes no tempo $t ;$

$S_{t}=$ Proporção de sadios no tempo $t$.

e onde

$D_{t}+S_{t}=1$

Variações proporcionais de $\mathrm{S}\left(\Delta \mathrm{S}_{\mathrm{t}} / \mathrm{S}_{\mathrm{t}}\right)$ num dado intervalo de tempo $(\Delta \mathrm{t})$ indicam a taxa de incidência pelo tempo, que será negativa porque $S$ decresce:

$$
\frac{\Delta S_{t}}{S_{t} \Delta t}=-I_{t}
$$

relação cujo limite para quando o intervalo de tempo tender a zero é a derivada

$$
\frac{d \mathrm{~S}_{\mathrm{t}}}{\mathrm{S}_{\mathrm{t}} d t}=\frac{1}{\mathrm{~S}_{\mathrm{t}}} \cdot \frac{d \mathrm{~S}_{\mathrm{t}}}{d t}=-\mathrm{I}_{\mathrm{t}}
$$

de onde

$$
\frac{d \mathrm{~S}_{\mathrm{t}}}{\mathrm{S}_{\mathrm{t}}}=-\mathrm{I}_{\mathrm{t}} d t \text { ou integrando-se dos dois lados } \int_{\mathrm{S}_{0}}^{\mathrm{S}_{\mathrm{t}}} \frac{d \mathrm{~S}_{\mathrm{t}}}{\mathrm{S}_{\mathrm{t}}}=\int_{0}^{\mathrm{t}}-\mathrm{I}_{\mathrm{t}} d t
$$

Dado que a integral da razão de uma função diferencial pela própria função é o logaritmo neperiano da função, a solução do lado esquerdo da equação é $\ln \left(\mathrm{S}_{\mathrm{t}}\right)$. Considerando-se que, em se tratando de uma 
integral definida, $\ln S_{t}$ pode ser escrito como $\ln S_{t}-\ln S_{0}$, ou por outra $\ln \left(\mathrm{S}_{\mathrm{t}} / \mathrm{S}_{0}\right)$, tem-se que

$$
\begin{aligned}
\ln \left(\frac{S_{t}}{S_{0}}\right) & =\int_{0}^{\mathrm{t}}-\mathrm{I}_{\mathrm{t}} d t \text {, de onde } \\
S_{t} & =S_{0} e^{-\int_{0}^{t} I_{t} d t}
\end{aligned}
$$

Como $D_{t}+S_{t}=1$, e $S_{0}=1$ (no tempo zero todos são sadios), o número de doentes acumulados até o tempo t é:

$$
D_{t}=1-e^{-\int_{0}^{t} I_{t} d t}, \text { a fórmula de Miettinen. }
$$

Se se propuser que, ao invés de acompanhar um grupo de sadios que progressivamente se torna doente, observe-se o acúmulo de doentes ao longo do tempo, tem-se situação idêntica. Neste caso, a observação do fenômeno pode ser representada por uma figura complementar à figura 14:

Figura 16 - Comportamento de um grupo de pessoas que se constitui conforme acumula ocorrências de doença ao longo do tempo

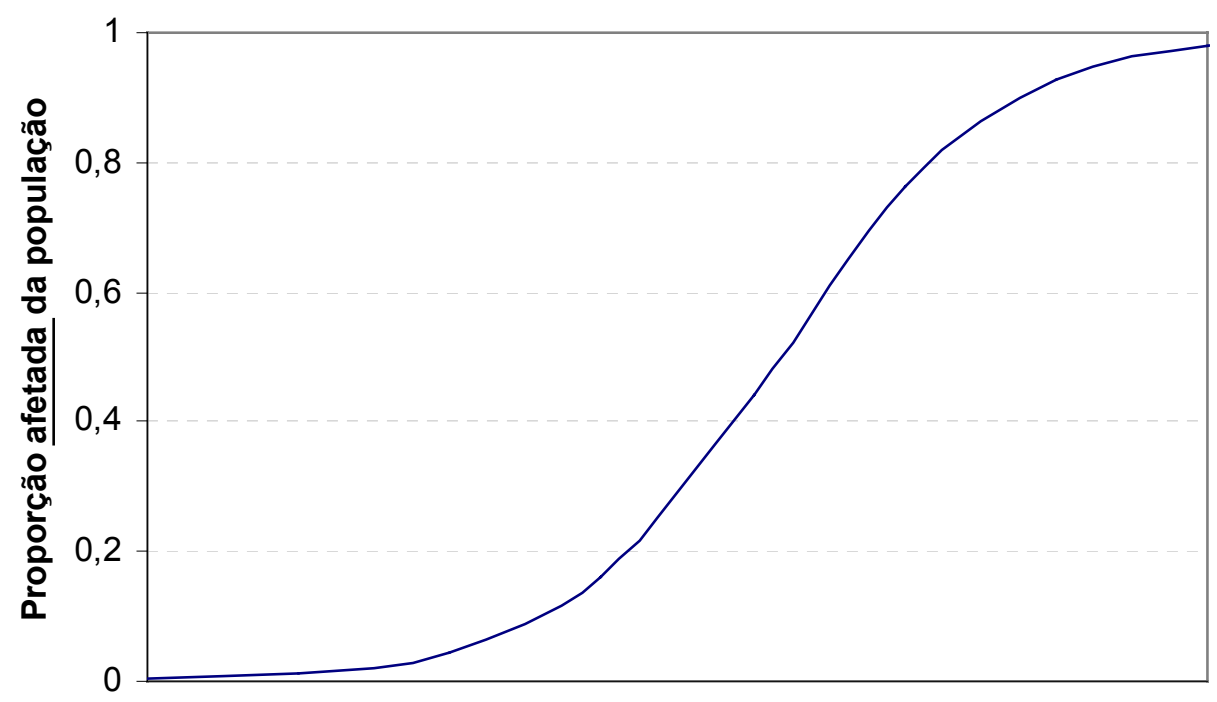


Neste caso calcula-se que variações de doentes $\left(\Delta \mathrm{D}_{\mathrm{t}}\right)$ num dado intervalo de tempo $(\Delta \mathrm{t})$ proporcionais aos sadios $\left(\mathrm{S}_{\mathrm{t}}\right.$, de forma que proporção de doentes por candidatos a doença,) para estimar a taxa de incidência para o tempo $t$, que será positiva porque $\mathrm{D}_{\mathrm{t}}$ cresce:

$$
\frac{\Delta D_{t} / \Delta \mathrm{t}}{\mathrm{S}_{\mathrm{t}}}=\mathrm{I}_{\mathrm{t}}
$$

O limite para quando o intervalo de tempo tender a zero é a derivada

$$
\frac{d \mathrm{D}_{\mathrm{t}}}{\mathrm{S}_{\mathrm{t}} d t}=\mathrm{I}_{\mathrm{t}}
$$

Como $D_{t}+S_{t}=1$, este limite pode ser re-escrito como

$$
\frac{d \mathrm{D}_{\mathrm{t}}}{d t} \cdot \frac{1}{1-\mathrm{D}_{\mathrm{t}}}=\mathrm{I}_{\mathrm{t}} \text { ou } \frac{d \mathrm{D}_{\mathrm{t}}}{1-\mathrm{D}_{\mathrm{t}}}=\mathrm{I}_{\mathrm{t}} d t
$$

que, como anteriormente, integrando-se dos dois lados resulta em

$$
-\ln \left(\frac{1-\mathrm{D}_{\mathrm{t}}}{1-\mathrm{D}_{0}}\right)=\int_{0}^{t} I_{t} d t
$$

Como $D_{0}$, número de doentes no tempo zero, é igual a zero, $1-\mathrm{D}_{0}=1, \mathrm{e}$ assim a expressão pode ser re-escrita como

$$
-\ln \left(1-\mathrm{D}_{\mathrm{t}}\right)=\int_{0}^{t} I_{t} d t \text { ou } \ln \left(1-\mathrm{D}_{\mathrm{t}}\right)=-\int_{0}^{t} I_{t} d t
$$

Fazendo-se o antilog, tem-se

$$
\left(1-\mathrm{D}_{\mathrm{t}}\right)=e^{-\int_{0}^{t} I_{t} d t} \text { ou } \mathrm{D}_{\mathrm{t}}=1-e^{-\int_{0}^{t} I_{t} d t}
$$

novamente o mesmo resultado de Miettinen. 
Para além da demonstração por cálculo de que a razão de derivadas é uma medida de efeito, parece de todo interessante que antes de sua aplicação, afira-se sua concordância com alguma outra forma de estimativa de risco bem estabelecida. Para isto, emprestando-se dados do mesmo projeto AFIRMAR que será objeto de análise no presente estudo, compara-se aqui - a título de exemplo - a razão de derivadas com uma regressão logística na aferição de LDL-colesterol como fator de risco para infarto do miocárdio.

O AFIRMAR é um estudo caso-controle onde casos são pessoas infartadas e controles são pessoas para as quais a presença de qualquer doença cardiovascular foi excluída. O gráfico abaixo mostra a freqüência acumulada de LDL-colesterol entre casos e controles, ajustando uma curva hipotética de distribuição acumulada de probabilidade normal

Figura 17 - Freqüências acumuladas e correspondentes funções de distribuição acumulada de probabilidade normal entre casos e controles

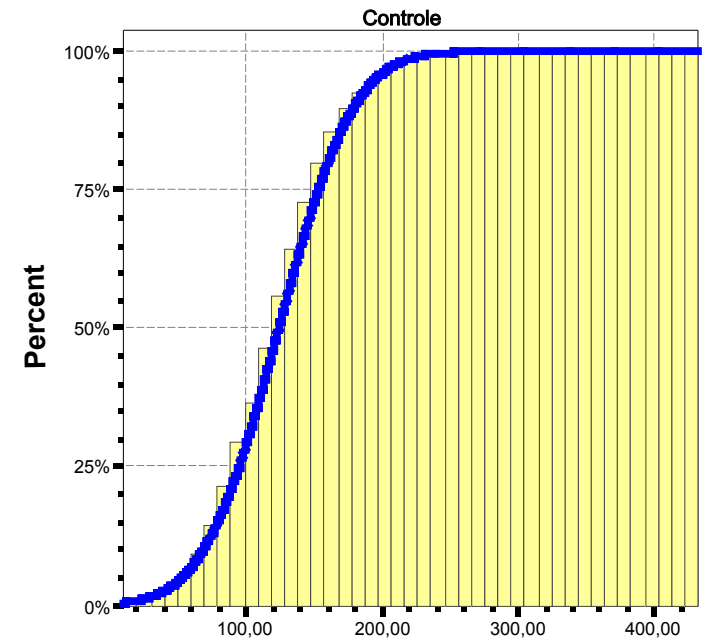

LDL

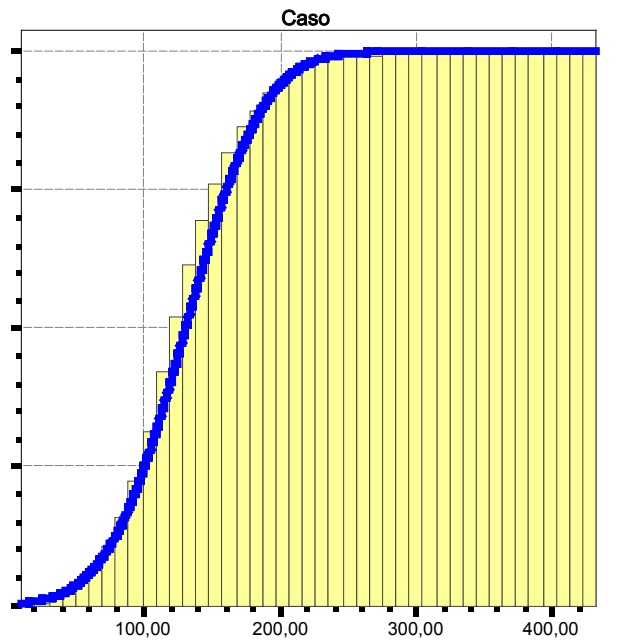

LDL

As correspondentes distribuições de freqüência relativa e funções densidade de probabilidade normal ajustadas, são apresentadas na figura 18, abaixo: 
Figura 18 - Distribuição de freqüências e correspondentes funções de densidade de probabilidade normal entre casos e controles

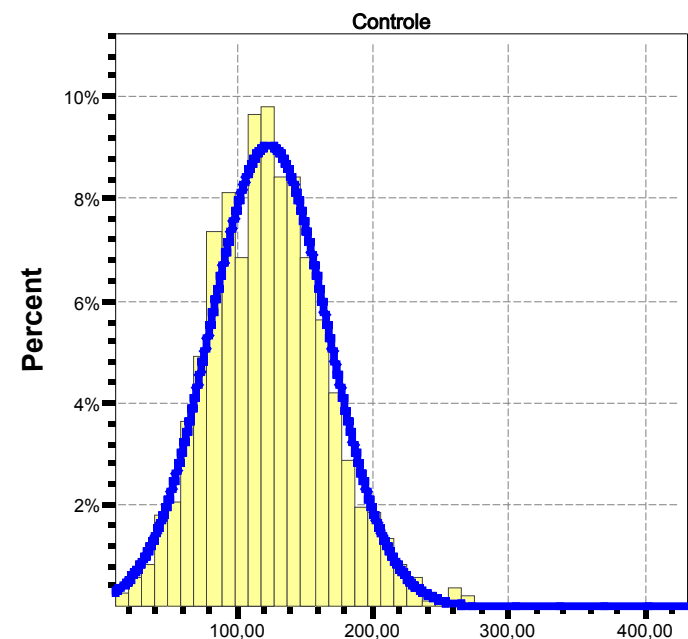

LDL

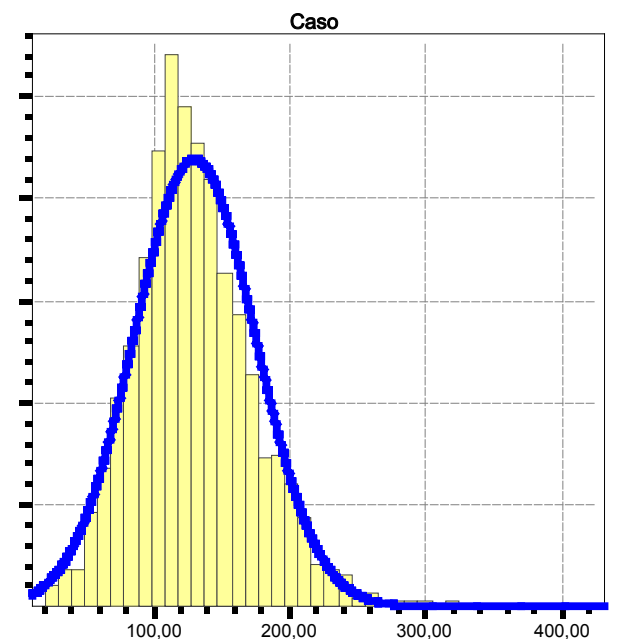

LDL

Os parâmetros das funções densidade de probabilidade normal, média e desvio padrão, são respectivamente 130,22 e 44,56 para casos e 123,75 e 43,15 para controles. Desta forma, as funções densidade, ou por outra, as derivadas da incidência acumulada ou risco de incidência, resultam no seguinte:

$$
\begin{aligned}
& f_{\text {caso }}(l d l)=\frac{1}{44,56 \sqrt{2 \pi}} e^{-\frac{1}{2}\left[\frac{(l d l-130,22)}{44,56}\right]^{2}} \\
& f_{\text {controle }}(l d l)=\frac{1}{43,15 \sqrt{2 \pi}} e^{-\frac{1}{2}\left[\frac{(l d l-123,75)}{43,15}\right]^{2}}
\end{aligned}
$$

A razão das derivadas de casos e controles resulta em

$$
\frac{f_{\text {caso }}(l d l)}{f_{\text {controle }}(l d l)}=0,97 e^{-\frac{1}{2}\left(-0,000033 l d l^{2}+0,0018 l d l+0,32\right)}
$$

Para expressar a razão como uma função análoga às funções originais, pode-se reduzir o polinômio do expoente a uma diferença de quadrados através dos seguintes passos: 
$0,97 e^{-\frac{1}{2}\left[\left(-0,000033 l d l^{2}+0,0018 l d l+0,32\right)\right]}$

o coeficiente da variável ao quadrado é posto como multiplicador do polinômio

$0,97 e^{-\frac{1}{2}\left[-0,000033\left(l d l^{2}-54,54545 l d l-9696,97\right)\right]}$

o termo médio é decomposto em duas metades e um quadrado da metade numérica é acrescentado e retirado da parte constante, de forma que ela não se altera

$0,97 e^{-\frac{1}{2}\left[-0,000033\left(l d l^{2}-2.27,273 l d l-9696,97-\left(27,273^{2}\right)+\left(27,273^{2}\right)\right)\right]}$

reúnem-se as partes que constituem um quadrado de diferença e calcula-se a nova constante

$0,97 e^{-\frac{1}{2}\left[-0,000033\left((l d l-27,273)^{2}-10440,79\right)\right]}$

faz-se o produto do multiplicador pela constante

$0,97 e^{-\frac{1}{2}\left[-0,000033\left((l d l-27,273)^{2}\right)+0,344546\right]}$

transforma-se o multiplicador numa fração para obter-se um denominador

$0,97 e^{-\frac{1}{2}\left[-\left(\frac{(l d l-27,273)^{2}}{30303,03}\right)+0,344546\right]}$

reduz-se o denominador a sua raiz quadrada para inclui-lo no quadrado de diferença

$0,97 e^{-\frac{1}{2}\left[-\left(\frac{l d l-27,273}{174,08}\right)^{2}+0,344546\right]}$

separa-se a soma de expoentes como produto de potencias

$0,97 e^{-\frac{1}{2}\left[-\left(\frac{l d l-27,273}{174,08}\right)^{2}\right]} e^{-1 / 2 \cdot 0,344546}$

a segunda potencia é uma constante e os negativos em produto se anulam

$0,97 e^{\frac{1}{2}\left[\left(\frac{l d l-27,273}{174,08}\right)^{2}\right]} 0,841749$

finaliza-se o cálculo

$\frac{f_{\text {caso }}(l d l)}{f_{\text {controle }}(l d l)}=0,81 e^{\frac{1}{2}\left(\frac{l d l-27,27}{174,08}\right)^{2}}$

Numa regressão logística pode-se estimar o efeito de colesterol sobre a ocorrência de infarto como uma razão de odds, identificando-se que as chances de infarto cresçam em 1,003 a cada acréscimo de unidade de LDL: 
Tabela 3 - Efeito de LDL-colesterol sobre a ocorrência de infarto em estimativa por regressão logística

\begin{tabular}{|c|c|c|c|c|c|}
\hline \multirow[b]{2}{*}{ Variáveis na equação } & \multirow[t]{2}{*}{ B } & \multirow{2}{*}{\multicolumn{2}{|c|}{ Sig. $\operatorname{Exp}(B)$}} & \multicolumn{2}{|c|}{$\begin{array}{c}\text { I.C. de } 95,0 \% \text { para } \\
\operatorname{Exp}(B)\end{array}$} \\
\hline & & & & Inferior & Superiol \\
\hline LDL & ,003 & 001 & 1,003 & 1,002 & 1,005 \\
\hline Constant &,- 290 &, 010 & ,748 & & \\
\hline
\end{tabular}

Esta estratégia só é possível porque para cada paciente se tem informação sobre seu status sim/não em relação à doença (caso/controle). No entanto, ela corresponde ao cálculo da razão das derivadas das funções de distribuição acumulada, ou razão das funções normais de distribuição do suposto fator predisponente, LDL, como mostra a figura abaixo:

Figura 19 - Comparação do efeito de LDL sobre a ocorrência de infarto agudo do miocárdio por regressão logística e por razão de derivadas

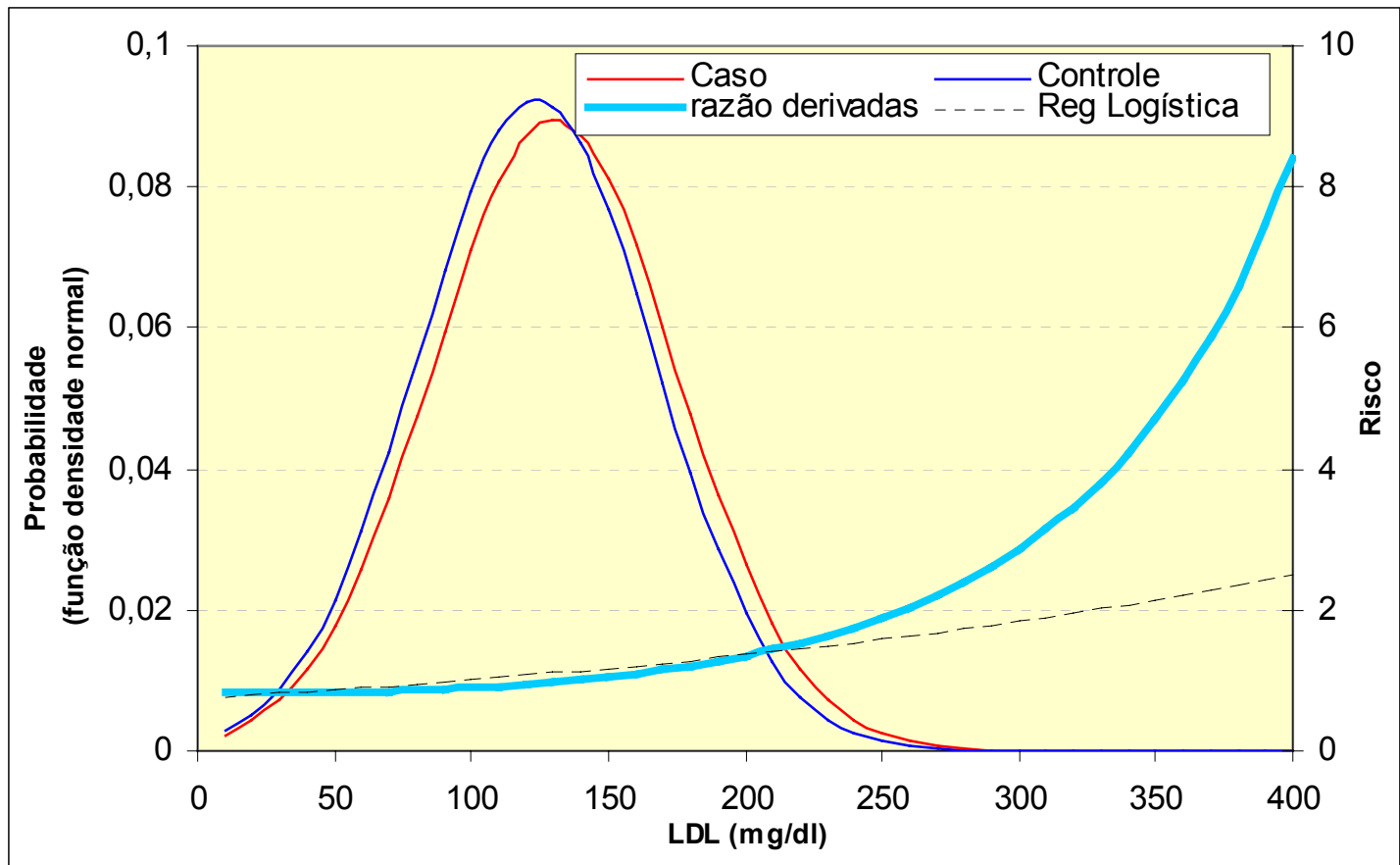

Ordenada esquerda exibe valores de probabilidade das funções densidade e ordenada direita exibe risco estimado por regressão logística (odds ratio) ou razão de derivadas (risco relativo)

$\mathrm{Na}$ figura pode-se notar que para valores até cerca de $225 \mathrm{mg} / \mathrm{dl}$ de $\mathrm{LDL}$, ambas as estratégias de estimativa de risco - risco relativo e odds ratio - têm diferenças muito pequenas. A partir deste ponto, onde cada função passa a ter uma projeção distinta, no entanto, está se escapando do domínio de valores de LDL: como sugerem as funções de densidade 
de probabilidade, valores desta ordem de grandeza são muito raros (desvio padronizado da média é 2,1 para casos e 2,3 para controles) e como corolário inferências neste espaço provavelmente são impróprias, quer por uma ou outra estimativa. Sobre a impropriedade de analisar-se um modelo para além de seu domínio, Miettinem ${ }^{59}$ afirma:

"A model addresses a particular range of a determinant only. Thus it is no liability of the model if outside this range a thoughtless observer calculates an inadmissible value for the parameter, a negative risk for a coronary event at zero blood pressure, for example." Pág. 258

Estas evidências, tanto do cálculo que mostra que a análise da função acumulada em nada difere da análise bem conhecida de estudo de coorte na forma sugerida por Miettinen quanto da concordância na estimativa de risco com uma técnica bem conhecida como a regressão logística, sugerem que dentro do domínio de valores de uma distribuição de medida de ocorrência, a razão de derivadas seja uma técnica de estimativa de risco confiável e consistente. Encontrará aplicação própria quando os efeitos a serem medidos não se refiram ao contraste doentes (casos)/ não doentes (controles), mas sim ao contraste entre classes de doentes. 
Resultados 


\section{O estudo AFIRMAR}

A tabela 4 mostra a distribuição de casos e controles segundo o sexo, bem como a idade média e seu desvio padrão para cada combinação de categorias.

Tabela 4 - Número e idade de pacientes estudados no projeto AFIRMAR, segundo grupo e sexo*

\begin{tabular}{|c|c|c|c|c|c|c|c|c|}
\hline \multirow[t]{3}{*}{ Grupo } & \multicolumn{8}{|c|}{ Sexo } \\
\hline & \multicolumn{4}{|c|}{ Masculino } & \multicolumn{4}{|c|}{ Feminino } \\
\hline & $\mathrm{n}$ & $\%$ & $\begin{array}{c}\text { Média de } \\
\text { idade }\end{array}$ & $\begin{array}{c}\text { Desvio } \\
\text { padrão de } \\
\text { idade }\end{array}$ & $\mathrm{n}$ & $\%$ & $\begin{array}{l}\text { Média de } \\
\text { idade }\end{array}$ & $\begin{array}{c}\text { Desvio } \\
\text { padrão de } \\
\text { idade }\end{array}$ \\
\hline caso & 1240 & $69,0 \%$ & 56,9 & 11,8 & 558 & $31,0 \%$ & 61,7 & 12,6 \\
\hline controle & 797 & $51,4 \%$ & 50,3 & 13,3 & 753 & $48,6 \%$ & 51,3 & 14,6 \\
\hline
\end{tabular}

A figura 20 abaixo destaca o contraste de comportamento do sexo entre casos e controles no total de pacientes recrutados para o estudo. A evidente superioridade de pacientes masculinos entre os casos deixou de ser examinada no estudo em favor do pareamento por sexo e idade, pelo que o plano de análise foi desenvolvido com vistas a investigar fatores de risco para infarto nos 1.279 pares de mesmo sexo e idade com diferença não maior que 5 anos, sem consideração dos 792 pacientes restantes.

Figura 20 - Distribuição de sexo entre os grupos de pacientes do estudo AFIRMAR

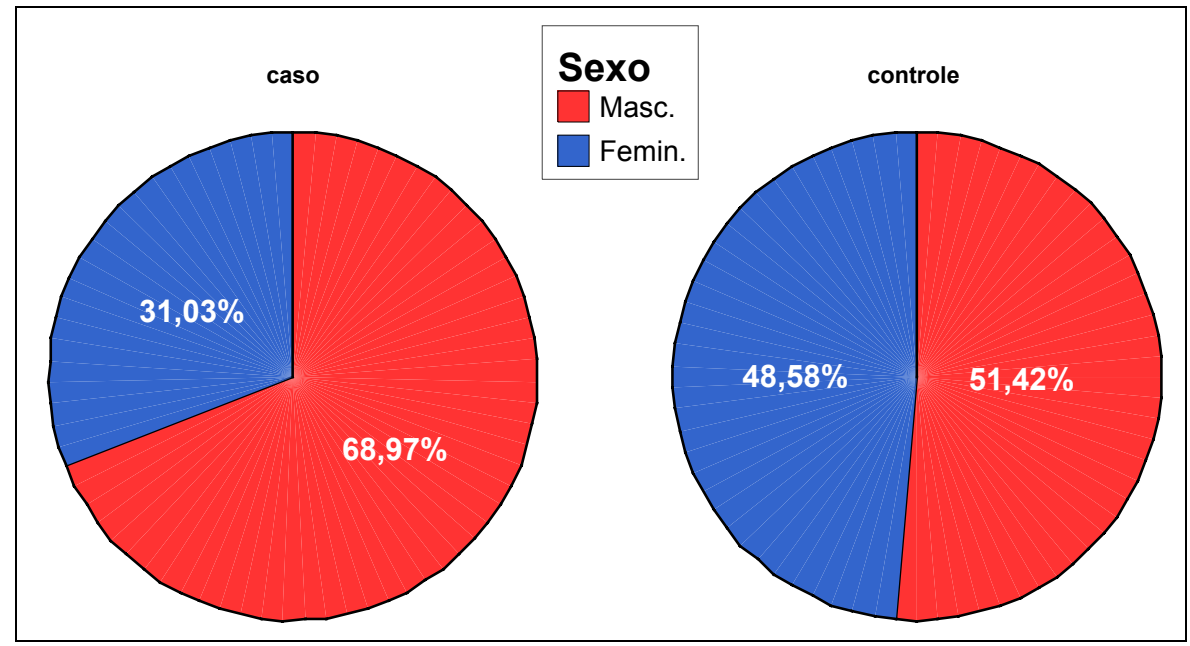

O recrutamento de hospitais para participação no estudo foi feito via

Sociedade Brasileira de Cardiologia e a participação acompanhada em 
seus congressos anuais. Embora todas as regiões do país tenham estado representadas, a concentração da especialidade nas regiões Sul e Sudeste levou a uma maior participação destas regiões no estudo, como mostra a tabela 5 e destaca a figura 18. São Paulo, Santa Catarina e Minas Gerais foram os Estados que mais contribuíram com o estudo (tabela 6).

Tabela 5 - Número de pacientes estudados no projeto AFIRMAR, segundo a região de origem, grupo e sexo

\begin{tabular}{|c|c|c|c|c|c|c|c|}
\hline \multirow[t]{3}{*}{ Região } & \multirow[t]{3}{*}{ Grupo } & \multicolumn{4}{|c|}{ Sexo } & \multicolumn{2}{|c|}{ Total } \\
\hline & & \multicolumn{2}{|c|}{ Masculino } & \multicolumn{2}{|c|}{ Feminino } & \multirow[t]{2}{*}{$\mathrm{n}$} & \multirow[t]{2}{*}{$\%$} \\
\hline & & $\mathrm{n}$ & $\%$ & $\mathrm{n}$ & $\%$ & & \\
\hline \multirow{3}{*}{ Norte } & caso & 39 & $72,2 \%$ & 15 & $27,8 \%$ & 54 & $100 \%$ \\
\hline & controle & 27 & $49,1 \%$ & 28 & $50,9 \%$ & 55 & $100 \%$ \\
\hline & Total & 66 & $60,6 \%$ & 43 & $39,4 \%$ & 109 & $100 \%$ \\
\hline \multirow{3}{*}{ Nordeste } & caso & 198 & $70,2 \%$ & 84 & $29,8 \%$ & 282 & $100 \%$ \\
\hline & controle & 85 & $37,3 \%$ & 143 & $62,7 \%$ & 228 & $100 \%$ \\
\hline & Total & 283 & $55,5 \%$ & 227 & $44,5 \%$ & 510 & $100 \%$ \\
\hline \multirow{3}{*}{ Sudeste } & caso & 662 & $67,6 \%$ & 317 & $32,4 \%$ & 979 & $100 \%$ \\
\hline & controle & 457 & $53,0 \%$ & 406 & $47,0 \%$ & 863 & $100 \%$ \\
\hline & Total & 1119 & $60,7 \%$ & 723 & $39,3 \%$ & 1842 & $100 \%$ \\
\hline \multirow{3}{*}{ Sul } & caso & 327 & $70,8 \%$ & 135 & $29,2 \%$ & 462 & $100 \%$ \\
\hline & controle & 215 & $57,0 \%$ & 162 & $43,0 \%$ & 377 & $100 \%$ \\
\hline & Total & 542 & $64,6 \%$ & 297 & $35,4 \%$ & 839 & $100 \%$ \\
\hline \multirow{3}{*}{ Centro-Oeste } & caso & 14 & $66,7 \%$ & 7 & $33,3 \%$ & 21 & $100 \%$ \\
\hline & controle & 14 & $48,3 \%$ & 15 & $51,7 \%$ & 29 & $100 \%$ \\
\hline & Total & 28 & $56,0 \%$ & 22 & $44,0 \%$ & 50 & $100 \%$ \\
\hline \multirow{3}{*}{ Brasil } & caso & 1240 & $69,0 \%$ & 558 & $31,0 \%$ & 1798 & $100 \%$ \\
\hline & controle & 798 & $51,4 \%$ & 754 & $48,6 \%$ & 1552 & $100 \%$ \\
\hline & Total & 2038 & $60,8 \%$ & 1312 & $39,2 \%$ & 3350 & $100 \%$ \\
\hline
\end{tabular}


Figura 21 - Participação proporcional das regiões brasileiras no estudo AFIRMAR

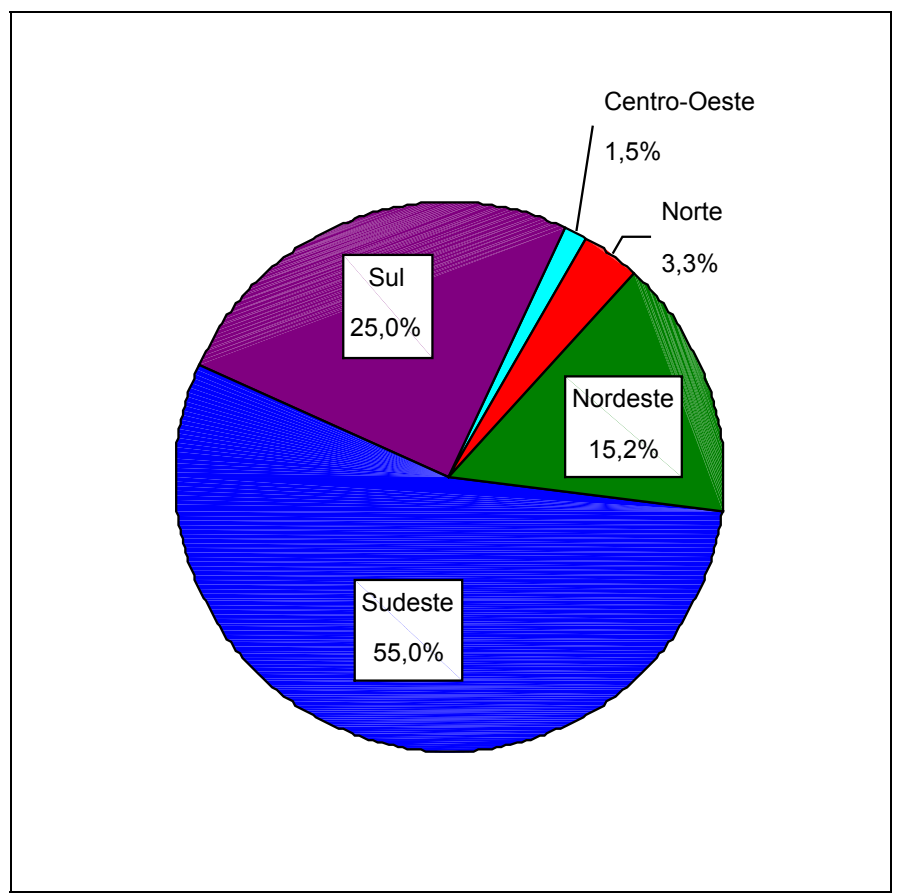

Tabela 6 - Origem dos pacientes do estudo AFIRMAR por Estado

\begin{tabular}{lcc}
\hline Estado & $\mathbf{n}$ & $\mathbf{\%}$ \\
\hline São Paulo & 1168 & 34,9 \\
Santa Catarina & 455 & 13,6 \\
Minas Gerais & 410 & 12,2 \\
Paraná & 192 & 5,7 \\
Rio Grande Sul & 192 & 5,7 \\
Rio de Janeiro & 178 & 5,3 \\
Bahia & 149 & 4,4 \\
Para & 109 & 3,3 \\
Alagoas & 94 & 2,8 \\
Pernambuco & 87 & 2,6 \\
Espírito Santo & 86 & 2,6 \\
Piauí & 60 & 1,8 \\
Ceara & 43 & 1,3 \\
Sergipe & 41 & 1,2 \\
Distrito Federal & 34 & 1 \\
Maranhão & 18 & 0,5 \\
Goiás & 16 & 0,5 \\
Paraíba & 12 & 0,4 \\
Rio G.do Norte & 6 & 0,2 \\
Total & 3350 & 100 \\
\hline
\end{tabular}




\section{O efeito do sexo sobre a ocorrência de infarto agudo do miocárdio no estudo AFIRMAR}

Para fins de comparação e valendo-se do fato que o estudo AFIRMAR foi um estudo caso-controle para os quais havia oportunidade de contraste do comportamento de doentes contra de não doentes, aqui os efeitos do sexo serão avaliados por três técnicas: regressão logística, regressão de Cox e razão de derivadas.

Tomando-se o total dos 3.348 pacientes com dados completos para sexo e idade, numa análise por regressão logística incondicional pode-se aferir o efeito do sexo sobre a presença de infarto agudo do miocárdio com controle para os efeitos da idade. A tabela 7 mostra os resultados desta análise, que sugere que, para uma mesma dada idade, o sexo masculino tenha o dobro das chances que o sexo feminino tem para apresentar doença.

Tabela 7 - Efeito do sexo masculino em contraste com o feminino para a condição presença de infarto (caso) com controle de idade, em análise por regressão logística

\begin{tabular}{lccccc}
\hline & \multirow{3}{*}{ B } & Sig. & Exp(B) & \multicolumn{2}{c}{$\begin{array}{c}\text { I.C. de 95,0\% para } \\
\text { Exp(B) }\end{array}$} \\
\cline { 2 - 6 } Variáveis na equação & & & & Inferior & Superior \\
\hline Sexo: masculino x feminino &, 885 &, 000 & 2,423 & 2,085 & 2,816 \\
Idade &, 048 &, 000 & 1,049 & 1,043 & 1,055 \\
\hline Constante & $-3,002,000$ &, 050 & & \\
\hline
\end{tabular}

Se apenas o grupo de doentes com infarto agudo do miocárdio, os casos, fosse tomado para análise de efeito do sexo sobre a incidência, o modelo de riscos proporcionais de Cox poderia ser aplicado, obtendo-se o resultado apresentado na tabela 8. Nesta abordagem, com ajuste dos dados para funções de dano sob a premissa de regularidade de efeito ao longo das idades (figura 22), se concluiria, numa medida síntese para um suposto efeito regular ao longo da vida (todas as idades), que entre as pessoas com infarto, os homens seriam cerca de $46 \%$ mais susceptíveis ao infarto do que as mulheres. 
Tabela 8 - Efeito do sexo masculino em contraste com o feminino para chances de infarto ao longo das idades entre pessoas infartadas (casos), em modelo de riscos proporcionais de Cox

\section{B Sig. $\operatorname{Exp(B)} \quad$ I.C. de $95,0 \%$ para $\operatorname{Exp}(B)$}

Variável na equação

Inferior

Superior

Sexo: masculino $x$ feminino

,376,000 1,457

1,317

1,612

Figura 22- Curvas de função de dano [Hazard Function = -Ig(sobrevida)] para cada sexo entre pessoas infartadas

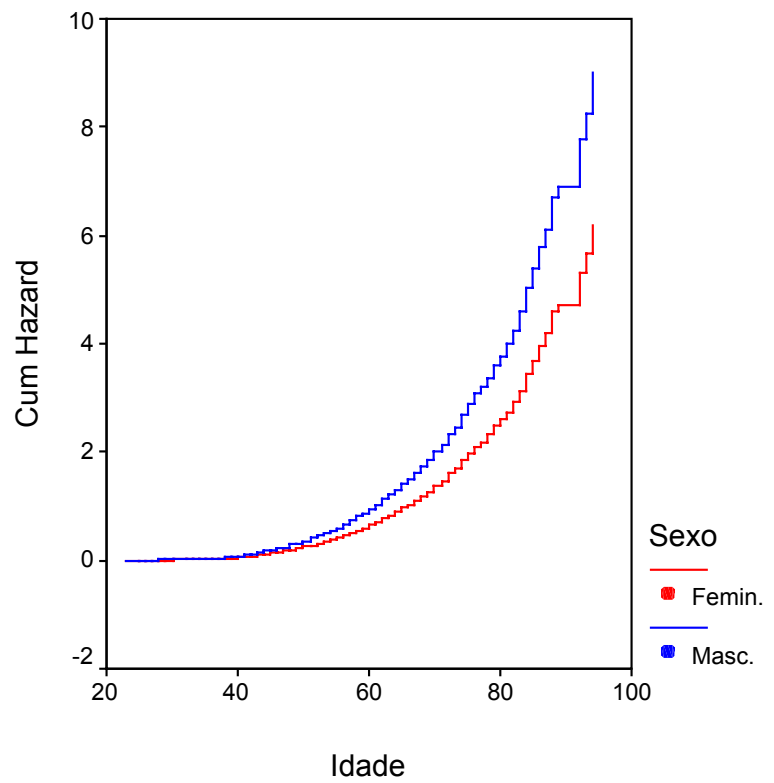

Com vistas à aplicação do modelo proposto de razão de derivadas, a exemplo da regressão de Cox, são tomados para análise os pacientes do grupo caso, pacientes com infarto agudo do miocárdio. A figura 23 mostra os histogramas de freqüência acumulada para cada sexo e o traçado de uma função de distribuição ajustada. 
Figura 23 - Histograma de freqüência acumulada de idade e correspondente função de distribuição ajustada para pacientes infartados do sexo masculino e feminino

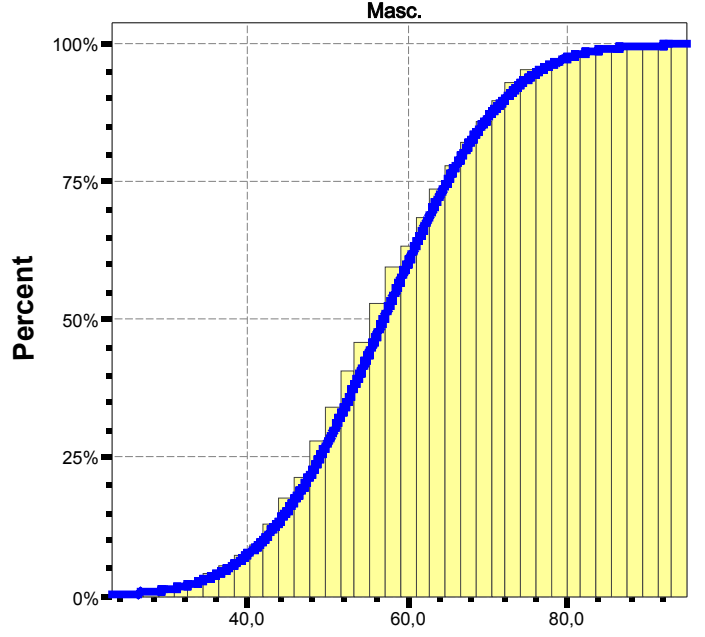

IDADE

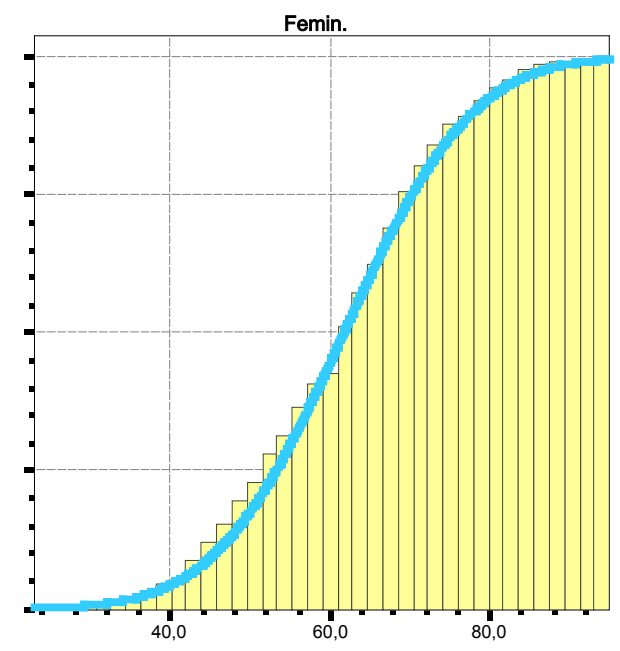

IDADE

As funções ajustadas aos dados empíricos de freqüência de cada sexo ajustam-se bem a funções logísticas ( $R^{2}$ para homens $=0,994$ e $R^{2}$ para mulheres $=0,995$ ) que, denotando-se a função para o sexo masculino pelo índice $\mathrm{H}$ e a função para o sexo feminino pelo índice $M$, tomam a seguinte forma

$$
\begin{aligned}
f_{H}(\text { idade }) & =\frac{1}{1+5538,23 \times 0,8593^{x}} \\
f_{M}(\text { idade }) & =\frac{1}{1+6051,40 \times 0,8684^{x}}
\end{aligned}
$$

e têm suas representações gráficas como apresentadas na figura 24 abaixo. 
Figura 24 - Curvas de funções de distribuição de probabilidade de idade ajustadas aos dados empíricos de homens e mulheres

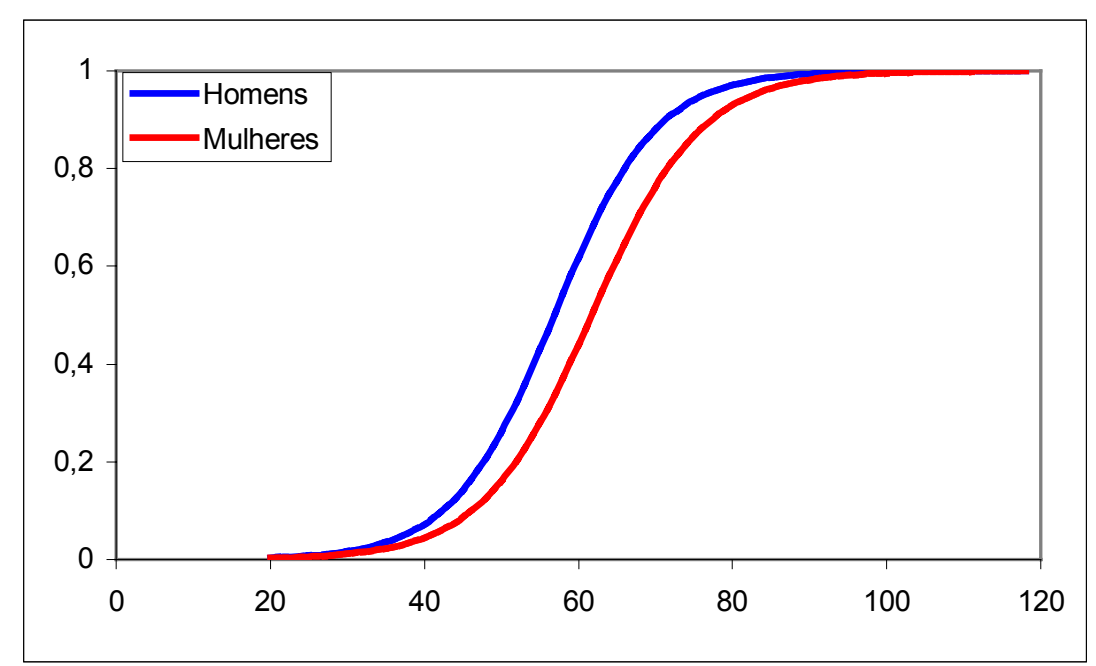

As derivadas destas funções, denotando as derivadas de probabilidades em relação a idade como dy/dx, são as seguintes:

$$
\begin{aligned}
& \frac{d y}{d x_{H}}=-5538,23 \times 0,8593^{x} \cdot \frac{\ln 0,8593}{\left(1+5538,23 \times 0,8593^{x}\right)^{2}} \\
& \frac{d y}{d x_{M}}=-6051,4 \times 0,8684^{x} \cdot \frac{\ln 0,8684}{\left(1+6051,4 \times 0,8684^{x}\right)^{2}}
\end{aligned}
$$

$\mathrm{Na}$ figura 25, apresenta-se um histograma de freqüências para cada sexo e o traçado de uma função densidade de probabilidade normal, que é também a derivada da função de distribuição, ajustada aos dados. $\mathrm{Na}$ figura 26, um gráfico de dispersão de valores de freqüência acumulada contra probabilidade acumulada esperada para uma distribuição normal, sugere um bom ajuste dos dados a este tipo de distribuição. 
Figura 25 - Histograma de freqüências de idade e correspondente função de densidade de probabilidade ajustada para pacientes infartados do sexo masculino e feminino

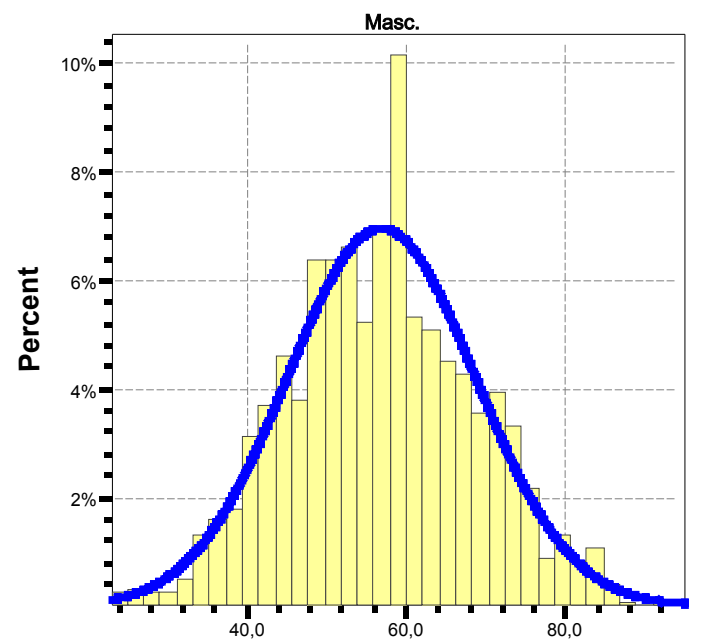

IDADE

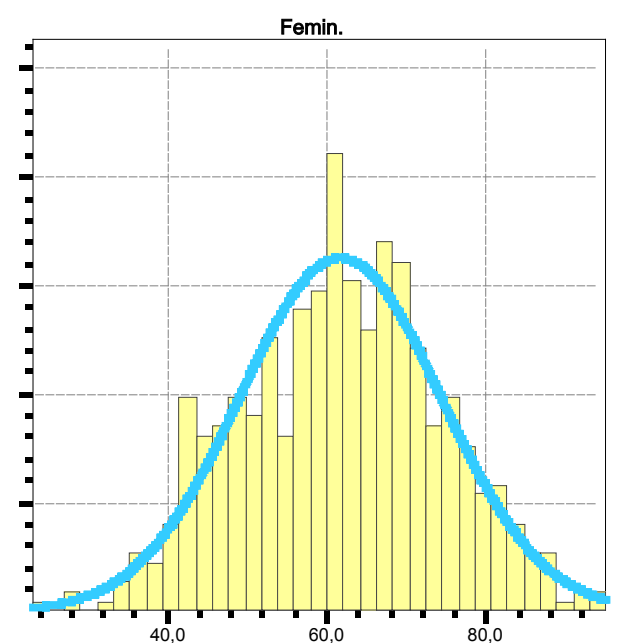

IDADE

Figura 26 - Ajuste das ocorrências de infarto ao longo dos valores de idade a uma função de distribuição normal
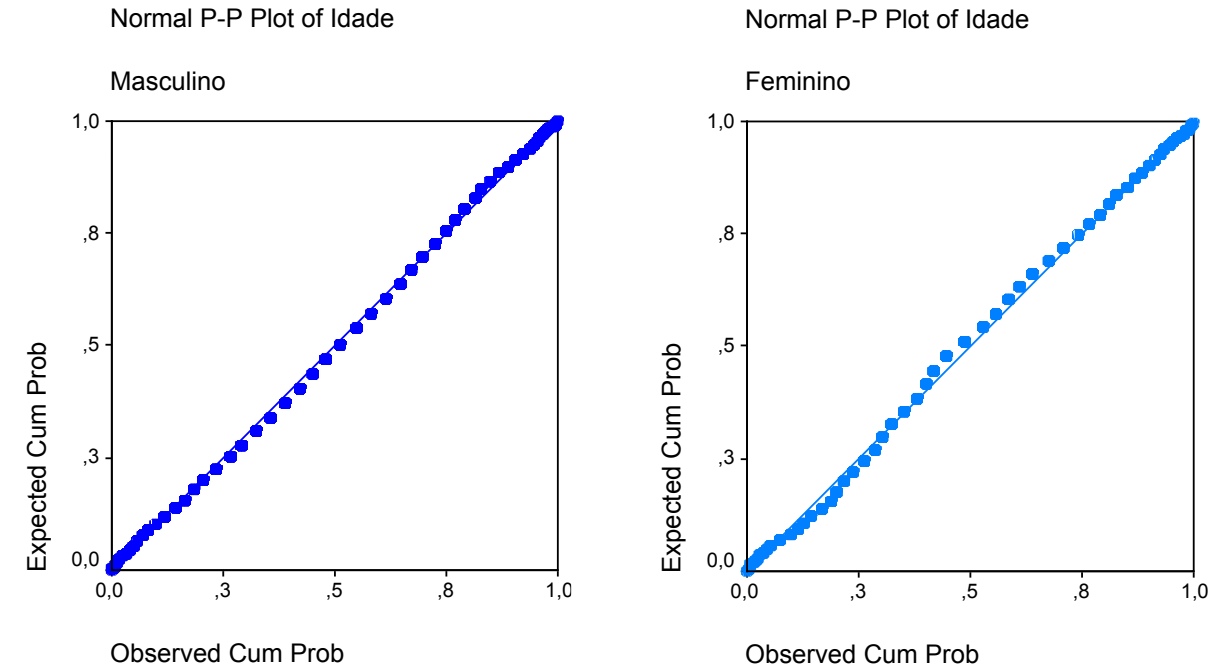

Dado este bom ajuste, as derivadas da função distribuição poderiam, sem perda de informação, ser expressas pela função densidade de probabilidade normal de acordo com os parâmetros característicos de média e desvio padrão. Novamente denotando-se a função para o sexo masculino pelo índice $\mathrm{H}$ e a função do sexo feminino pelo índice $M$, estas funções teriam a seguinte forma 
$f_{H}($ idade $)=\frac{1}{11,79 \sqrt{2 \pi}} e^{-\frac{1}{2}\left[\frac{(x-56,89)}{11,79}\right]^{2}}$

$f_{M}($ idade $)=\frac{1}{12,61 \sqrt{2 \pi}} e^{-\frac{1}{2}\left[\frac{(x-61,69)}{12,61}\right]^{2}}$

As funções (3) e (5) não diferem por mais do que 0,005 e as (4) e (6) tampouco por mais do que 0,004, como mostram as figuras 27 e 28 abaixo.

Figura 27 - Comparação da função densidade de probabilidade (FDP) normal (5) e derivada da função logística ajustada aos dados empíricos (3) em homens

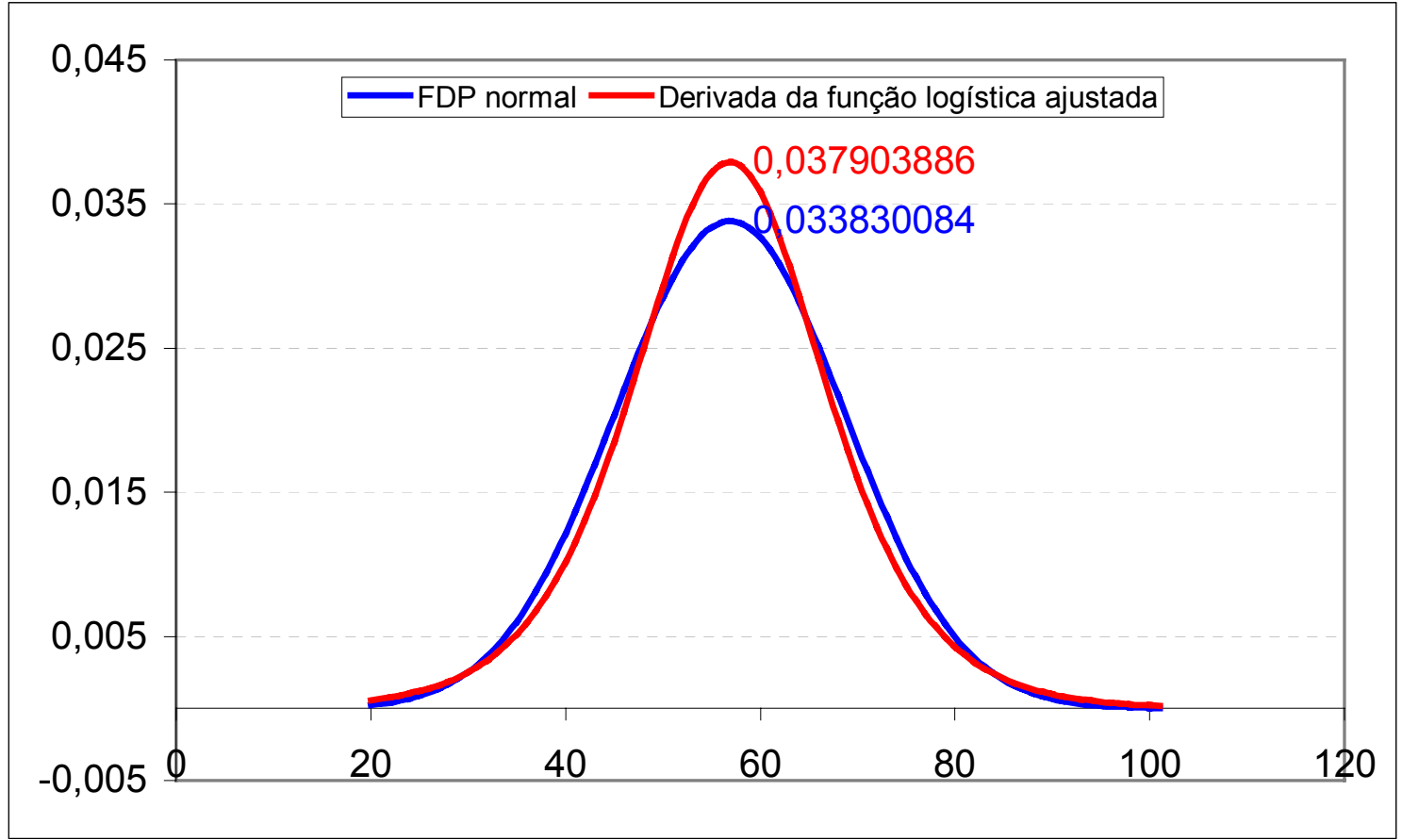


Figura 28 - Comparação da função densidade de probabilidade (FDP) normal (6) e derivada da função logística ajustada aos dados empíricos (4) em mulheres

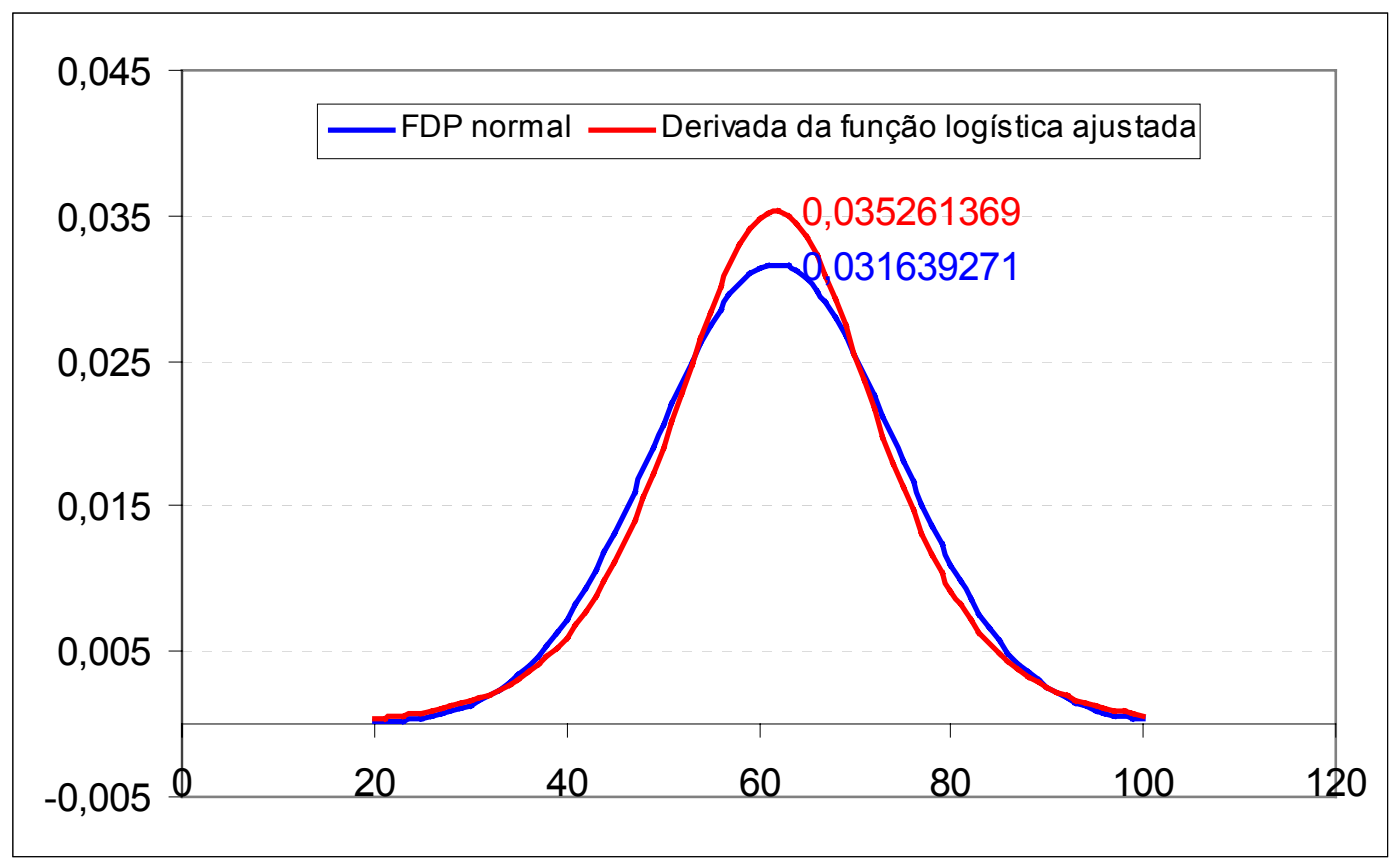

A razão das derivadas expressas em (5) e (6) é calculada como

$$
\frac{f_{H}}{f_{M}}=1,06955 e^{-\frac{1}{2}\left(0,000905 x^{2}-0,04262 x-0,64983\right)}
$$

que, para analogia com as funções descritas em (5) e (6), através de uma redução do expoente a uma diferença de quadrados, pode também ser expressa como

$$
\frac{f_{H}}{f_{M}}=1,902266 e^{-\frac{1}{2}\left(\frac{x-23,54696}{33,24112}\right)^{2}}
$$

Há que se destacar que, como a razão de duas funções de distribuição de probabilidade normal resulta numa função Cauchy de distribuição de probabilidades (cujos parâmetros são distintos dos da normal - média e desvio padrão), os valores que aparecem no expoente não devem ser interpretados como média e desvio padrão da função razão de derivadas. 
Na figura 29, derivadas e razão de derivadas são apresentadas em conjunto, distinguindo-se um eixo de coordenadas para as primeiras e outro para segunda. Neste gráfico pode-se distinguir o ponto em que as derivadas de ambos os sexos assumem o mesmo valor e cuja razão, como corolário, resulta na unidade. Este ponto de inflexão onde os efeitos do sexo masculino deixam de superar os do sexo feminino pode ser identificado pela função razão de derivadas como 61,2 anos.

Figura 29 - Derivadas das funções distribuição de idades em cada sexo e a razão de derivadas homens : mulheres*

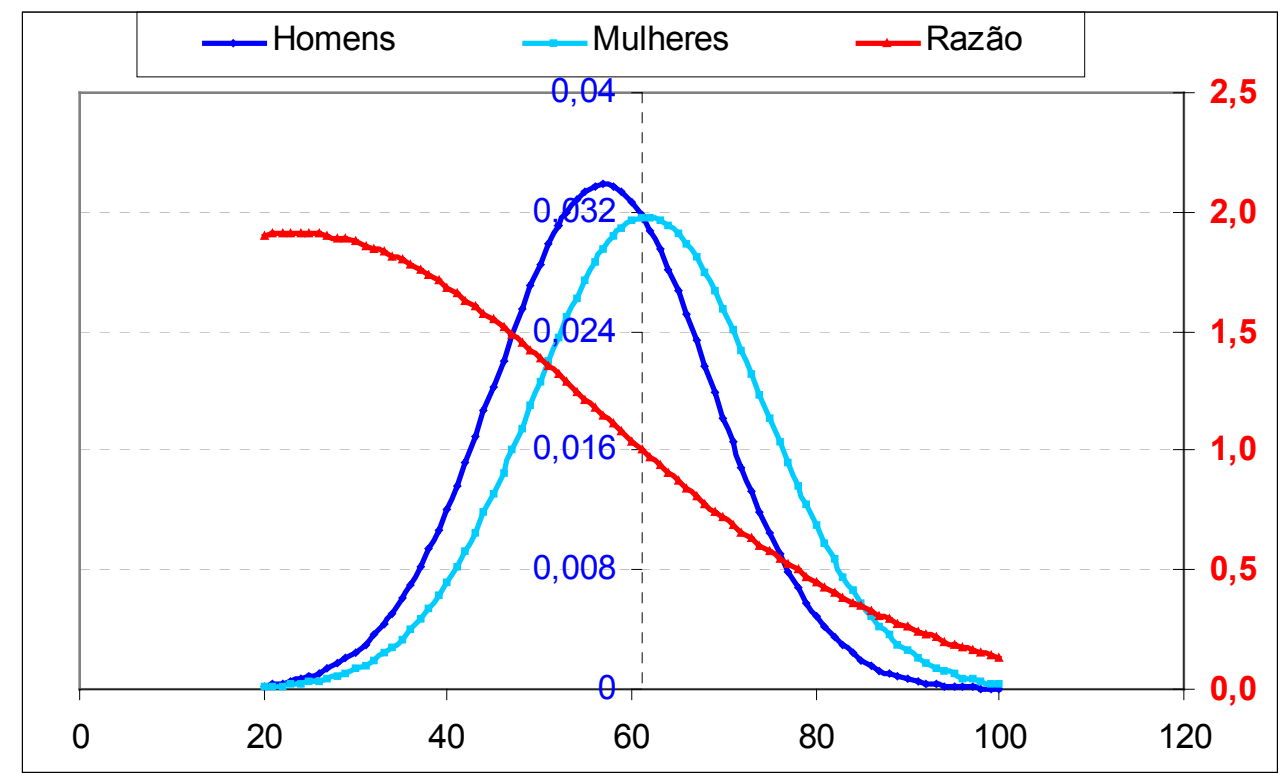

*eixo esquerdo de ordenadas com valores de probabilidade das funções densidade de probabilidade normal e eixo direito de ordenadas com valores da razão destas funções

$\mathrm{Na}$ figura 29 pode-se ainda ver que entre as idades de 20 a 40 anos, $\mathrm{O}$ infarto agudo do miocárdio expressa-se entre homens com uma força que é de 1,5 a 2 vezes superior à das mulheres, o que cai para cerca 1,5 a 1 nos 20 anos subseqüentes. Enquanto os homens de uma superioridade sobre as mulheres de cerca de 2 aos 20 anos levam 40 anos para atingir a igualdade, as mulheres invertem esta relação, da igualdade atingem o dobro dos homens, em apenas 20 anos (razão H:M aos 80 anos é cerca de $0,5)$. Aplicando-se a equação (8) pode-se obter resposta sobre a relação entre os sexos em qualquer idade. 
Os resultados da regressão logística (tabela 7) não são comparáveis com os resultados da razão de derivadas porque cada análise examinou um universo distinto, casos e controles na regressão logística e apenas casos na razão de derivadas. Já comparação com a regressão de Cox (tabela 8) é apta, uma vez que o mesmo universo, casos, foi analisado. O valor de 1,45 sugerido pela regressão de Cox, que é interpretado como um efeito médio regular ao longo de todas as idades, na razão de derivadas é identificado como uma situação particular, observável quando o valor de idade é de 48 anos. 
Comentários 
O presente estudo teve como objetivo propor e testar uma estratégia metodológica que elucide relações não aparentes a outras abordagens, com vistas a contribuir com o alargamento do conhecimento de objetos de interesse científico. A proposição de uma estratégia metodológica é seu objetivo geral, entendido como matéria de interesse para a Epidemiologia, e o seu teste é o objetivo específico, entendido como matéria de interesse para a Cardiologia, como uma contribuição ao conhecimento das relações entre sexo e ocorrência de infarto agudo do miocárdio.

A Epidemiologia não é estritamente uma Ciência Formal como a Matemática e a Lógica mas é, reconhecidamente, a disciplina das Ciências da Saúde em que a forma, a estrutura lógica e epistemológica do conhecimento científico, encontra seu espaço de reflexão. Rothman ${ }^{60}$ reconhece que a identidade da Epidemiologia enquanto disciplina científica está fortemente ligada ao estabelecimento de um cabedal de princípios, métodos e técnicas de investigação que se desenvolveram ao longo do século XX. De forma semelhante, Dever ${ }^{61}$, em capítulo de livro dedicado à discussão do papel da epidemiologia em administração de serviços de saúde, comenta que a "epidemiologia tem sido mais considerada como um método do que como uma ciência independente". De fato, beneficiando-se da colaboração que estabelece com as Ciências Formais, v.g. Matemática \& Estatística, a epidemiologia contribui com o estabelecimento de métodos de análise para diferentes especialidades médicas e biológicas.

Quando John Graunt ${ }^{62}$, em 1662, estudou a mortalidade por peste ele escreveu:

"Now (com as tabelas de óbitos por ano) it is manifest of it self, in which of these years most died; but in which of them was the greatest Mortality of all Diseases in general, or of the Plague in particular, we discover thus. In the year 1592, and 1636, we finde the proportion of those dying of the Plague in the whole to be near alike, that is about 10 to 23 . or 11 to 25 . or as about two to five." 
O destaque (we discover thus - nós descobrimos assim:) é colocado para mostrar que Graunt, um dos precursores da Epidemiologia, embora estivesse tratando de um objeto específico, a peste, estabelecia uma estratégia metodológica (comparação de proporções) que poderia, e de fato seria, estendida para o estudo de outros objetos. Da mesma forma, James Lind $^{63}$, em 1753, tendo o escorbuto como objeto de investigação, escreveu:

"On the 20th of May, 1747, I took twelve patients in the scurvy on board the Salisbury at sea. Their cases were as similar as I could have them."

Em destaque está sua estratégia de comparar marinheiros tratados (ingestão de cítricos) com marinheiros não tratados que não diferissem entre si senão por este atributo, o que lançava as bases metodológicas do ensaio clínico, extrapolando de muito o objeto estudado.

Timothy Lenoir, professor de História e Filosofia da Ciência em Stanford, numa extensa obra reflexiva sobre a institucionalização das disciplinas científicas $^{64}$, sugere que, dentro de um dado contexto historicamente definido, estas disciplinas emerjam da modelagem de relações entre dois domínios, um fenomenológico e um teórico. Para Lenoir, estes modelos são "approximate representations of the phenomena and at the same time articulations of theories by means of currently available representational techniques". Lenoir entende que é a reificação de um conjunto de práticas, crenças, teorias, técnicas, etc. no campo da ciência o que primeiro caracteriza uma disciplina científica, que a institucionaliza. Ou seja, a disciplina científica torna-se coisa (res) independentemente de ter uma coisa específica como objeto de estudo. Esta abstração do objeto é característica das Ciências Formais, o que permitiu a Russel ironizar a Matemática assim:

"Thus mathematics may be defined as the subject in which we never know what we are talking about, nor whether what we are saying is true ${ }^{, 65}$ 
A interface entre o fenomenológico e o teórico conceitual, ainda que não esgote a identidade da Epidemiologia, parece ser-lhe um importante mister. A pesquisa de desenvolvimento metodológico é nos dias atuais, segundo Doll ${ }^{66}$, tarefa imperiosa da Epidemiologia:

"Classical methods of epidemiological research are proving less and less productive as the simple problems are being successfully solved. They will doubtless continue to be used to make new discoveries from time to time ... but without some brilliant new inspirations, the rate of discovery of new facts of any importance by the use of these classical methods must be expected to slow down."

No presente estudo, foi-se buscar modelagem na abstração da Matemática onde talvez ela seja mais assombrosamente exercida: no Cálculo.

Examinando fenômenos em suas expressões infinitamente diminutas, o Cálculo trata das coisas nos limites da existência e da não existência, o que levou George Berkeley ${ }^{67}$ (1685-1753) a argüir:

"And what are these Fluxions (derivadas)? The Velocities of evanescent Increments? And what are these same evanescent Increments? They are neither finite Quantities nor Quantities infinitely small, nor yet nothing. May we not call them the Ghosts of departed Quantities?"

Para Berkeley, bispo da igreja anglicana em Dublin, a crença nos infinitesimais em nada devia à crença em Deus. O seu livro "The analyst" tinha um título alternativo de "A Discourse Addressed to an Infidel Mathematician", o matemático infiel sendo o astrônomo Edmond Halley, amigo de Newton que teve importante papel na publicação do Principia matematica, onde o Cálculo é descrito. No livro, Berkeley, após comentar o esoterismo das derivadas de $2^{\mathrm{a}}, 3^{\mathrm{a}}$ ou maior ordem, ironiza o ateu Halley escrevendo:

"But he who can digest a second or third Fluxion, a second or third Difference, need not, methinks, be squeamish about any Point in Divinity."

É, no entanto, na assombrosa abstração que o pensamento encontra a estrutura conceitual para conhecer os fenômenos empíricos. Robert 
Kaplan ${ }^{68}$, professor de matemática em Harvard, contando a história do zero e descrevendo o desafio que foi para o intelecto humano conciliar a contagem nula e a não contagem, transcreve um trecho do livro de Matemática de Bhaskara, o Vija-Ganita, onde se lê:

"I revere the unapparent primary matter ... for it is the sole element of all which is apparent ... the arithmetic of known quantity ... is founded on that of unknown quantity; and ... questions to be solved can hardly be understood ... without the application of unknown quantity; and ... questions to be solved can hardly be understood by any, and not at all by such as have dull apprehensions, without the application of unknown quantity..."

Em aplicando o Cálculo, o presente estudo trabalha com a abstração de medir ocorrências como razão (rate) de proporções de afetados por unidades infinitesimais de idade e de comparar (ratio) estas medidas em sub-espaços complementares de um universo de homogêneo de pessoas doentes. É deste conceito abstrato que lida com quantidades desconhecidas que, como sugere Bhaskara, busca-se alcançar o conhecimento de quantidades conhecidas; da razão de derivadas, o conhecimento de quando a morbidade de um sexo supera a de outro sexo. Miettinen, em capítulo de livro recente ${ }^{69}$, sugere que também prefere ver a Epidemiologia como aparentada às Ciências Formais (... epidemiology, like morphology etc., is not a science per se but an aspect of a multitude of health sciences) porque deva se ocupar de conceitos, os quais distingue entre conceitos genéricos e específicos da Epidemiologia:

"Concepts are the elements with which thought operates. The concepts that pertain to epidemiologic research may be classified, most broadly, as those that have to do with the general context of epidemiologic research and those that are ones of epidemiologic research itself.

Among specific concepts, ..., the first-order focus needs to be on concepts pertaining to rates of occurrence. ... The concept of theoretical rate varying among subdomains leads to the epidemiologic concept of determinant." 
A razão de derivadas, concebida neste estudo para elucidar o efeito do sexo sobre a ocorrência do infarto agudo do miocárdio, trabalhou exatamente com a idéia de uma 'theoretical rate varying among subdomains' para esclarecer um 'determinant'de ocorrência. Ao lidar com o Cálculo, no entanto, buliu com os conceitos assombrosos que the são subjacentes e, ainda, com sua má fama de ser extremamente difícil e complicado ... De fato, Silvano P. Thompson em seu clássico "Calculus made easy" ${ }^{70}$ acrescenta o seguinte subtítulo ao livro: "Being a verysimplest introduction to those beautiful methods of reckoning which are generally called by the terrifying names of the DIFFERENTIAL CALCULUS and the INTEGRAL CALCULUS".

De fato, não há como negar que o Cálculo seja uma técnica complexa para cuja perfeita familiaridade o interessado pode precisar de uma muito longa dedicação. Martin Gardner, que revê e atualiza o livro de Thompson citado acima, no prefácio à edição de 1998 comenta que os livros modernos de cálculo com freqüência têm mais de mil páginas e mais de mil exercícios assustadores. No entanto, comenta ainda como os computadores vieram a aliviar boa parte do trabalho envolvido na estimação de derivadas e integrais e termina seu texto com o seguinte parágrafo:

\footnotetext{
"Calculus is the mathematics of change. If you are not a mathematician or scientist, or don't intend to become one, there is no need for you to master the techniques for solving calculus problems by hand. But if you avoid acquiring some insight into the essentials of calculus, into what James (William James, filósofo americano do século XIX) called its philosophy, you will miss a great intellectual adventure. You will miss an exhilarating glimpse into one of the most marvelous, most useful creations of those small and mysterious computers inside our heads"
}

A técnica da razão de derivadas proposta neste estudo envolve muito Cálculo (substantivo próprio) e muito cálculo (substantivo comum):

1. Ajuste de uma função às ocorrências do fenômeno estudado segundo uma dimensão contínua, como uma trajetória, o que já envolve 
Cálculo (limite de uma função testada com minimização de erro) e muito cálculo;

2. Derivação desta função, que envolve conhecimento de Cálculo e muito cálculo;

3. Razão das duas derivadas, último passo que na verdade envolve pouco cálculo e conhecimentos elementares de Álgebra.

Os grandes desafios estão, portanto, nos passos 1 e 2 . No entanto, eles são muito facilitados com o uso de computadores e eventualmente de alguma malícia - no bom sentido, como agudeza de espírito. Para os computadores existem inúmeros aplicativos matemáticos e estatísticos que oferecem facilidades de ajuste de função. Basta que o investigador examine seus dados num gráfico de dispersão, suponha tentativamente uma função e o aplicativo calcula os parâmetros da função que oferecem o melhor ajuste. Muitos aplicativos, dados um conjunto de dados empíricos, testam simultaneamente diversas funções e medem seus ajustes, restando ao investigador escolher, entre as de melhor desempenho, aquela cujos parâmetros the dêem melhor oportunidade de interpretação do fenômeno que esteja estudando.

A título de exemplo, apenas como exercício de ajuste de função, tome-se o número de artigos brasileiros no campo da Saúde registrado nas bases ISI (Institute for Scientific Information) no período de 1990 a 2002, renomeados de 0 a 12 . Sabe-se que a produção científica brasileira vem crescendo expressivamente nos últimos anos: qual seria a função que melhor descreveria este comportamento? Um gráfico de dispersão destes dados tem o aspecto mostrado abaixo: 
Figura 30 - Número de artigos brasileiros do campo da Saúde registrado nas bases do ISI entre 1990 e 2002

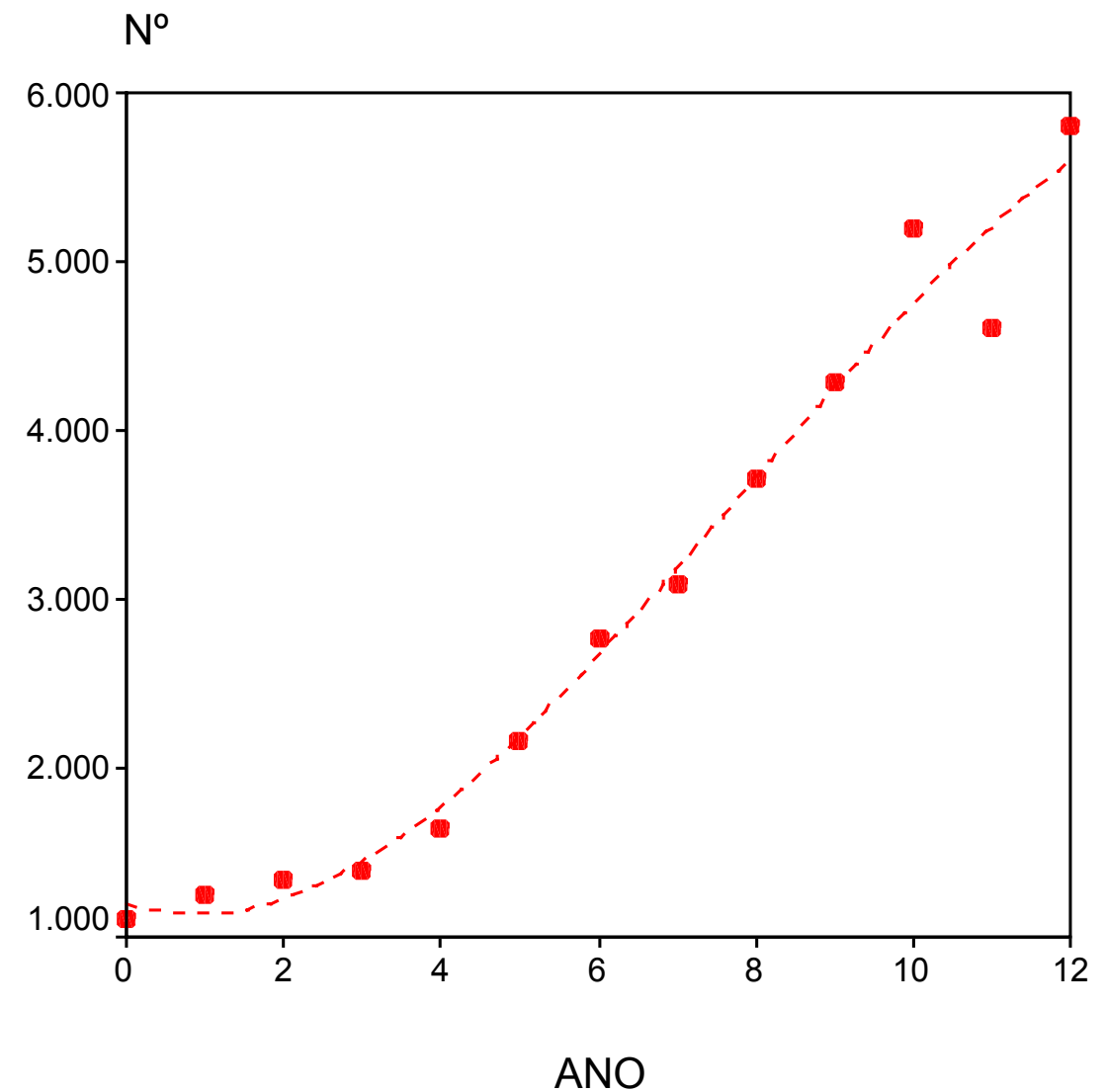

A linha tracejada é uma suposição de função que descreva as ocorrências genericamente. Seu aspecto sugere uma função exponencial, talvez logística, talvez cúbica. Usando-se o SPSS (pacote estatístico) pode-se testar estas hipóteses e ainda uma alternativa de função linear, obtendo-se como resultado:

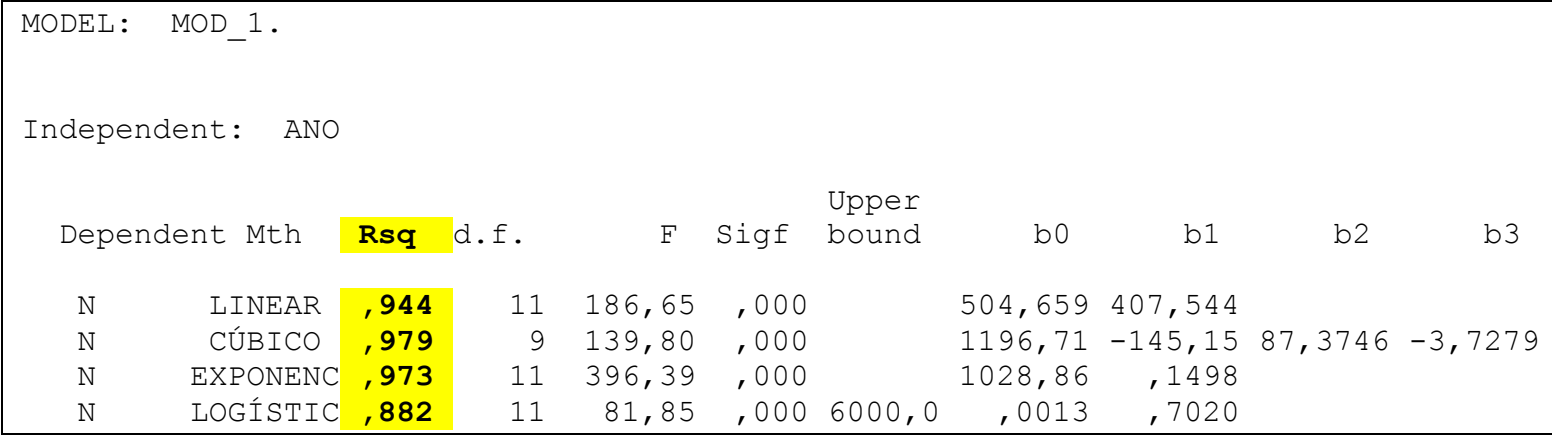


O comportamento de cada uma das quatro alternativas consideradas pode ser ainda examinado graficamente num output default desta análise no SPSS:

Figura 31 - Gráficos de funções testadas para ajuste às observações empíricas de número de artigos brasileiros em Ciências da Saúde registrado no ISI entre 1990 e 2002

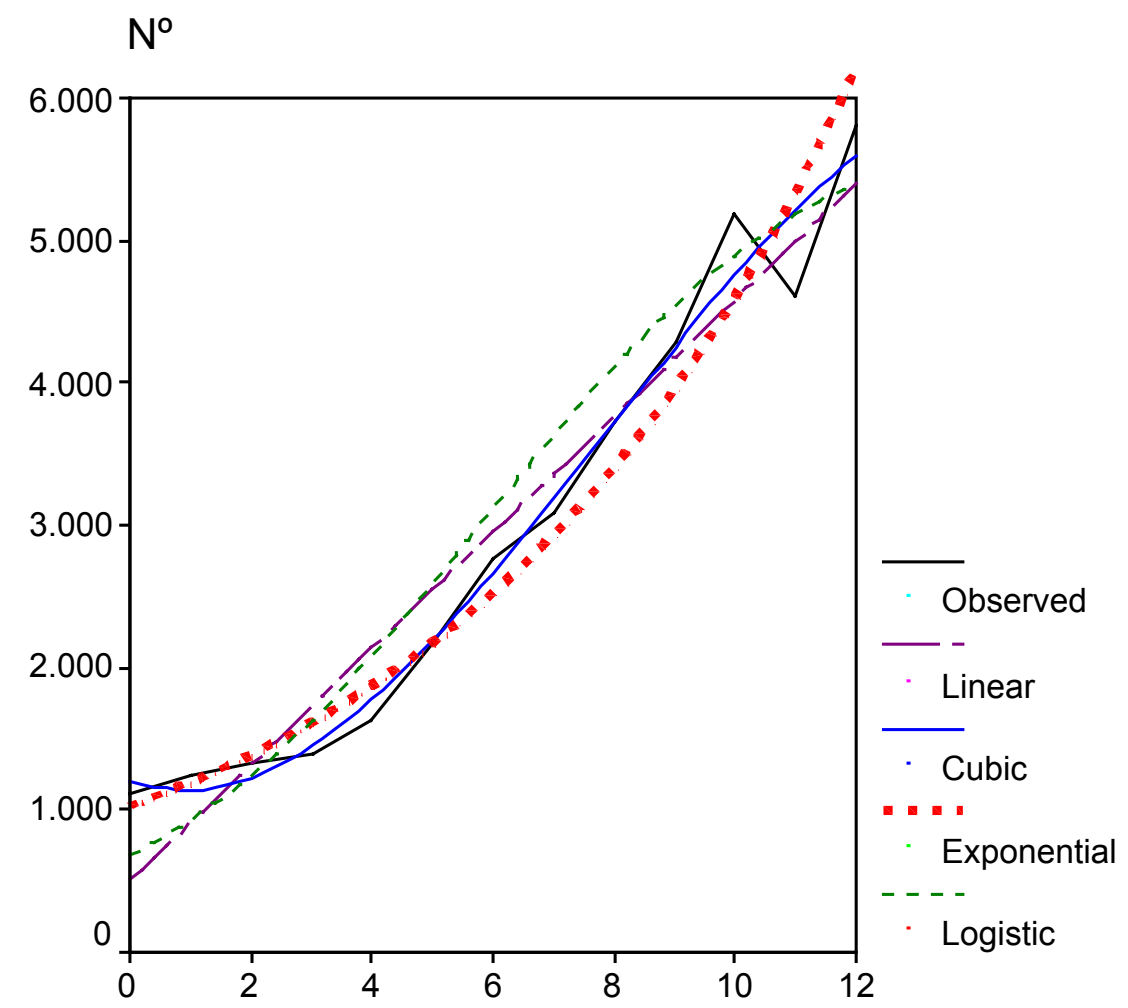

ANO

Examinando-se o ajuste de cada alternativa na coluna Rsq (Coeficiente de determinação, $\mathrm{R}^{2}$ ), nota-se que os modelos de melhor ajuste são o cúbico, o exponencial e o linear. Para o modelo linear, a derivada é uma constante, a inclinação da reta $\left(b_{1}=407,544\right)$, e se este modelo satisfizesse 0 investigador, seu problema já estaria resolvido sem grandes desafios.

Entre as alternativas função cúbica e função exponencial, a primeira tem um ajuste melhor por apenas 0,006, uma vantagem que em nada compensaria a dificuldade subseqüente de interpretação de uma função polinomial. A melhor alternativa resta então como a função exponencial y = $1028,86 e^{1498 x}$. A derivação de função com a independente como expoente 
poderia requerer alguma habilidade de Cálculo, mas recorrendo-se a um aplicativo de domínio público (Graphmat) pode-se obter gráficos de funções e cálculo de derivadas. No gráfico abaixo, tem-se um exemplo com este aplicativo, mostrando que a derivada procurada é $154,12 \mathrm{e}^{1498 x}$

Figura 32 - Gráfico da função exponencial ajustada e sua derivada

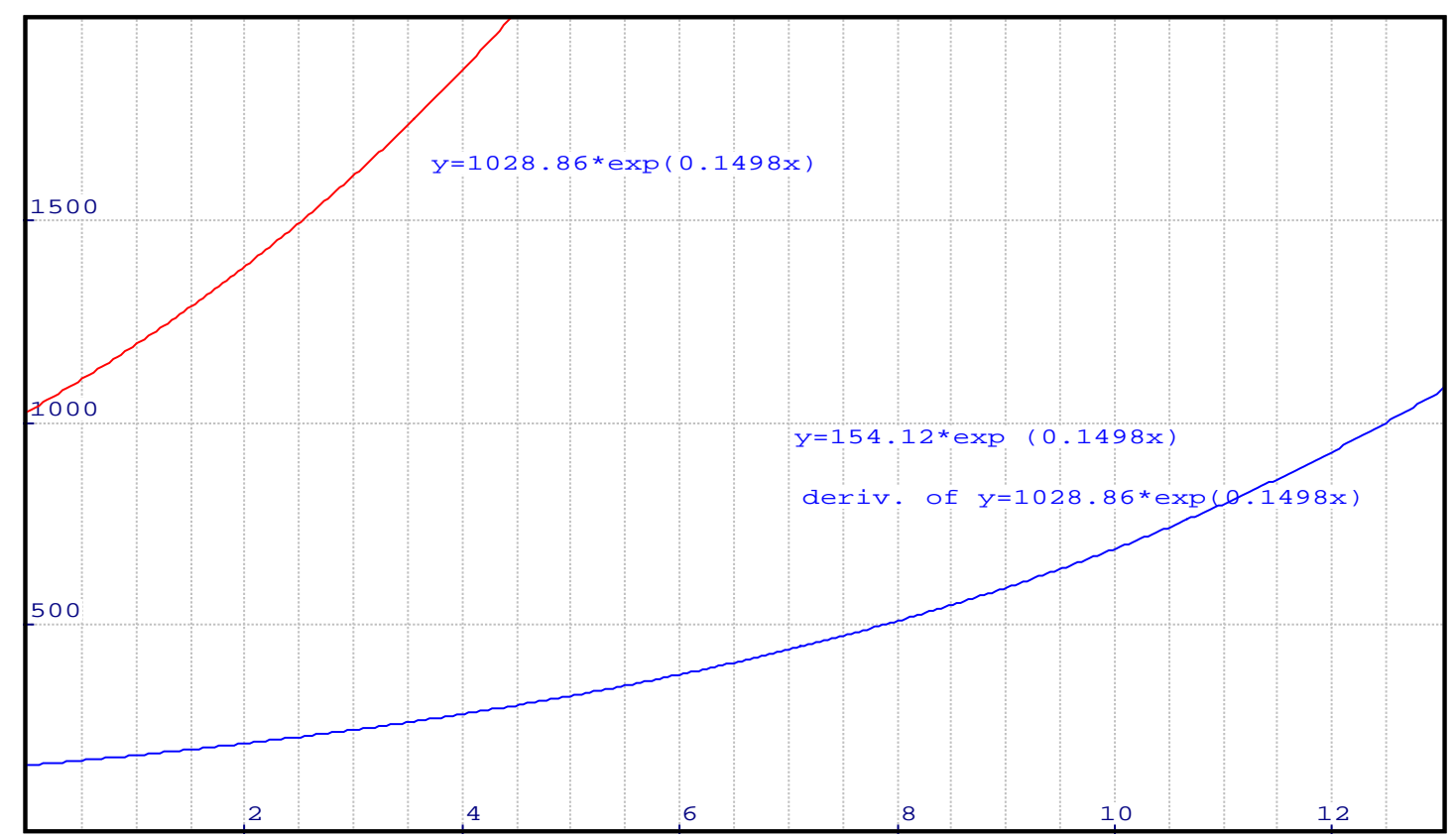

Se ao investigador interessasse uma comparação do perfil brasileiro de produção científica na Saúde contra o perfil de um outro país, repetindo as mesmas operações com os dados deste país ele obteria uma derivada correspondente e fazendo a razão entre as duas, operação sem grande dificuldade, estimaria o efeito da condição Brasil contra a condição outro país.

Com este exemplo pode-se endossar e sustentar a opinião de Martin Gardner de que, dado o auxílio de computadores, o investigador não precisa privar-se do encanto do Cálculo por causa das dificuldades de cálculo, podendo ater-se a conhecer os "princípios filosóficos" do Cálculo e recorrer aos computadores para árdua tarefa dos cálculos.

Superado o receio com os cálculos, considere-se agora a malícia. Quando o investigador estiver interessado em fenômenos biológicos, com freqüência ele estará em situação semelhante a do presente estudo, onde a 
distribuição de ocorrências do fenômeno segue uma distribuição normal. Nesta situação, tendo em vista que a derivada da função distribuição de probabilidade é a função densidade e que esta, seguindo um padrão normal (Gaussiano), é definida pelos parâmetros média e desvio padrão, não há cálculos a fazer: a derivada já está definida.

No presente estudo, depois de confirmada a normalidade de distribuição das ocorrências de infarto segundo a idade entre homens e mulheres (Figura 26), constatou-se que as funções densidade de probabilidade normal eram muito próximas às derivadas das funções logísticas ajustadas às freqüências acumuladas (Figuras 27 e 28), podendo-se usar as funções densidade sem risco de qualquer erro muito importante. Desta forma, os passos para aplicação da técnica de razão de derivadas como medida de efeito poderiam ser re-escritos como:

1. Ao invés de ajuste de uma função à distribuição acumulada de freqüências, examina-se se as observações seguem um padrão de distribuição normal usando-se, por exemplo, um gráfico tipo "normal P-P" como na Figura 26;

2. Define-se as derivadas segundo os parâmetros de média e desvio padrão;

3. Calcula-se a razão das duas derivadas a serem comparadas.

O cálculo da razão (passo 3) é uma operação simples, mas pode ainda ser mais facilitada usando-se um computador. Por exemplo, usando-se uma planilha MS-Excel ter-se-ia uma programação como:

\begin{tabular}{|c|c|c|c|}
\hline $\begin{array}{c}\text { variável } \\
\text { estudada }\end{array}$ & Grupo 1 & Grupo 2 & $\begin{array}{c}\text { razão } \\
\text { derivadas }\end{array}$ \\
\hline A2 & =DIST.NORM(A2;Média;Desvio Padrão;FALSO) & =DIST.NORM(A2;Média;Desvio Padrão;FALSO) & $=$ =B2/C2 \\
\hline
\end{tabular}

Neste extrato de uma planilha MS-Excel, A2 representa primeira coluna e segunda linha (primeira linha é usada para títulos) e é a célula onde entra o primeiro valor da variável considerada - no presente estudo a idade dos pacientes infartados. Na segunda coluna entram as definições da derivada 
como função densidade normal do grupo para o qual se expressa o evento, anotando-se sua média e desvio padrão. $\mathrm{Na}$ terceira coluna entram as definições da derivada como função densidade normal do grupo referente, anotando-se igualmente sua média e desvio padrão. Na quarta coluna define-se a razão como grupo 1 / grupo 2, identificados pelas células (B2 e C2) onde aparecem seus valores calculados. No presente estudo, para o intervalo de idades entre 25 e 30 anos, os valores calculados para números inteiros de idade são:

\begin{tabular}{|c|c|c|c|}
\hline idade & Masculino & Feminino & razão \\
\hline 25 & 0,000872 & 0,000459 & 1,90 \\
\hline 26 & 0,001093 & 0,000576 & 1,90 \\
\hline 27 & 0,001361 & 0,000719 & 1,89 \\
\hline 28 & 0,001681 & 0,000892 & 1,89 \\
\hline 29 & 0,002062 & 0,001099 & 1,88 \\
\hline 30 & 0,002511 & 0,001345 & 1,87 \\
\hline
\end{tabular}

A razão de derivadas mostra-se, portanto, como uma técnica de estimação de efeito que, embora lastreada em complexa abstração matemática, é conceitualmente simples e operacionalmente muito fácil. Segundo Einstein, "When the solution is simple, God is answering" ${ }^{171}$. Aplicada ao objetivo específico deste estudo, a razão de derivadas vem a elucidar uma inquietação do cardiologista: até que idade considerar a mulher menos sujeita que o homem ao infarto do miocárdio.

O cardiologista aprecia as inúmeras evidências epidemiológicas de que a mulher esteja menos sujeita ao infarto. Igualmente aprecia as evidências da fisiologia do menacma, que colocam a mulher em situação protegida. Aprecia ainda que a simples reposição hormonal não reconstitui integralmente a proteção fisiológica do menacma. Aprecia também que, em adoecendo em idade mais avançada, a mulher com freqüência associe à doença coronariana outros fatores agravantes que são mais prevalentes nesta faixa etárea, como a hipertensão e o diabetes, e que como corolário ela tenda então a ter casos clínicos mais graves e de pior prognóstico. Não 
aprecia, no entanto, que a relação homem / mulher seja reduzida a medidas resumo que, fazendo tabula rasa das diferenças ao longo das idades, sempre sugiram uma superioridade masculina. O cardiologista se lembra da famosa advertência de Horácio: - "est modus in rebus"72. A frase completa de Horácio é "Est modus in rebus, sunt certi denique fines" (tentativamente: há um modo para as coisas, afinal há limites estabelecidos) e constitui-se numa recomendação de moderação para excessos que estejam ultrapassando o tolerável. A lembrança de Horácio não vem por acaso: modus, em latim, significa modo, maneira, ritmo, mas significa também medida (est modus in rebus = há uma justa medida para tudo). A inquietação do cardiologista é por uma medida mais justa.

Ao cardiologista, a medida da relação masculino / feminino como uma medida resumo genérica, única, singular, é muito simples, ou ainda, é simplória. Voltando a Einstein, que louvava o divino da simplicidade, ele também dizia: - "Everything should be made as simple as possible, but not simpler".

Quando, em se buscando uma medida de efeito de sexo sobre a ocorrência do infarto agudo do miocárdio, a razão de derivadas provê uma função ao invés de uma medida singular, a solução continua sendo simples, apenas não tão simples. O que pode surpreender o desavisado é uma medida não se expressar por um número, mas por uma função. No entanto, uma medida é sempre uma função. Quando se usam os números naturais para se fazer contagens discretas de um dado conjunto de coisas, está se fazendo uma operação como $\mu(x): X \rightarrow \mathbb{N}$, onde $\mathrm{x} \quad(x \in X: \mathrm{x}$ é um elemento do conjunto $X$ ) é levado ( $\rightarrow$ : mapeado) para um número natural $(\mathbb{N})$ que o representa. Uma medida pode se expressar por um número singular na situação particular em que a função seja constante: no exemplo de ajuste de funções discutido acima (Figura 31) a derivada da reta (medida da velocidade de produção científica em Ciências da Saúde no Brasil) resultou numa figura singular porque é uma função constante. Na Webpage 
da Virginia Commonwealth University, de Vancouver, no Canadá, lê-se a seguinte definição de medida:

"Measurement:

Mapping of an ontological event to an epistemological proposition. ... Together with prediction, the connection between the formal and natural systems in Rosen's modeling relation."

Virginia Commonwealth University, Complexity Discussion Group: http://www.vcu.edu/complex/glossary.htm, em 14/06/2004

A razão de derivadas mapeia o que é (ontológico) a relação homem / mulher no infarto do miocárdio segundo a idade para uma medida de efeito que é uma interpretação de como a intensidade do fenômeno em homens supera esta intensidade em mulheres (proposição epistemológica, estratégia de aquisição de conhecimento). Resultando esta medida na função (8), o cardiologista tem agora uma informação que é simples mas não simplória e que responde a suas inquietações: a cada situação particular de idade, ele pode avaliar o efeito relativo de um sexo em relação a outro.

O gráfico da função (8) na figura 29 permite ainda ao cardiologista perceber que a superioridade do sexo masculino é sempre decrescente. De fato, a função (8) é uma função Cauchy, mas nos limites do domínio de idades considerado (20 a 100 anos), comporta-se como uma exponencial decrescente, ou uma logística decrescente assimptótica ao zero. Seria descabido querer considerar o comportamento da relação homem /mulher fora deste domínio próprio de manifestação do evento estudado, como já se comentou quando da comparação entre regressão logística e razão de derivadas (figura 19) para a qual se lembrou o comentário de Miettinen: "A model addresses a particular range of a determinant only".

No entanto, voltando às reflexões de Einstein sobre as coisas serem simples mas não mais do simples, ao observar-se a figura 29 , nota-se que os efeitos se expressam com diferentes intensidades ao longo das idades. 
No gráfico abaixo, as tangentes da função (8) nos pontos 25 e 50 anos são destacadas:

Figura 33 - Força de expressão dos riscos avaliados pela razão de derivadas da função (8) nas idades de 25 e 50 anos

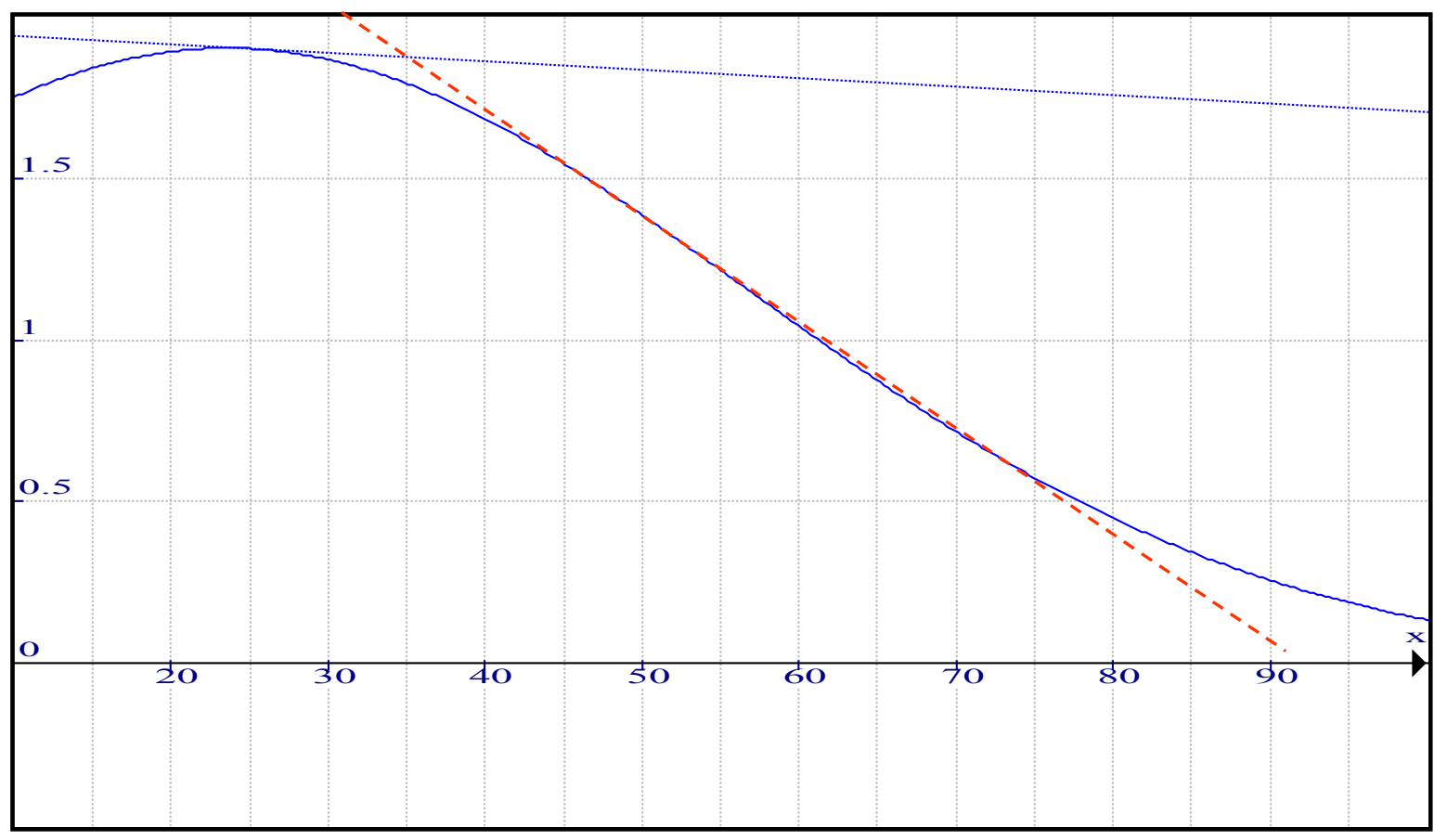

Estas tangentes são as derivadas da função (8) nos pontos escolhidos. Aos 25 anos, o risco homem/ mulher é de 1,9, com uma tangente de inclinação $-0,003$, enquanto que aos 50 anos, o risco homem/ mulher é de 1,4, com uma tangente de inclinação $-0,03$. Ao analisar a situação de uma mulher com vistas ao diagnóstico de infarto do miocárdio, aos 25 suas chances são a metade da de um homem de mesma idade e esta tendência é razoavelmente estável: a superioridade masculina decresce a 3 miléssimos por ano. Já a situação de uma mulher de 50 anos, suas chances não só são maiores (0,7 a dos homens) como a vantagem masculina decresce muito mais rapidamente: dez vezes mais que no caso da mulher de 25 anos. Nestas duas situações, os juízos que se formam sobre a situação protegida da mulher são distintos: aos 50 anos o cardiologista já deve ser mais cauteloso pois não só a vantagem feminina é menor como também ela está se esvaindo mais rapidamente, um alerta para a ação do clínico. 
O que agora se discute é a derivada da razão de derivadas ou, por outra, uma segunda derivada. Esta discussão talvez seja perdulária para o caso do sexo no infarto do miocárdio uma vez que, sendo a função razão de derivadas sempre decrescente e sabendo-se que a igualdade entre os sexos é atingida aos 61,2 anos, o cardiologista pode formar o mesmo juízo apenas considerando que aos 25 anos a mulher está protegida e a 36,2 anos de alcançar os homens enquanto que aos 50 anos ela está menos protegida e a apenas 11,2 anos da igualdade. No entanto, a discussão de uma segunda derivada não é ociosa porque em outras situações esta informação pode vir a ser muito relevante.

No gráfico abaixo, figura 34, cria-se uma situação hipotética onde uma função semelhante à função (8) teria um domínio mais largo a ser considerado. Sua derivada mostra as velocidades variáveis dos lados ascendente e descendente e permite comparar riscos de igual valor num e noutro lado da curva da função. Como exemplo, tome-se o risco $=2$ : tanto o valor 1,7 quanto o valor 2,3 da abscissa levam ao mesmo risco mas, no entanto, os valores correspondentes da derivada desta função (em azul, a segunda derivada) para estes valores de ordenada são +3,4 e -3,4, respectivamente. Como corolário, os juízos que se formam são distintos para um mesmo nível de risco: um risco dobrado e aumentando deve sugerir intervenção mas um risco dobrado porém diminuindo pode sugerir a cautela de um acompanhamento ao invés de uma intervenção. 
Figura 34 - Hipotética função de razão de derivadas e sua derivada ( $\left(2^{a}\right.$ derivada em relação ao fenômeno estudado)

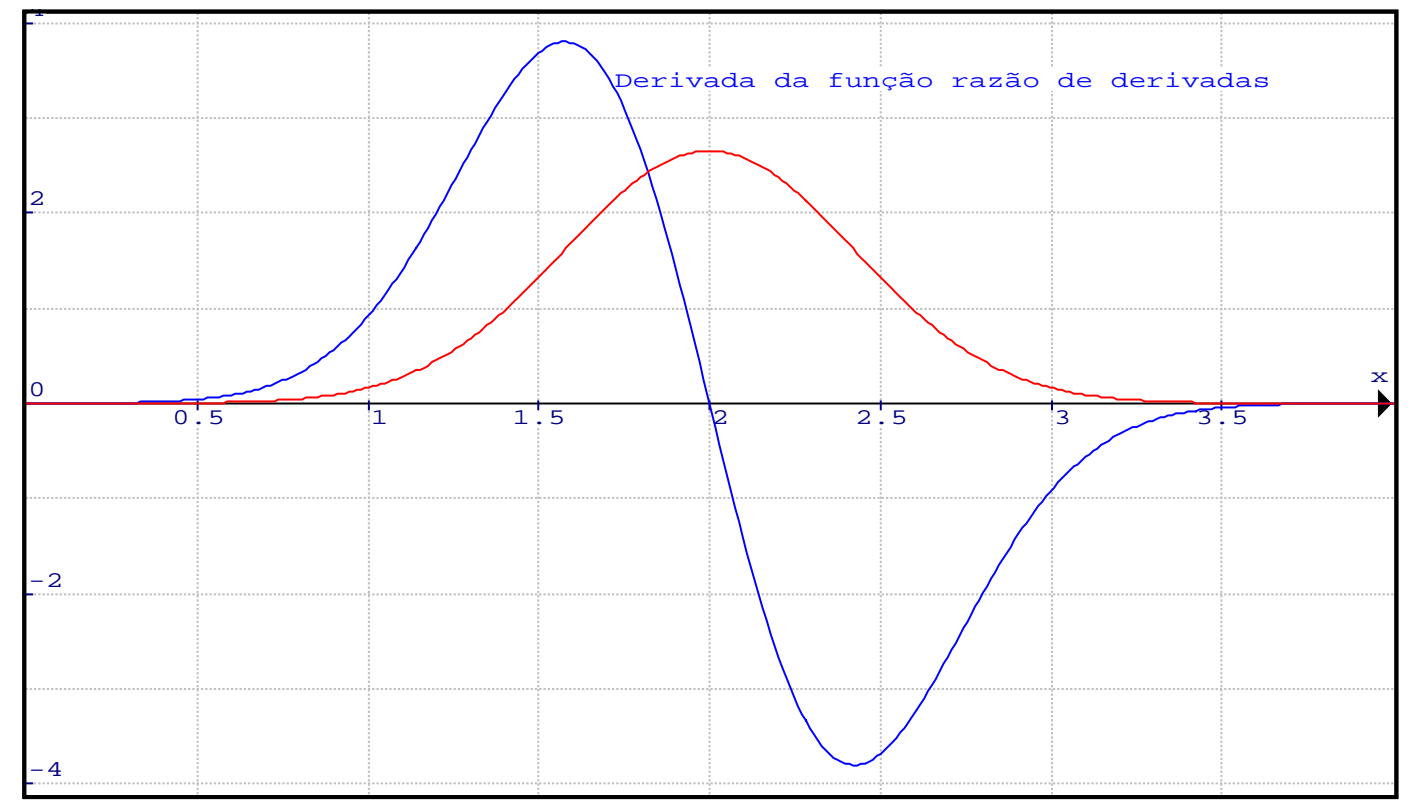

Como matéria de interesse para a generalização do conceito de razão de derivadas como medida de efeito, que se registre aqui a potencial importância da derivada da razão de derivadas. Para fins práticos do exame do efeito do sexo sobre a ocorrência do infarto, no entanto, que se deixe estes 'ghosts of departed quantities' descansarem.

Aos céticos à moda de Berkeley, a razão de derivadas num espaço complementado como o de mulheres e homens infartados poderá parecer um exercício ocioso já que sempre partições que mostrem risco serão compensadas por outras partições que mostrem proteção. O risco seria apenas relativo e propriedade da parte, não do todo. Descartes, no entanto, em seu "Discours de la Methode pour bien conduire sa raison, et chercher la verité dans les sciences ${ }^{\prime 73}$, estabelece quatro preceitos para a investigação científica:

1. da dúvida: nada tomar por verdade sem evidência própria;

2. do exame das partes para conhecer o todo, em suas próprias palavras: "Le second, de diviser chacune des difficultés que 
j'examinerois, en autant de parcelles qu'il se pourroit, et qu'il seroit requis pour les mieux résoudre";

3. da recomposição do todo: pela ordenação das partes ainda que em pensamento quando a ordem não Ihes seja imanente;

4. da generalização: em cada caso com enumerações tão completas e revisões tão genéricas de forma que nada seja omitido.

Portanto, de acordo com o segundo preceito de Descartes, é o conhecimento das partes que instrui o conhecimento do todo. Para o conhecimento dos efeitos do sexo sobre a idade de ocorrência do infarto não é contraditório mas mandatório que se examine as partes. $O$ todo esconde informações que só um processo de dierese e síntese é capaz de revelar. Que no todo haja superioridade masculina é sabido ; é nas variações em partes - idades específicas, intervalos de idade - que reside a inquietação.

Aos otimistas, por outro lado, parecerá elucidado o efeito do sexo sobre a ocorrência do infarto segundo a idade. No entanto, há que se lembrar que quando os efeitos são conhecidos, as causas não são conhecidas. A história da hipótese causal para proteção hormonal é exemplar porque, embora consistente, não subsistiu à investigação mais acurada. Do presente estudo pode-se aprender detalhes de como varia a idade de ocorrência do infarto segundo o sexo, mas isto é efeito, não causa. Pascal em seu famoso "Pensées" de $1660^{74}$, lembrava Santo Agostinho:

- "Rem viderunt, causam non viderunt" (Viram a coisa, não viram a causa) e completava:

- For the effects are perceptible by sense, and the causes are visible only to the intellect.

O presente estudo mediu o sensível provido pelo estudo AFIRMAR, o resto pertence ao intelecto. É inferência, não dedução, e esta implica juízo sobre evidencias, o que extrapola de longe a simples medida. Rothman ${ }^{75}$, em seu livro "Modern Epidemiology", termina capitulo dedicado à inferência causal 
em epidemiologia com comentários de Bradford Hill que aqui são emprestados para também terminar esta reflexão sobre a razão de derivadas e sua aplicação na avaliação de efeito do sexo sobre a idade de ocorrência do infarto agudo do miocárdio:

"All scientific work is incomplete - whether it be observational or experimental. All scientific work is liable to be upset or modified by advancing knowledge. That does not confer upon us a freedom to ignore the knowledge we already have, or to postpone the action that it appears to demand at a given time." 
Conclusão 
Do presente estudo pôde-se concluir:

1. A razão de derivadas é uma medida de efeito semelhante à razão de incidência (incidence rate ratio) no sentido que estima um risco relativo como razão de proporções entre dois grupos submetidos a comparação;

2. A razão de derivadas é uma medida de efeito semelhante à razão de danos (hazard rate ratio) no sentido que permite estimar efeitos relativos entre classes de um grupo homogêneo onde todos os indivíduos possuem o atributo estudado e as classes se definem por atributos complementares entre si;

3. A razão de derivadas permite estimar o efeito relativo de uma classe em relação a outra para manifestação do atributo comum em partições do espaço original que revelam contrastes não aparentes na análise do grupo como um todo;

4. A razão de derivadas aplicada a um grupo homogêneo de pessoas infartadas estudadas no Brasil permitiu conhecer o efeito do sexo sobre ocorrência da doença ao longo das idades;

5. Homens em relação a mulheres têm duas vezes mais chances de infarto aos vinte anos, relação que progressivamente se inverte para chances dobradas para mulheres em relação aos homens aos oitenta anos;

6. A idade de 61,2 é o ponto de inflexão onde a superioridade masculina passa a ceder lugar à feminina. 
Reference List

1. Beaglehole R. Global cardiovascular disease prevention: time to get serious. Lancet 2001;358:661-3.

2. Projeto MONICA. http://www4.ktl.fi/monica// . 17-3-2004.

3. Lotufo PA. Mortalidade Precoce por Doenças do Coração no Brasil. Comparação com Outros Países. Arquivos Brasileiros de Cardiologia 1998;70:321-5.

4. Lessa I. Trends in Productive Years of Life Lost to Premature Mortality Due to Coronary Heart Disease. Arquivos Brasileiros de Cardiologia 2002;79:617-22.

5. DATASUS. www.datasus.gov.br . 17-3-2004.

6. de Lolio C.A., Lotufo P.A., Lira A.C., Zanetta D.M., Massad E. Mortality trends due to myocardial ischemia in capital cities of the metropolitan areas of Brazil, 1979-89. Arquivos Brasileiros de Cardiologia 1995;64:213-6.

7. Mansur AP, Souza MFM, Timerman A, Ramires JAF. Trends of the risk of death due to circulatory, cerebrovascular, and ischemic heart diseases in 11 Brazilian capitals from 1980 to 1998. Arquivos Brasileiros de Cardiologia 2002;79:277-84.

8. Linnersjo A, Hammar N, Gustavsson A, Reuterwall C. Recent time trends in acute myocardial infarction in Stockholm, Sweden. International Journal of Cardiology 2000;76:17-21.

9. Messner T, Lundberg V, Bostrom S, Huhtasaari F, Wikstrom B. Trends in event rates of first and recurrent, fatal and non-fatal acute myocardial infarction, and 28-day case fatality in the Northern Sweden MONICA area 1985-98. Scandinavian Journal of Public Health 2003;31:51-9.

10. Garcia J, Elosua R, Diaz MJT, Uriarte CA, Zurriaga O, Segura A et al. Myocardial infarction. Population case-fatality in seven Spanish autonomous communities: the IBERICA study. Medicina Clinica 2003;121:606-12.

11. Manuel DG, Leung M, Nguyen K, Tanuseputro $P$, Johansen $H$. Burden of cardiovascular disease in Canada. Canadian Journal of Cardiology 2003;19:997-1004.

12. Witt BJ,.Roger VL. Sex differences in heart disease incidence and prevalence: implications for intervention. Expert Opinion on Pharmacotherapy 2003;4:675-83. 
13. Mehilli J, Kastrati A, Dirschinger J, Pache J, Seyfarth M, Blasini R et al. Sex-based analysis of outcome in patients with acute myocardial infarction treated predominantly with percutaneous coronary intervention. Jama-Journal of the American Medical Association 2002;287:210-5.

14. Marques-Vidal $P$, Ruidavets JB, Amouyel $P$, Ducimetiere $P$, Arveiler $\mathrm{D}$, Montaye $\mathrm{M}$ et al. Change in cardiovascular risk factors in France, 1985-1997. European Journal of Epidemiology 2004;19:25-32.

15. Moynac D.L. Manuel de pathologie et de clinique médicales. Paris: Librairie H. Lauwereyns, 1877.

16. Lichtlen P.R. History of coronary heart disease. Z Kardiol 2002;91:IV/56-IV/59.

17. The Project Gutenberg Etext of The Evolution of Modern Medicine, Carnegie-Mellon University.

http://onlinebooks.library.upenn.edu/webbin/gutbook/lookup?num=15 $\underline{66} \cdot 17-3-2004$.

18. Stampfer MJ, Colditz GA, Willett WC, Manson JE, Rosner B, Speizer FE et al. Postmenopausal Estrogen Therapy and CardiovascularDisease - 10-Year Follow-Up from the Nurses Health Study

3. New England Journal of Medicine 1991;325:756-62.

19. Grodstein F, Stampfer MJ, Manson JE, Colditz GA, Willett WC, Rosner B et al. Postmenopausal estrogen and progestin use and the risk of cardiovascular disease. New England Journal of Medicine 1996;335:453-61.

20. Rossouw JE, Anderson GL, Prentice RL, LaCroix AZ, Kooperberg C, Stefanick ML et al. Risks and benefits of estrogen plus progestin in healthy postmenopausal women - Principal results from the Women's Health Initiative randomized controlled trial. Jama-Journal of the American Medical Association 2002;288:321-33.

21. Hulley S, Grady D, Bush T, Furberg C, Herrington D, Riggs B et al. Randomized trial of estrogen plus progestin for secondary prevention of coronary heart disease in postmenopausal women. Jama-Journal of the American Medical Association 1998;280:605-13.

22. Cherry N, Gilmour K, Hannaford P, Heagerty A, Khan MA, Kitchener $\mathrm{H}$ et al. Oestrogen therapy for prevention of reinfarction in postmenopausal women: a randomised placebo controlled trial. Lancet 2002;360:2001-8.

23. Mendelsohn ME,.Karas RH. Mechanisms of disease: The protective effects of estrogen on the cardiovascular system. New England Journal of Medicine 1999;340:1801-11. 
24. Fletcher SW,.Colditz GA. Failure of estrogen plus progestin therapy for prevention. Jama-Journal of the American Medical Association 2002;288:366-8.

25. Rossouw JE. Hormones for coronary disease - full circle. Lancet 2002;360:1996-7.

26. Redberg RF, Cannon RO, Merz NB, Lerman A, Reis SE, Sheps DS. Women's Ischemic Syndrome Evaluation - Current status and future research directions - Report of the National Heart, Lung and Blood Institute Workshop - October 2-4, 2002 - Section 2 - Stable ischemia: Pathophysiology and gender differences. Circulation 2004;109:E47E49.

27. King KM, Ghali WA, Faris PD, Curtis MJ, Galbraith PD, Graham MM et al. Sex differences in outcomes after cardiac catheterization Effect modification by treatment strategy and time. Jama-Journal of the American Medical Association 2004;291:1220-5.

28. Carroll K, Majeed A, Firth C, Gray J. Prevalence and management of coronary heart disease in primary care: population-based crosssectional study using a disease register. Journal of Public Health Medicine 2003;25:29-35.

29. Chang WC, Kaul P, Westerhout CM, Graham MM, Fu YL, Chowdhury $T$ et al. Impact of sex on long-term mortality from acute myocardial infarction vs unstable angina. Archives of Internal Medicine 2003;163:2476-84.

30. Rosengren A, Thelle DS, Koster M, Rosen M. Changing sex ratio in acute coronary heart disease: data from Swedish national registers 1984-99. Journal of Internal Medicine 2003;253:301-10.

31. Moraes RS, Fuchs FD, Moreira LB, Wiehe M, Pereira GM, Fuchs SC. Risk factors for cardiovascular disease in a Brazilian populationbased cohort study. International Journal of Cardiology 2003;90:20511.

32. Heer T, Schiele R, Schneider S, Gitt AK, Wienbergen H, Gottwik M et al. Gender differences in acute myocardial infarction in the era of reperfusion (The MITRA registry). American Journal of Cardiology 2002;89:511-7.

33. Mehilli J, Kastrati A, Dirschinger J, Pache J, Seyfarth M, Blasini R et al. Sex-based analysis of outcome in patients with acute myocardial infarction treated predominantly with percutaneous coronary intervention. Jama-Journal of the American Medical Association 2002;287:210-5.

34. Mueller C, Neumann FJ, Roskamm H, Buser P, Hodgson JM, Perruchoud AP et al. Women do have an improved long-term 
outcome after non-ST-elevation acute coronary syndromes treated very early and predominantly with percutaneous coronary intervention - A prospective study in 1,450 consecutive patients. Journal of the American College of Cardiology 2002;40:245-50.

35. Conti RAS, Solimene MC, Luz PL, Benjó AM, Lemos-Neto PA, Ramires JAF. Comparison between young males and females with acute myocardial infarction. Arquivos Brasileiros de Cardiologia 2002;79:518-25.

36. Roger VL, Jacobsen SJ, Weston SA, Pellikka PA, Miller TD, Bailey $\mathrm{KR}$ et al. Sex differences in evaluation and outcome after stress testing. Mayo Clinic Proceedings 2002;77:638-45.

37. Maclntyre K, Stewart S, Capewell S, Chalmers JWT, Pell JP, Boyd J et al. Gender and survival: A population-based study of 201,114 men and women following a first acute myocardial infarction. Journal of the American College of Cardiology 2001;38:729-35.

38. Schreiner PJ, Niemela M, Miettinen $H$, Mahonen M, Ketonen M, Immonen-Raiha $\mathrm{P}$ et al. Gender differences in recurrent coronary events - The FINMONICA MI register. European Heart Journal 2001;22:762-8.

39. Sibai AM, Fletcher A, Hills M, Campbell O. Non-communicable disease mortality rates using the verbal autopsy in a cohort of middle aged and older populations in Beirut during wartime, 1983-93. Journal of Epidemiology and Community Health 2001;55:271-6.

40. Grundy SM, Pasternak R, Greenland P, Smith S, Fuster V. Assessment of cardiovascular risk by use of multiple-risk-factor assessment equations - A statement for healthcare professionals from the American Heart Association and the American College of Cardiology. Journal of the American College of Cardiology 1999;34:1348-59.

41. Grundy SM, Pasternak R, Greenland P, Smith S, Fuster V. Assessment of cardiovascular risk by use of multiple-risk-factor assessment equations - A statement for healthcare professionals from the American Heart Association and the American College of Cardiology. Circulation 1999;100:1481-92.

42. Truelsen $\mathrm{T}$, Mahonen M, Tolonen H, Asplund K, Bonita R, Vanuzzo $D$. Trends in stroke and coronary heart disease in the WHO MONICA project. Stroke 2003;34:1346-52.

43. Mcewan SR, Daly F, Forbes CD, Belch JJF. The Scottish Heart and Arterial Risk Prevention (SHARP) survey of cardiovascular risk: Regional differences. Scottish Medical Journal 2001;46:108-10. 
44. De Henauw S, De Bacquer D, de Smet P, Kornitzer M, De Backer G. Trends and regional differences in coronary risk factors in two areas in Belgium: final results from the MONICA Ghent-Charleroi study. Journal of Cardiovascular Risk 2000;7:347-57.

45. Hense HW, Schulte $H$, Lowel H, Assmann G, Keil U. Framingham risk function overestimates risk of coronary heart disease in men and women from Germany - results from the MONICA Augsburg and the PROCAM cohorts. European Heart Journal 2003;24:937-45.

46. Thomsen TF, Mcgee D, Davidsen M, Jorgensen T. A cross-validation of risk-scores for coronary heart disease mortality based on data from the Glostrup Population Studies and Framingham Heart Study. International Journal of Epidemiology 2002;31:817-22.

47. Piegas LS, Avezum A, Pereira JCR, Neto JMR, Hoepfner C, Farran JA et al. Risk factors for myocardial infarction in Brazil. American Heart Journal 2003;146:331-8.

48. Pivetta, M. Infarto - O que causa ou evita. Pesquisa FAPESP 79. 2002. São Paulo, FAPESP.

Ref Type: Magazine Article

49. Rothman JR. Modern Epidemiology. Boston, MA, USA: Little, Brown and Co., 1986, páginas 35-40.

50. Gordis L. Estimating risk and inferring causality in epidemiology. In Gordis L, ed. Epidemiology and health risk assessment, pp 51-60. New York, NY, USA: Oxford University Press, 1988.

51. Logistic regression analysis. In Kleinbaum DG, Kupper LL, Muller KE, Nizam A, eds. Applied regression analysis and other multivariate methods, pp 656-86. Pacific Grove, CA, USA: Duxbury Press, 1998.

52. Miettinen O. Estimability and Estimation in Case-Referent Studies. American Journal of Epidemiology 1976;103:226-35.

53. Rodrigues L,.Kirkwood BR. Case-Control Designs in the Study of Common Diseases - Updates on the Demise of the Rare Disease Assumption and the Choice of Sampling Scheme for Controls. International Journal of Epidemiology 1990;19:205-13.

54. Batschelet $\mathrm{E}$. Introdução à matemática para biocientistas. Rio de Janeiro e São Paulo: Interciência e EDUSP, 1978.

55. Armitage P, Berry G. Statistical methods in medical research. Oxford, UK: Blackwell Scientific Publications, 1987.

56. Pereira, J. C. R., Baltar, V. T., and Amato, R. V. Razão de derivadas como medida de efeito em epidemiologia. CD-ROM. 2003. São José 
do Rio Preto, XXVI CONGRESSO NACIONAL DE MATEMÁTICA APLICADA E COMPUTACIONAL (CNMAC).

57. Holford TR. Life Tables with Concomitant Information. Biometrics 1976;32:587-97.

58. Avezum, A. Fatores de risco associados com infarto agudo do miocárdio na região metropolitana de São Paulo. 1-183. 28-6-2002. Universidade de São Paulo, Faculdade de Medicina.

59. Miettinen O. Theoretical epidemiology. New York, NY, USA: John Wiley \& Sons, 1985.

60. Rothman JR. Op. Cit., páginas 1-6.

61. Dever GEA. A Epidemiologia na Administração de Serviços de Saúde. São Paulo: Pioneira, 1988.

62. Graunt J. Natural and political observations mentioned in a following index, and made upon bills of mortality. In Wilcox WF, ed. Natural and political observations made upon bills of mortality by John Graunt, Baltimore: Johns Hopkins Press, 1937.

63. Lind J. A Treatise of the Scurvy. Edinburgh: Sands, Murray \& Cochran, 1753.

64. Lenoir T. Instituting science - The cultural production of scientific disciplines. Stanford (CA): Stanford University Press, 1997.

65. Apud Costa N. O conhecimento científico. São Paulo: Discurso Editorial, 1999.

66. Doll R. Lecture at the 6th Summer Course of the European Educational Programme in Epidemiology, Florence. Apud: Saracci R. Introducing the history of epidemiology. In Olsen J, Saracci R, Trichopoulos D, eds. Teaching epidemiology, pp 1-19. Oxford: Oxford University Press, 2003.

67. Berkeley G. The Analyst or, A Discourse Addressed to an Infidel Mathematician; Wherein it is examined whether the Object, Principles and Inferences of the modern Analysis are more distinctly conceived, or more evidently deduced, than Religious Mysteries and Points of Faith. Disponível em página de David R. Wilkins, Trinity College, Dublin : http://www.maths.tcd.ie/pub/HistMath/People/Berkeley/ACIndex.html \#Berkeley, em 15/06/2004. London: Printed for J. Tonson in the Strand, 1734.

68. Kaplan R. The nothing that is. Oxford: Oxford Unversity Press, 1999. 
69. Miettinen O. Important concepts in epidemiology. In Olsen J., Saracci $\mathrm{R}$, Trichopoulos D, eds. Teaching epidemiology, pp 33-40. Oxford: Oxford University Press, 2003.

70. Thompson SP, Gardner M. Calculus made easy. New York: St. Martin's Press, 1998.

71. Hjemmeside, R. Citater fra...Albert Einstein. Niels Bohr Institutet, Kobenhavns Universitet. http://www.fys.ku.dk/ raben/einstein/ . 12-62004.

72. Quintus Horatius Flaccus. Satires I, Book I - Webpage da The Society for Ancient Languages na University of Alabama in Huntsville, USA.

http://www.uah.edu/student life/organizations/SAL/claslattexts/horac e/sermones101.html . 15-6-2004.

73. Descartes, R. Discours de la Methode pour bien conduire sa raison, et chercher la verité dans les sciences. Association de Bibliophiles Universels: http://abu.cnam.fr/cgi-bin/donner html?methode3 . 16-62004.

74. Pascal, B. Pensées, translated by W. F. Trotter. Christian Classics Ethereal Library:

http://www.ccel.org/p/pascal/pensees/pensees c.htm . 17-6-2004.

75. Rothman JR. Op. Cit., páginas 7-21. 